STANDARD FORMAT

AND CONTENT

OF SAFETY ANALYSIS REPORTS FOR NUCLEAR POWER PLANTS

(Revision 1)

Prepared by the Regulatory Staff

U.S. Atomic Energy Commission Issued October, 1972 


\section{DISCLAIMER}

This report was prepared as an account of work sponsored by an agency of the United States Government. Neither the United States Government nor any agency Thereof, nor any of their employees, makes any warranty, express or implied, or assumes any legal liability or responsibility for the accuracy, completeness, or usefulness of any information, apparatus, product, or process disclosed, or represents that its use would not infringe privately owned rights. Reference herein to any specific commercial product, process, or service by trade name, trademark, manufacturer, or otherwise does not necessarily constitute or imply its endorsement, recommendation, or favoring by the United States Government or any agency thereof. The views and opinions of authors expressed herein do not necessarily state or reflect those of the United States Government or any agency thereof. 


\section{DISCLAIMER}

Portions of this document may be illegible in electronic image products. Images are produced from the best available original document. 


\title{
STANDARD FORMAT AND CONTENT OF \\ SAFETY ANALYSIS REPORTS FOR NUCLEAR POWER PLANTS
}

\author{
(Revision 1)
}

Prepared by the Regulatory Staff U.S. Atomic Energy Commission Issued October, 1972

This report was prepared as an account of work
sponsored by the United States Government. Neither
the United States nor the United States Atomic Energy
Commission, nor any of their employees, nor any of
their contractors, subcontractors, or their employees,
makes any warranty, express or implied, or assumes any
legal liability or responsibility for the accuracy, com-
pleteness or usefulness of any information, apparatus,
product or process disclosed, or represents that its use
would not infringe privately owned rights.




\section{FOREWORD}

Section 50.34 of $10 \mathrm{CFR}$ Part 50 of the regulations of the Atomic Energy Commission requires that each application for a construction permit for a nuclear reactor facility shall include a Preliminary Safety Analysis Report (PSAR), and that each application for a license to operate such a facility shall include a Final Safety Analysis Report (FSAR). Section 50.34 specifies in general terms the information to be supplied in these Safety Analysis Reports (SARs). Further information was provided in a "Guide to the Organization and Contents of Safety Analysis Reports" issued by the AEC on June 30, 1966.

In the course of reviewing applications for construction permits and operating licenses in the past several years, the AEC regulatory staff has found that most SARs as initially submitted do not provide sufficient information to permit the staff to conclude its review and it has been necessary for the staff to make specific requests for additional information. These requests, which are available in the AEC Public Document Room in the Dockets for individual cases, are a source of additional guidance to applicants.

In 1970, the Commission began issuance of a series of Safety Guides to inform applicants of solutions to specific safety issues that are acceptable to the regulatory staff and the Advisory Committee on Reactor Safeguards. In 1971, a new series of Information Guides was initiated to list needed information that is frequently omitted from applications.

On November 18, 1971, the AEC Director of Regulation announced* that effective immediately the regulatory staff would make a preliminary review of each application for a construction permit or an operating license to determine whether sufficient information is included. If it is clear that a responsible effort has not been made to provide the information needed by the staff for its review, the licensing review would not be started until the application is reasonably complete. The Director of Regulation also indicated that additional guidance would be issued shortly. In accordance, in February 1972 the Commission distributed for information and comment the proposed "Standard Format and Content of Safety Analysis Reports for Nuclear Power Plants." It provided a standard format for Safety Analysis Reports and identified the principal information needed. Numerous comments were received and resulted in this revised document reflecting those comments and superseding the February 1972 issue and the guide issued in 1966.

* AEC Press Release No. 5-25-71. See also amendments to 10 CFR $\$ 2.101$ published in the Federal Register on July 28, 1972 (37 FR 15127) to become effective 30 days after publication. 
While conformance with the Standard Format is not required, the Standard Format does represent a format acceptable to the regulatory staff. Thus, while Safety Analysis Reports with differing formats will be acceptable to the staff if they provide an adequate basis for the findings required for the issuance of a license or permit, the staff review time for such reports may be longer and there is a greater likelihood that the information will be regarded by the staff as incomplete.

As developments in the nuclear industry occur the Commission's requirements for information prior to issuance of construction permits and operating licenses may need modification and revisions to the contents of the Standard Format will be made to accommodate these new requirements. Any revisions of the Commission's needs for information will be conveyed to the industry and the public in various ways such as (1) amendments to the Standard Format, (2) in the Information Guide series, (3) as part of future Safety Guides, or (4) in Public Announcements. 


\section{TABLE OF CONTENTS}

FOREWORD

PAGE NO.

INTRODUCTION

Purpose and Applicability $\ldots \ldots \ldots \ldots \ldots \ldots \ldots \ldots \ldots \ldots \ldots \ldots \ldots \ldots$

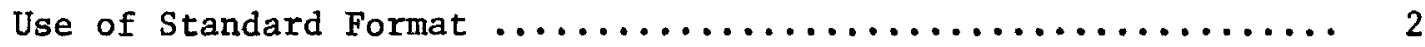

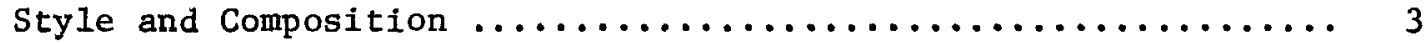

STANDARD FORMAT AND CONTENT OF SAFETY ANALYSIS REPORTS FOR NUCLEAR

POWER PLANTS .................................... 1.0

CHAPTER 1.0 INTRODUCTION AND GENERAL DESCRIPTION OF PLANT

1.1 Introduction $\ldots \ldots \ldots \ldots \ldots \ldots \ldots \ldots \ldots \ldots \ldots \ldots \ldots \ldots \ldots \ldots \ldots$

1.2 General Plant Description $\ldots \ldots \ldots \ldots \ldots \ldots \ldots \ldots \ldots \ldots \ldots \ldots$

1.3 Comparison Tables $\ldots \ldots \ldots \ldots \ldots \ldots \ldots \ldots \ldots \ldots \ldots \ldots \ldots \ldots \ldots$

1.3.1 Comparisons with Similar Facility Designs .......... 1.3-1

1.3.2 Comparison of Final and Preliminary Information........ 1.3-1

1.4 Identification of Agents and Contractors $\ldots \ldots \ldots \ldots \ldots \ldots \ldots \ldots 1$

1.5 Requirements for Further Technical Information $\ldots \ldots \ldots \ldots \ldots . .1$

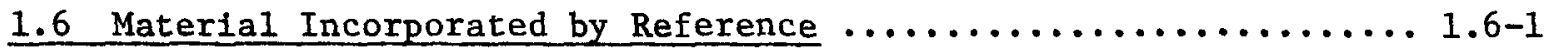

CHAPTER 2.0 SITE CHARACTERISTICS

2.1 Geography and Demography $\ldots \ldots \ldots \ldots \ldots \ldots \ldots \ldots \ldots \ldots \ldots \ldots \ldots . \ldots . \ldots$

2.1 .1 Site Location $\ldots \ldots \ldots \ldots \ldots \ldots \ldots \ldots \ldots \ldots \ldots \ldots \ldots \ldots \ldots \ldots \ldots . . \ldots \ldots$ 
TABLE OF CONTENTS (cont'd)

PAGE NO.

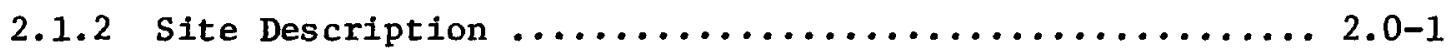

2.1.3 Population and Population Distribution ............ 2. 0-1

2.1.4 Uses of Adjacent Lands and Waters $\ldots \ldots \ldots \ldots \ldots \ldots \ldots .2 . \ldots \ldots$

$\underline{2.2}$ Nearby Industrial, Transportation and Military Facilities .... 2.2-1

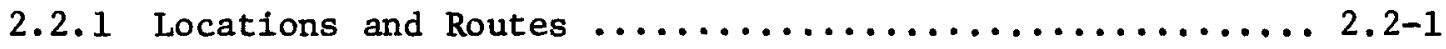

2.2 .2 Descriptions $\ldots \ldots \ldots \ldots \ldots \ldots \ldots \ldots \ldots \ldots \ldots \ldots \ldots \ldots \ldots \ldots . . \ldots \ldots$

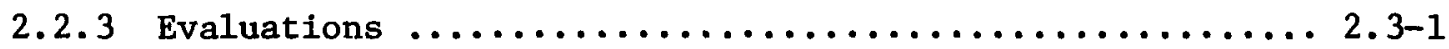

2.3 Meteorology $\ldots \ldots \ldots \ldots \ldots \ldots \ldots \ldots \ldots \ldots \ldots \ldots \ldots \ldots \ldots \ldots \ldots \ldots . \ldots \ldots$

2.3.1 Regional Climatology $\ldots \ldots \ldots \ldots \ldots \ldots \ldots \ldots \ldots \ldots \ldots \ldots \ldots . . \ldots \ldots \ldots$

2.3.2 Local Meteorology ........................ 2.3-2

2.3.3 Onsite Meteorological Measurements Programs .......... 2.3-3

2.3.4 Short Term (Accident) Diffusion Estimates ........... 2.3-3

2.3.5 Long Term (Routine) Diffusion Estimates ........... 2.3-3

2.4 Hydrologic Engineering $\ldots \ldots \ldots \ldots \ldots \ldots \ldots \ldots \ldots \ldots \ldots \ldots \ldots \ldots \ldots$

2.4.1 Hydrologic Description .................... 2.4-1

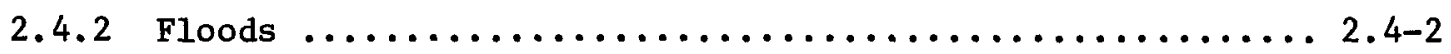

2.4.3 Probable Maximum Flood (PMF) on Streams and Rivers .... 2.4-3

2.4.4 Potential Dam Failures (Seismically Induced) ........ 2.4-5

2.4.5 Probable Maximum Surge and Seiche Flooding .......... 2.4-6 
TABLE OF CONTENTS (cont'd)

PAGE NO.

2.4.6 Probable Maximum Tsunami Flooding $\ldots \ldots \ldots \ldots \ldots \ldots \ldots, 2.4-8$

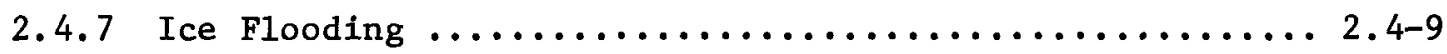

2.4.8 Cooling Water Canals and Reservoirs .............. 2.4-9

2.4.9 Channe1 Diversions $\ldots \ldots \ldots \ldots \ldots \ldots \ldots \ldots \ldots \ldots \ldots \ldots .4 .4 .4$

2.4.10 Flooding Protection Requirements $\ldots \ldots \ldots \ldots \ldots \ldots \ldots .2 .4-9$

2.4.11 Low Water Considerations $\ldots \ldots \ldots \ldots \ldots \ldots \ldots \ldots \ldots \ldots, 2.4-10$

2.4.12 Environmental Acceptance of Effluents $. . \ldots \ldots \ldots \ldots \ldots .2 .4-11$

2.4 .13 Groundwater $\ldots \ldots \ldots \ldots \ldots \ldots \ldots \ldots \ldots \ldots \ldots \ldots \ldots \ldots, 2.4-11$

2.4.14 Technical Specifications and Emergency Operation

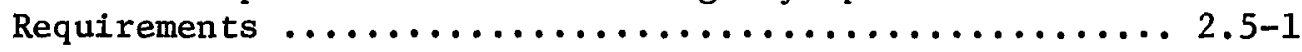

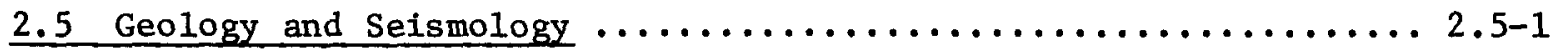

2.5.1 Basic Geologic and Seismic Information $\ldots \ldots \ldots \ldots \ldots \ldots .5 .1$

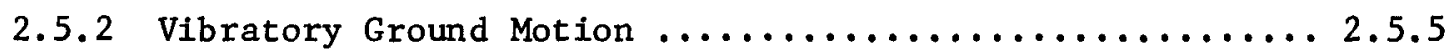

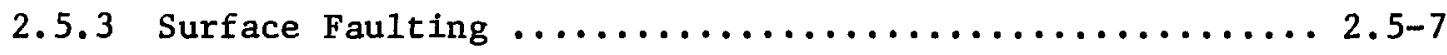

2.5.4 Stability of Subsurface Materials $\ldots \ldots \ldots \ldots \ldots \ldots \ldots .2 .5$

2.5 .5 Slope Stability $\ldots \ldots \ldots \ldots \ldots \ldots \ldots \ldots \ldots \ldots \ldots \ldots \ldots, 2.5-11$

CHAPTER 3.0 DESIGN OF STRUCTURES,

COMPONENTS, EQUIPMENT, AND SYSTEMS

3.1 Conformance With AEC General Design Criteria $\ldots \ldots \ldots \ldots \ldots, 3.0-1$

3.2 Classification of Structures, Components and Systems $\ldots \ldots \ldots . . .1$

3.2.1 Seismic Classification $\ldots \ldots \ldots \ldots \ldots \ldots \ldots \ldots \ldots \ldots \ldots, 0,0,1$

3.2.2 System Quality Group Classification $\ldots \ldots \ldots \ldots \ldots \ldots \ldots .2-1$ 
PAGE NO.

3.3 Wind and Tornado Loadings $\ldots \ldots \ldots \ldots \ldots \ldots \ldots \ldots \ldots \ldots \ldots . \ldots \ldots . \ldots \ldots$

3.3.1 Wind Loadings $\ldots \ldots \ldots \ldots \ldots \ldots \ldots \ldots \ldots \ldots \ldots \ldots \ldots \ldots . . \ldots \ldots \ldots$

3.3.2 Tornado Loadings $\ldots \ldots \ldots \ldots \ldots \ldots \ldots \ldots \ldots \ldots \ldots \ldots . \ldots \ldots$. $3-1$

3.4 Water Leve1 (Flood) Design $\ldots \ldots \ldots \ldots \ldots \ldots \ldots \ldots \ldots \ldots \ldots \ldots .4 \ldots \ldots \ldots$

3.4 .1 Flood Elevations $\ldots \ldots \ldots \ldots \ldots \ldots \ldots \ldots \ldots \ldots \ldots \ldots \ldots .4 . \ldots \ldots \ldots$

3.4.2 Phenomena Considered in Design Loading Calculations .... 3.4-1

3.4.3 Flood Force Application $\ldots \ldots \ldots \ldots \ldots \ldots \ldots \ldots \ldots \ldots \ldots \ldots .4 .1$

3.4.4 Flood Protection ........................... 3.

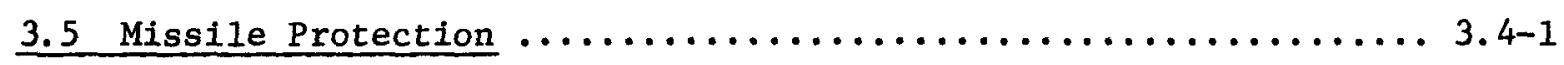

3.5.1 Missile Barriers and Loadings ................ 3.4-1

3.5.2 Missile Selection $\ldots \ldots \ldots \ldots \ldots \ldots \ldots \ldots \ldots \ldots \ldots \ldots \ldots \ldots .4 . \ldots \ldots$

3.5.3 Selected Missiles ........................ 3.6-1

3.5.4 Barrier Design Procedures $\ldots \ldots \ldots \ldots \ldots \ldots \ldots \ldots \ldots \ldots \ldots .6 \ldots \ldots$

3.5.5 Missile Barrier Features ................... 3.6-1

\subsection{Protection Against Dynamic Effects Associated}

With the Postulated Rupture of Piping $\ldots \ldots \ldots \ldots \ldots \ldots \ldots . \ldots .6 .1$

3.6.1 Systems in which Design Basis Piping Breaks Occur ..... 3.6-1

3.6.2 Design Basis Piping Break Criteria .............. 3.6-1

3.6.3 Design Loading Combinations $\ldots \ldots \ldots \ldots \ldots \ldots \ldots \ldots \ldots$. $\ldots \ldots$.

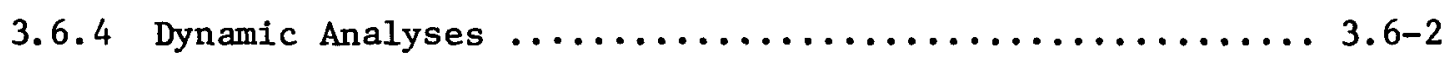

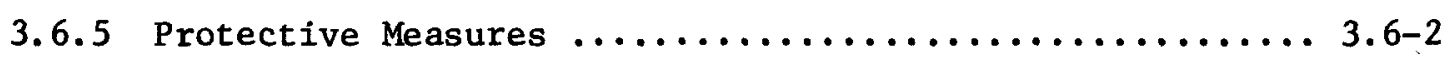


PAGE NO.

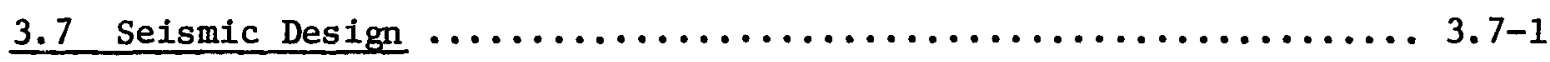

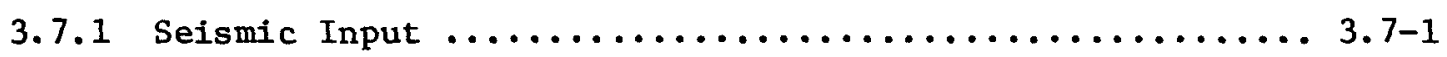

3.7.2 Seismic System Analysis $\ldots \ldots \ldots \ldots \ldots \ldots \ldots \ldots \ldots \ldots ., 3.6 \ldots \ldots$

3.7.3 Seismic Subsystem Analysis $\ldots \ldots \ldots \ldots \ldots \ldots \ldots \ldots \ldots .7 .4$

3.7.4 Seismic Instrumentation Program $\ldots \ldots \ldots \ldots \ldots \ldots \ldots . . \ldots .6$

3.7.5 Seismic Design Control $\ldots \ldots \ldots \ldots \ldots \ldots \ldots \ldots \ldots \ldots \ldots .6 .1$

3.8 Design of Category I Structures $\ldots \ldots \ldots \ldots \ldots \ldots \ldots \ldots \ldots \ldots .8 \ldots \ldots \ldots$

3.8.1 Concrete Containment $\ldots \ldots \ldots \ldots \ldots \ldots \ldots \ldots \ldots \ldots \ldots .6 .1$

3.8.2 Steel Containment System $\ldots \ldots \ldots \ldots \ldots \ldots \ldots \ldots \ldots \ldots .6 .6 .6$

3.8.3 Concrete and Structural Steel Internal

Structures of Steel or Concrete Containments ........ 3.8-6

3.8.4 0ther Category I Structures $\ldots \ldots \ldots \ldots \ldots \ldots \ldots \ldots \ldots . . .6 .8$

3.8.5 Foundations and Concrete Supports $\ldots \ldots \ldots \ldots \ldots \ldots \ldots .8 .9$

3.9 Mechanical Systems and Components $\ldots \ldots \ldots \ldots \ldots \ldots \ldots \ldots \ldots .9 .1$

3.9.1 Dynamic System Analysis and Testing $\ldots \ldots \ldots \ldots \ldots \ldots . . . . .9-1$

3.9.2 ASME Code Class 2 and 3 Components ................. 3.9

3.9.3 Components Not Covered by ASME Code .............. 3.10-1

3.10 Seismic Design of Category I Instrumentation and Electrical

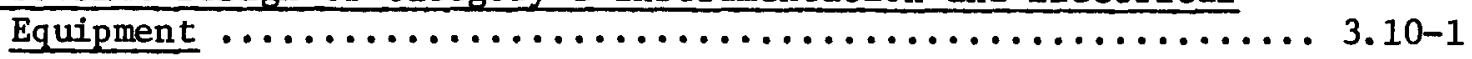

3.10.1 Seismic Design Criteria $\ldots \ldots \ldots \ldots \ldots \ldots \ldots \ldots \ldots \ldots \ldots .11-1$

3.10.2 Analyses, Testing Procedures and Restraint Measures ... 3.11-1 
TABLE OF CONTENTS (cont'd)

PAGE NO.

3.11 Environmental Design of Mechanical and Electrical

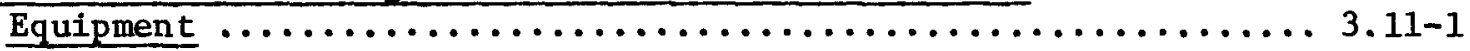

3.11.1 Equipment Identification $\ldots \ldots \ldots \ldots \ldots \ldots \ldots \ldots \ldots \ldots \ldots \ldots$. $11-2$

3.11.2 Qualification Tests and Analyses ............... 3.11-2

3.11.3 Qualification Test Results .................. 3.11-2

3.11 .4 Loss of Ventilation ....................... 3.11-2

CHAPTER 4.0 - REACTOR

4.1 Summary Description $\ldots \ldots \ldots \ldots \ldots \ldots \ldots \ldots \ldots \ldots \ldots \ldots \ldots \ldots \ldots$

4.2 Mechanical Design $\ldots \ldots \ldots \ldots \ldots \ldots \ldots \ldots \ldots \ldots \ldots \ldots \ldots \ldots \ldots$

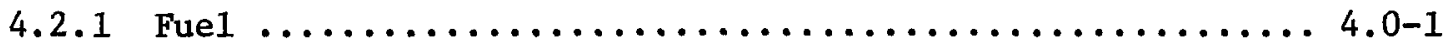

4.2.2 Reactor Vesse1 Internals .................... 4.2-1

4.2.3 Reactivity Control Systems ................... 4.2-2

4.3 Nuclear Design $\ldots \ldots \ldots \ldots \ldots \ldots \ldots \ldots \ldots \ldots \ldots \ldots \ldots \ldots \ldots \ldots \ldots . \ldots . \ldots .1$

4.3.1 Design Bases $\ldots \ldots \ldots \ldots \ldots \ldots \ldots \ldots \ldots \ldots \ldots \ldots \ldots \ldots \ldots . . \ldots \ldots \ldots$

4.3.2 Description $\ldots \ldots \ldots \ldots \ldots \ldots \ldots \ldots \ldots \ldots \ldots \ldots \ldots \ldots \ldots . . \ldots \ldots \ldots$

4.3.3 Analytical Methods ....................... 4.3-5

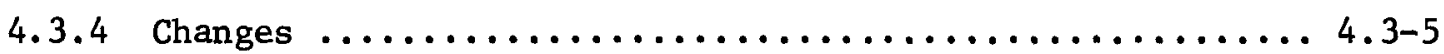

4.4 Thermal and Hydraulic Design $\ldots \ldots \ldots \ldots \ldots \ldots \ldots \ldots \ldots \ldots . \ldots . \ldots . \ldots$

4.4.1 Design Bases ............................ 4.4-1

4.4 .2 Description $\ldots \ldots \ldots \ldots \ldots \ldots \ldots \ldots \ldots \ldots \ldots \ldots \ldots \ldots \ldots \ldots .4 .4$

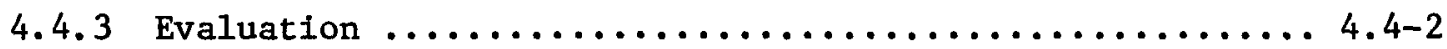

4.4.4 Testing and Verification .................. 4.4-4

4.4.5 Instrumentation Requirements ................ 4.4-4 
TABLE OF CONTENTS (cont'd)

PAGE NO.

\section{CHAPTER 5.0 REACTOR COOLANT SYSTEM AND CONNECTED SYSTEMS}

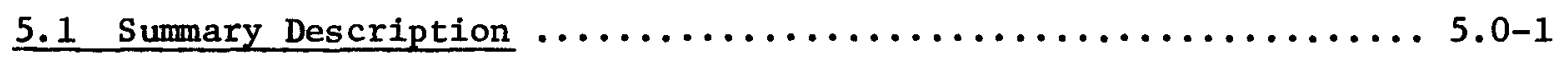

5.1.1 Schematic Flow Diagram $\ldots \ldots \ldots \ldots \ldots \ldots \ldots \ldots \ldots \ldots \ldots, 5.0,1$

5.1.2 Piping and Instrumentation Diagram .............. 5.0-1

5.1 .3 Elevation Drawing $\ldots \ldots \ldots \ldots \ldots \ldots \ldots \ldots \ldots \ldots \ldots \ldots, 5.2-1$

5.2 Integrity of Reactor Coolant Pressure Boundary $\ldots \ldots \ldots \ldots \ldots .2-1$

5.2.1 Design of Reactor Coolant Pressure Boundary Components.. 5.2-1

5.2.2 Overpressurization Protection $\ldots \ldots \ldots \ldots \ldots \ldots \ldots \ldots \ldots .6 .2-5$

5.2.3 General Material Considerations ................ 5.2-5

5.2 .4 Fracture Toughness $\ldots \ldots \ldots \ldots \ldots \ldots \ldots \ldots \ldots \ldots \ldots \ldots .2-6$

5.2.5 Austenitic Stainless Steel $\ldots \ldots \ldots \ldots \ldots \ldots \ldots \ldots \ldots \ldots .2-8$

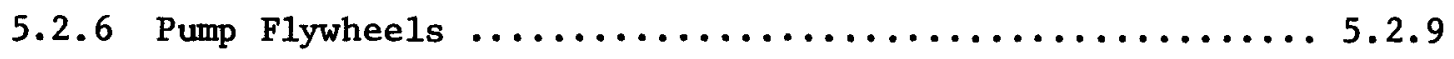

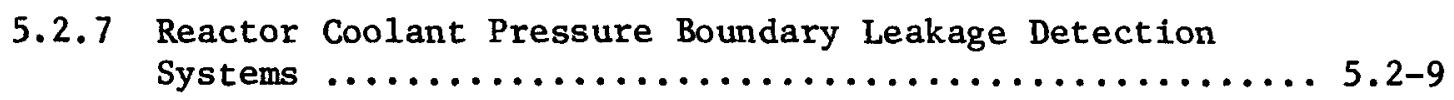

5.2.8 Inservice Inspection Program $\ldots \ldots \ldots \ldots \ldots \ldots \ldots \ldots \ldots .2 .11$

$\underline{5.3}$ Thermal Hydraulic System Design $\ldots \ldots \ldots \ldots \ldots \ldots \ldots \ldots \ldots \ldots .3 .3 .1$

5.3.1 Analytical Methods and Data ................... 5.3-1

5.3.2 Operating Restrictions on Pumps $\ldots \ldots \ldots \ldots \ldots \ldots \ldots \ldots . . \ldots \ldots .1$

5.3.3 Power-Flow Operating Map (BWR) $\ldots \ldots \ldots \ldots \ldots \ldots \ldots \ldots .6 .1$

5.3.4 Temperature-Power Operating Map (PWR) $\ldots \ldots \ldots \ldots \ldots \ldots .3 .1$

5.3.5 Load Following Characteristics ................. 5.3 1 


\section{TABLE OF CONTENTS (cont'd)}

PAGE NO.

5.3 .6 Transient Effects $\ldots \ldots \ldots \ldots \ldots \ldots \ldots \ldots \ldots \ldots \ldots \ldots \ldots \ldots . \ldots \ldots \ldots$

5.3.7 Thermal and Hydraulic Characterics Summary Table ..... 5.3-1

5.4 Reactor Vessels and Appurtenances $\ldots \ldots \ldots \ldots \ldots \ldots \ldots \ldots \ldots . \ldots . \ldots . \ldots$

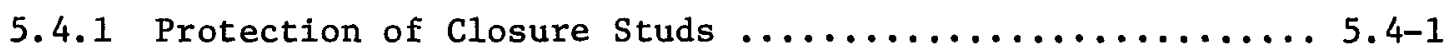

5.4.2 Special Processes for Fabrication and Inspection ...... 5.4-1

5.4.3 Features for Improved Reliability ............... 5.4-1

5.4 .4 Quality Assurance Surveillance ................. 5.4-1

5.4.5 Materials and Inspections $\ldots \ldots \ldots \ldots \ldots \ldots \ldots \ldots \ldots . \ldots \ldots$. 4 .

5.4 .6 Reactor Vesse1 Design Data .................. 5.4-1

5.4 .7 Reactor Vessel Schematic ................... 5.4-1

5.5 Component and Subsystem Design $\ldots \ldots \ldots \ldots \ldots \ldots \ldots \ldots \ldots \ldots \ldots$. $\ldots \ldots$.

5.5 .1 Reactor Coolant Pumps ..................... 5. 5-1

5.5 .2 Steam Generators $\ldots \ldots \ldots \ldots \ldots \ldots \ldots \ldots \ldots \ldots \ldots \ldots \ldots . \ldots \ldots \ldots$

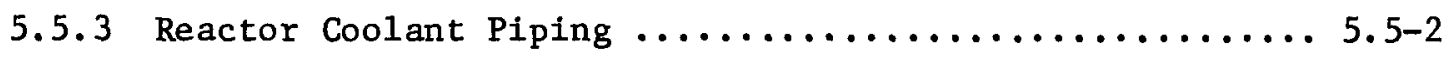

5.5.4 Main Steam Line Flow Restrictions .............. 5.5-2

5.5.5 Main Steam Line Isolation System ............. 5.5-2

5.5.6 Reactor Core Isolation Cooling System ........... 5.5-2 


\section{TABLE OF CONTENTS (cont'd)}

PAGE NO.

5.5.7 Residual Heat Removal System ................ 5.5-2

5.5.8 Reactor Coolant Cleanup System ............... 5.5-2

5.5.9 Main Steam Line and Feed Water Piping ............ 5.6-1

5.5 .10 Pressurizer $\ldots \ldots \ldots \ldots \ldots \ldots \ldots \ldots \ldots \ldots \ldots \ldots \ldots \ldots \ldots . \ldots \ldots \ldots$

5.5.11 Pressurizer Relief Tank ..................... 5.6-1

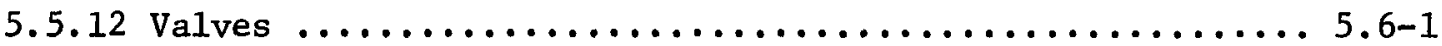

5.5 .13 Safety and Relief Valves ................... 5.6-1

5.5 .14 Component Supports $\ldots \ldots \ldots \ldots \ldots \ldots \ldots \ldots \ldots \ldots \ldots \ldots \ldots \ldots .6 \ldots 1$

5.6 Instrumentation Requirements $\ldots \ldots \ldots \ldots \ldots \ldots \ldots \ldots \ldots \ldots \ldots \ldots . . \ldots .6 . \ldots$

CHAPTER 6.0 - ENGINEERED SAFETY FEATURES

6.1 General $\ldots \ldots \ldots \ldots \ldots \ldots \ldots \ldots \ldots \ldots \ldots \ldots \ldots \ldots \ldots \ldots \ldots \ldots \ldots \ldots \ldots$

6.2 Containment Systems $\ldots \ldots \ldots \ldots \ldots \ldots \ldots \ldots \ldots \ldots \ldots \ldots \ldots \ldots \ldots \ldots \ldots$

6.2.1 Containment Functional Design ................. 6.2-1

6.2 .2 Containment Heat Removal Systems $\ldots \ldots \ldots \ldots \ldots \ldots \ldots \ldots .6 . \ldots$

6.2.3 Containment Air Purification and Cleanup Systems ..... 6. $\mathbf{\imath}-7$

6.2 .4 Containment Isolation Systems $\ldots \ldots \ldots \ldots \ldots \ldots \ldots \ldots \ldots \ldots . \ldots . \ldots$

6.2.5 Combustible Gas Control in Containment ........... 6.2-11

6.3 Emergency Core Cooling System $\ldots \ldots \ldots \ldots \ldots \ldots \ldots \ldots \ldots \ldots \ldots . \ldots .1$

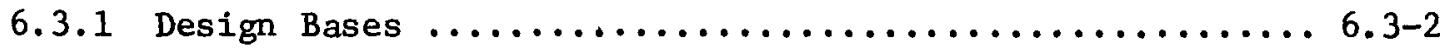

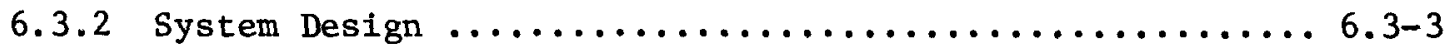

6.3 .3 Performance Evaluation $\ldots \ldots \ldots \ldots \ldots \ldots \ldots \ldots \ldots \ldots \ldots . \ldots \ldots$ 
PAGE NO.

6.3 .4 Tests and Inspections $\ldots \ldots \ldots \ldots \ldots \ldots \ldots \ldots \ldots \ldots \ldots \ldots$

6.3.5 Instrumentation Requirements $\ldots \ldots \ldots \ldots \ldots \ldots \ldots \ldots \ldots \ldots . \ldots .4$

6.4 Habitability Systems $\ldots \ldots \ldots \ldots \ldots \ldots \ldots \ldots \ldots \ldots \ldots \ldots \ldots \ldots \ldots . \ldots \ldots$

6.4.1 Habitability Systems Functional Design ............ 6.4-2

$6 . \mathrm{X}$ Other Engineered Safety Features $\ldots \ldots \ldots \ldots \ldots \ldots \ldots \ldots \ldots \ldots . \ldots . . \ldots$

$6 . \mathrm{x} .1$ Design Bases $\ldots \ldots \ldots \ldots \ldots \ldots \ldots \ldots \ldots \ldots \ldots \ldots \ldots \ldots \ldots \ldots \ldots \ldots$

$6 . x .2$ System Design $\ldots \ldots \ldots \ldots \ldots \ldots \ldots \ldots \ldots \ldots \ldots \ldots \ldots \ldots \ldots \ldots . \ldots \ldots$

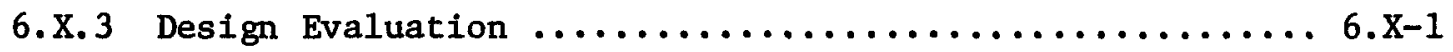

$6 . \mathrm{X} .4$ Tests and Inspections $\ldots \ldots \ldots \ldots \ldots \ldots \ldots \ldots \ldots \ldots \ldots \ldots \ldots$

6.X.5 Instrumentation Requirements $\ldots \ldots \ldots \ldots \ldots \ldots \ldots \ldots \ldots \ldots . \ldots . \ldots$

CHAPTER 7.0 - INSTRUMENTATION AND CONTROLS

7.1 Introduction $\ldots \ldots \ldots \ldots \ldots \ldots \ldots \ldots \ldots \ldots \ldots \ldots \ldots \ldots \ldots \ldots \ldots \ldots$

7.1.1 Identification of Safety Related Systems .......... 7.0-1

7.1.2 Identification of Safety Criteria ............... 7.0-1

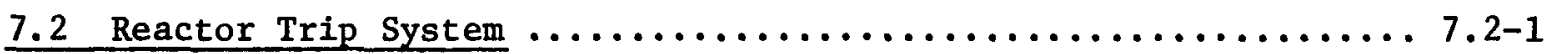

7.2 .1 Description $\ldots \ldots \ldots \ldots \ldots \ldots \ldots \ldots \ldots \ldots \ldots \ldots \ldots \ldots \ldots \ldots . \ldots \ldots$

7.2 .2 Analysis $\ldots \ldots \ldots \ldots \ldots \ldots \ldots \ldots \ldots \ldots \ldots \ldots \ldots \ldots \ldots \ldots \ldots \ldots \ldots \ldots$

7.3 Engineered Safety Feature Systems $\because \ldots \ldots \ldots \ldots \ldots \ldots \ldots \ldots \ldots \ldots . . \ldots 1$

7.3 .1 Description $\ldots \ldots \ldots \ldots \ldots \ldots \ldots \ldots \ldots \ldots \ldots \ldots \ldots \ldots \ldots . \ldots \ldots . \ldots \ldots$

7.3.2 Analysis $\ldots \ldots \ldots \ldots \ldots \ldots \ldots \ldots \ldots \ldots \ldots \ldots \ldots \ldots \ldots \ldots \ldots \ldots . \ldots \ldots$. 4.1 
TABLE OF CONTENTS (cont'd)

PAGE NO.

7.4 Systems Required for Safe Shutdown $\ldots \ldots \ldots \ldots \ldots \ldots \ldots \ldots \ldots \ldots .4 .1$

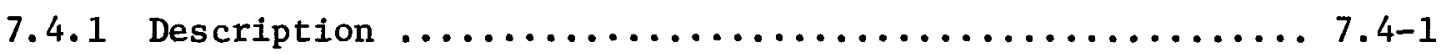

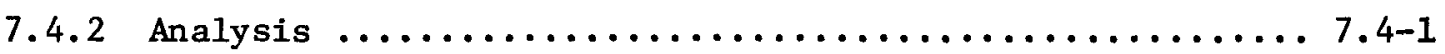

7.5 Safety Related Display Instrumentation $\ldots \ldots \ldots \ldots \ldots \ldots \ldots \ldots \ldots$. $7 . \ldots 1$

7.5 .1 Description $\ldots \ldots \ldots \ldots \ldots \ldots \ldots \ldots \ldots \ldots \ldots \ldots \ldots \ldots \ldots \ldots . . \ldots \ldots \ldots$

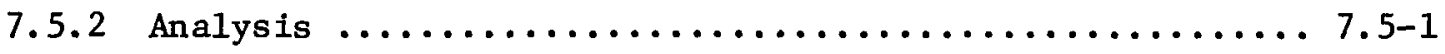

7.6 All 0ther Systems Required for Safety $\ldots \ldots \ldots \ldots \ldots \ldots \ldots \ldots \ldots$. . . .

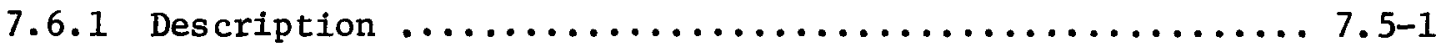

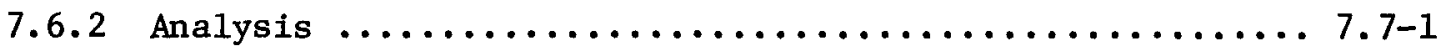

7.7 Control Systems Not Required for Safety $\ldots \ldots \ldots \ldots \ldots \ldots \ldots \ldots 7.7-1$

7.7 .1 Description $\ldots \ldots \ldots \ldots \ldots \ldots \ldots \ldots \ldots \ldots \ldots \ldots \ldots \ldots \ldots \ldots .7 . \ldots \ldots \ldots$

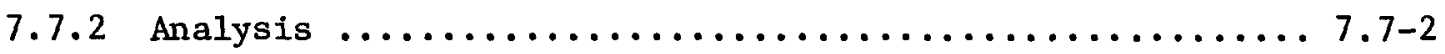

CHAPTER 8.0 - ELECTRIC POWER

8.1 Introduction $\ldots \ldots \ldots \ldots \ldots \ldots \ldots \ldots \ldots \ldots \ldots \ldots \ldots \ldots \ldots \ldots \ldots$

8.2 Offsite Power System $\ldots \ldots \ldots \ldots \ldots \ldots \ldots \ldots \ldots \ldots \ldots \ldots \ldots \ldots \ldots$

8.2 .1 Description $\ldots \ldots \ldots \ldots \ldots \ldots \ldots \ldots \ldots \ldots \ldots \ldots \ldots \ldots \ldots . \ldots . \ldots .1$

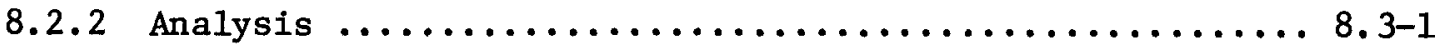

8.3 Onsite Power Systems $\ldots \ldots \ldots \ldots \ldots \ldots \ldots \ldots \ldots \ldots \ldots \ldots \ldots \ldots . \ldots \ldots$

8.3.1 A-C Power Systems ........................ 8.1

8.3.2 D-C Power Systems ....................... 8. 3-5 
TABLE OF CONTENTS (cont'd)

PAGE NO.

CHAPTER 9.0 - AUXILIARY SYSTEMS

9.1 Fuel Storage and Handling $\ldots \ldots \ldots \ldots \ldots \ldots \ldots \ldots \ldots \ldots . . \ldots \ldots, 0.1$

9.1.1 New Fuel Storage $\ldots \ldots \ldots \ldots \ldots \ldots \ldots \ldots \ldots \ldots \ldots . . .6 .1$

9.1 .2 Spent Fuel Storage $\ldots \ldots \ldots \ldots \ldots \ldots \ldots \ldots \ldots \ldots \ldots . . \ldots .1-1$

9.1.3 Spent Fuel Pool Cooling and Cleanup System .......... 9.1-1

9.1.4 Fuel Handling System $\ldots \ldots \ldots \ldots \ldots \ldots \ldots \ldots \ldots \ldots \ldots . ., 9.2-1$

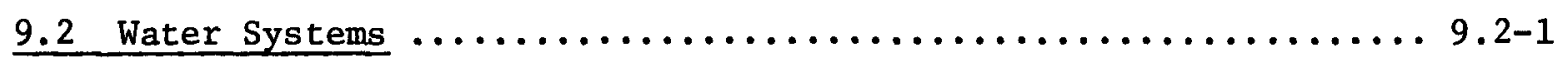

9.2.1 Station Service Water System $\ldots \ldots \ldots \ldots \ldots \ldots \ldots \ldots \ldots .2-2$

9.2.2 Cooling System for Reactor Auxiliaries $\ldots \ldots \ldots \ldots \ldots . .9 .2-2$

9.2.3 Demineralized Water Make-Up System $\ldots \ldots \ldots \ldots \ldots \ldots \ldots .9 .2-2$

9.2.4 Potable and Sanitary Water Systems $\ldots \ldots \ldots \ldots \ldots \ldots \ldots .2-2$

9.2.5 U1 timate Heat Sink $\ldots \ldots \ldots \ldots \ldots \ldots \ldots \ldots \ldots \ldots \ldots . . .1$

9.2.6 Condensate Storage Facilities $\ldots \ldots \ldots \ldots \ldots \ldots \ldots \ldots . . .6 .3$

9.3 Process Auxiliaries $\ldots \ldots \ldots \ldots \ldots \ldots \ldots \ldots \ldots \ldots \ldots \ldots . . \ldots .6 .1$

9.3.1 Compressed Air Systems $\ldots \ldots \ldots \ldots \ldots \ldots \ldots \ldots \ldots \ldots \ldots .9 .3-2$

9.3.2 Process Sampling System $\ldots \ldots \ldots \ldots \ldots \ldots \ldots \ldots \ldots \ldots .9 .6 .2$

9.3.3 Equipment and Floor Drainage System $\ldots \ldots \ldots \ldots \ldots \ldots .9 .3-2$

9.3.4 Chemical, Volume Control, and Liquid Poison Systems .... 9.3-2

9.3.5 Failed Fuel Detection System $\ldots \ldots \ldots \ldots \ldots \ldots \ldots \ldots \ldots .4 . \ldots .1$

9.4 Air Conditioning, Heating, Cooling, and Ventilation Systems ... 9.4-1

9.4.1 Control Room $\ldots \ldots \ldots \ldots \ldots \ldots \ldots \ldots \ldots \ldots \ldots \ldots \ldots . ., 9.4 .1$

9.4.2 Auxiliary Building $\ldots \ldots \ldots \ldots \ldots \ldots \ldots \ldots \ldots \ldots \ldots \ldots .4 .4 .1$ 
PAGE NO.

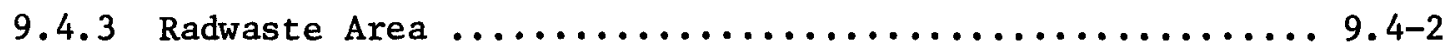

9.4 .4 Turbine Building $\ldots \ldots \ldots \ldots \ldots \ldots \ldots \ldots \ldots \ldots \ldots \ldots . \ldots \ldots . \ldots \ldots$

9.5 Other Auxiliary Systems $\ldots \ldots \ldots \ldots \ldots \ldots \ldots \ldots \ldots \ldots \ldots \ldots \ldots \ldots . . \ldots .1$

9.5 .1 Fire Protection System ...................... 9.5-1

9.5 .2 Communication Systems $\ldots \ldots \ldots \ldots \ldots \ldots \ldots \ldots \ldots \ldots \ldots \ldots . \ldots . \ldots . \ldots$

9.5 .3 Lighting Systems $\ldots \ldots \ldots \ldots \ldots \ldots \ldots \ldots \ldots \ldots \ldots \ldots \ldots \ldots \ldots$

9.5.4 Diese1 Generator Fuel 0il Storage and Transfer System .. 9.5-2

9.5.5 Diesel Generator Cooling Water System ............. 9.5-2

9.5.6 Diesel Generator Starting System ............... 9.5-2

9.5.7 Diesel Generator Lubrication System ............. 9.5-2

CHAPTER 10.0 - STEAM AND POWER CONVERSION SYSTEM

10.1 Summary Description $\ldots \ldots \ldots \ldots \ldots \ldots \ldots \ldots \ldots \ldots \ldots \ldots \ldots \ldots \ldots$.

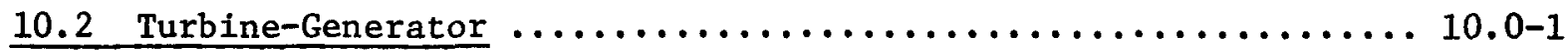

10.2.1 Design Bases ............................. 10.0-1

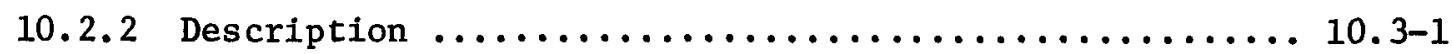

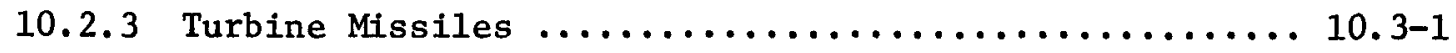

10.2 .4 Evaluation $\ldots \ldots \ldots \ldots \ldots \ldots \ldots \ldots \ldots \ldots \ldots \ldots \ldots \ldots \ldots \ldots . \ldots \ldots$

10.3 Main Steam Supply system $\ldots \ldots \ldots \ldots \ldots \ldots \ldots \ldots \ldots \ldots \ldots \ldots \ldots . \ldots 10 . \ldots 1$

10.3.1 Design Bases ............................ 10.3-1

10.3.2 Description $\ldots \ldots \ldots \ldots \ldots \ldots \ldots \ldots \ldots \ldots \ldots \ldots \ldots \ldots \ldots$ 10.4-1

10.3.3 Evaluation $\ldots \ldots \ldots \ldots \ldots \ldots \ldots \ldots \ldots \ldots \ldots \ldots \ldots \ldots \ldots . \ldots \ldots . \ldots \ldots$ 
PAGE NO.

10.3.4 Inspection and Testing Requirements ............ 10.4-1

10.3.5 Water Chemistry ........................ 10.4-1

10.4 Other Features of Steam and Power Conversion System $\ldots \ldots \ldots$ 10.4-1

10.4.1 Main Condensers ......................... 10.4-2

10.4.2 Main Condensers Evacuation System .............. 10.4-2

10.4.3 Turbine Gland Sealing System ................ 10.4-2

10.4.4 Turbine Bypass System .................... 10.4-2

10.4.5 Circulating Water System .................. 10.4-3

10.4.6 Condensate Clean-Up System ................. 10.4-3

10.4.7 Condensate and Feedwater Systems .............. 10.4-3

10.4.8 Steam Generator Blowdown Systems .............. 10.4-3

CHAPTER 11.0 - RADIOACTIVE WASTE MANAGEMENT

11.1 Source Terms $\ldots \ldots \ldots \ldots \ldots \ldots \ldots \ldots \ldots \ldots \ldots \ldots \ldots \ldots \ldots \ldots \ldots \ldots, 11.0,1$

11.2 Liquid Waste Systems $\ldots \ldots \ldots \ldots \ldots \ldots \ldots \ldots \ldots \ldots \ldots \ldots \ldots \ldots \ldots \ldots$

11.2.1 Design Objectives ....................... 11.2-1

11.2.2 Systems Descriptions ..................... 11.2-1

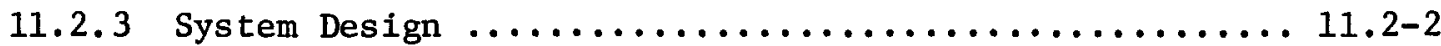

11.2.4 Operating Procedures ..................... 11.2-2

11.2.5 Performance Tests ....................... 11.2-2

11.2 .6 Estimated Releases $\ldots \ldots \ldots \ldots \ldots \ldots \ldots \ldots \ldots \ldots \ldots \ldots \ldots \ldots . \ldots \ldots \ldots$

11.2.7 Release Points ......................... 11.3-1 
PAGE NO.

11.2 .8 Dilution Factors $\ldots \ldots \ldots \ldots \ldots \ldots \ldots \ldots \ldots \ldots \ldots \ldots \ldots \ldots$ 11.3-1

11.2.9 Estimated Doses ........................ 11.3-1

11.3 Gaseous Waste Systems $\ldots \ldots \ldots \ldots \ldots \ldots \ldots \ldots \ldots \ldots \ldots \ldots \ldots \ldots \ldots$

11.3 .1 Design Objectives $\ldots \ldots \ldots \ldots \ldots \ldots \ldots \ldots \ldots \ldots \ldots \ldots \ldots \ldots$ 11.3-1

11.3.2 Systems Descriptions ..................... 11.3-1

11.3.3 System Design $\ldots \ldots \ldots \ldots \ldots \ldots \ldots \ldots \ldots \ldots \ldots \ldots \ldots \ldots \ldots \ldots$ 11.3-2

11.3 .4 Operating Procedures $\ldots \ldots \ldots \ldots \ldots \ldots \ldots \ldots \ldots \ldots \ldots \ldots \ldots \ldots$

11.3 .5 Performance Tests $\ldots \ldots \ldots \ldots \ldots \ldots \ldots \ldots \ldots \ldots \ldots \ldots \ldots$ 11.3-3

11.3 .6 Estimated Releases $\ldots \ldots \ldots \ldots \ldots \ldots \ldots \ldots \ldots \ldots \ldots \ldots \ldots$ 11.3-3

11.3 .7 Release Points ......................... 11.3-3

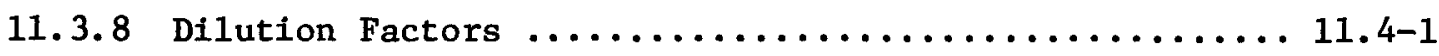

11.3.9 Estimated Doses ...................... 11.4-1

11.4 Process and Effluent Radiological Monitoring Systems $\ldots . . . .11 .4-1$

11.4.1 Design Objectives ....................... 11.4-1

11.4.2 Continuous Monitoring .................... 11.4-1

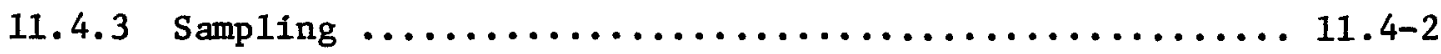

11.4.4 Inservice Inspections, Calibration, and Maintenance .. 11.4-2

11.5 Solid Waste System $\ldots \ldots \ldots \ldots \ldots \ldots \ldots \ldots \ldots \ldots \ldots \ldots \ldots \ldots \ldots \ldots 11.5-1$

11.5 .1 Design Objectives $\ldots \ldots \ldots \ldots \ldots \ldots \ldots \ldots \ldots \ldots \ldots \ldots \ldots \ldots \ldots$ 11.5-1

11.5 .2 System Inputs $\ldots \ldots \ldots \ldots \ldots \ldots \ldots \ldots \ldots \ldots \ldots \ldots \ldots \ldots \ldots$ 11.5-1

11.5.3 Equipment Description .................... 11.5-1 
PAGE NO.

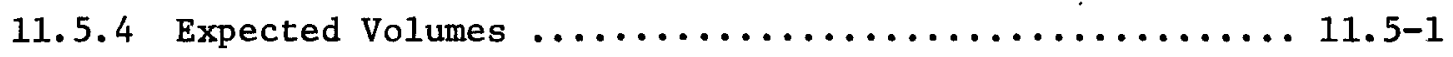

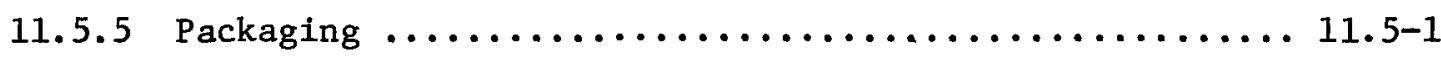

11.5 .6 Storage Facilities $\ldots \ldots \ldots \ldots \ldots \ldots \ldots \ldots \ldots \ldots \ldots, 11.6-1$

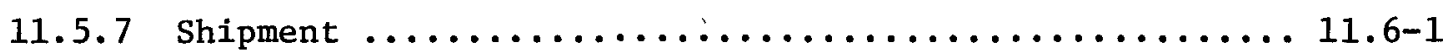

11.6 Offsite Radiological Monitoring Program $\ldots \ldots \ldots \ldots \ldots \ldots \ldots . . \ldots 11.6-1$

11.6.1 Expected Background $\ldots \ldots \ldots \ldots \ldots \ldots \ldots \ldots \ldots \ldots \ldots, 11.6-1$

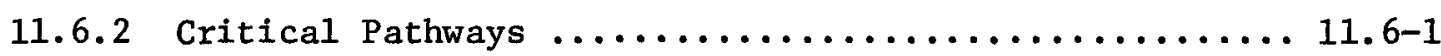

11.6.3 Sampling Media, Locations and Frequency $\ldots \ldots \ldots \ldots \ldots 11.6-2$

11.6.4 Analytical Sensitivity $\ldots \ldots \ldots \ldots \ldots \ldots \ldots \ldots \ldots \ldots \ldots \ldots \ldots \ldots \ldots, 11.6-2$

11.6.5 Data Analysis and Presentation $\ldots \ldots \ldots \ldots \ldots \ldots \ldots \ldots, 11.6-2$

11.6.6 Program Statistical Sensitivity $\ldots \ldots \ldots \ldots \ldots \ldots \ldots \ldots .11 .6-2$

CHAPTER 12.0 - RADIATION PROTECTION

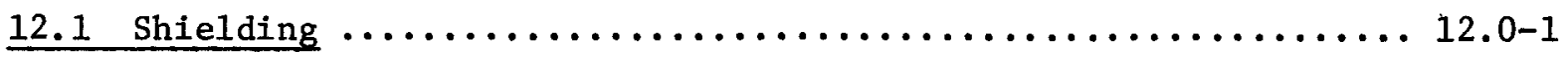

12.1.1 Design Objectives $\ldots \ldots \ldots \ldots, \ldots \ldots \ldots \ldots \ldots \ldots \ldots, 12.0-1$

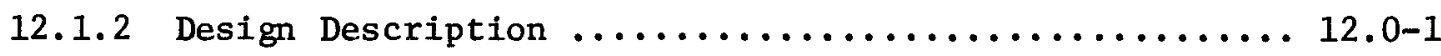

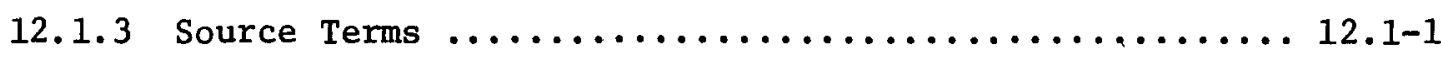

12.1.4 Area Monitoring $\ldots \ldots \ldots \ldots \ldots \ldots \ldots \ldots \ldots \ldots \ldots \ldots \ldots \ldots \ldots \ldots \ldots \ldots, 12.1$

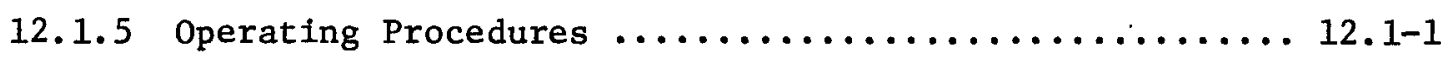

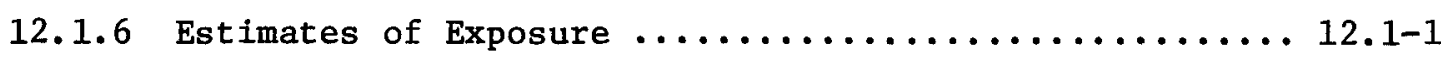

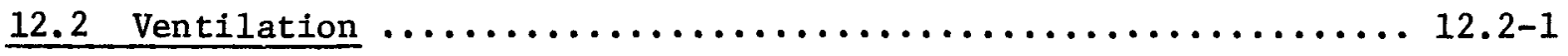


PAGE NO.

12.2.1 Design Objectives ....................... 12.2-1

12.2.2 Design Description $\ldots \ldots \ldots \ldots \ldots \ldots \ldots \ldots \ldots \ldots \ldots \ldots \ldots \ldots$ 12.2-1

12.2.3 Source Terms $\ldots \ldots \ldots \ldots \ldots \ldots \ldots \ldots \ldots \ldots \ldots \ldots \ldots \ldots \ldots \ldots$ 12.2-1

12.2.4 Airborne Radisactivity Monitoring .............. 12.3-1

12.2.5 Operating Procedures .................... 12.3-1

12.2.6 Estimates of Inhalation Doses $\ldots \ldots \ldots \ldots \ldots \ldots \ldots \ldots \ldots$ 12.3-1

12.3 Health Physics Program $\ldots \ldots \ldots \ldots \ldots \ldots \ldots \ldots \ldots \ldots \ldots \ldots \ldots \ldots$ 12.3-1

12.3.1 Program Objectives ...................... 12.3-1

12.3.2 Facilities and Equipment $\ldots \ldots \ldots \ldots \ldots \ldots \ldots \ldots \ldots \ldots \ldots$

12.3.3 Personnel Dosimetry ..................... 12.3-2

\section{CHAPTER 13.0 - CONDUCT OF OPERATIONS}

13.1 Organizational Structure of Applicant $\ldots \ldots \ldots \ldots \ldots \ldots \ldots \ldots$ 13.0

13.1.1 Corporate Organization $\ldots \ldots \ldots \ldots \ldots \ldots \ldots \ldots \ldots \ldots \ldots$ 13.0.1

13.1.2 Operating Organization $\ldots \ldots \ldots \ldots \ldots \ldots \ldots \ldots \ldots \ldots \ldots \ldots 1-1$

13.1.3 Qualification Requirements for Nuclear Plant Personne1 ................................13.1-1

13.2 Training Program $\ldots \ldots \ldots \ldots \ldots \ldots \ldots \ldots \ldots \ldots \ldots \ldots \ldots \ldots \ldots \ldots . \ldots \ldots$

13.2.1 Program Description ...................... 13.2-1

13.2.2 Retraining Program ...................... 13.2-2

13.2.3 Replacement Training ..................... 13.3-1

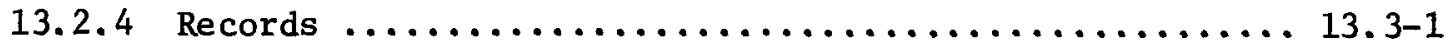


PAGE NO.

13.3 Emergency Planning $\ldots \ldots \ldots \ldots \ldots \ldots \ldots \ldots \ldots \ldots \ldots \ldots \ldots \ldots \ldots \ldots \ldots, 13.1$

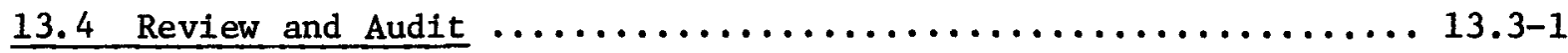

13.4.1 Review and Audit - Construction ................. 13.4-1

13.4.2 Review and Audit - Test and Operation $\ldots \ldots \ldots \ldots \ldots$ 13.4-1

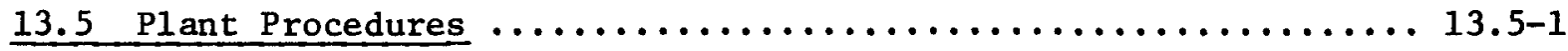

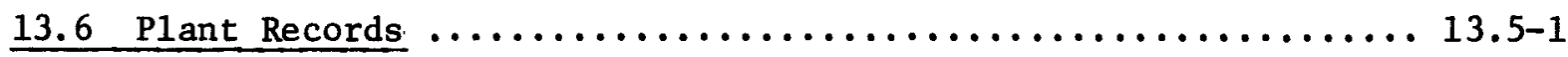

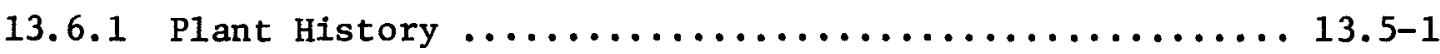

13.6.2 Operating Records $\ldots \ldots \ldots \ldots \ldots \ldots \ldots \ldots \ldots \ldots \ldots \ldots .13 .5-1$

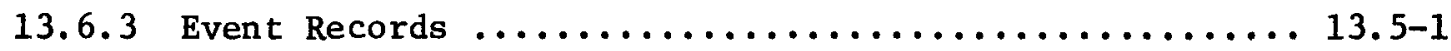

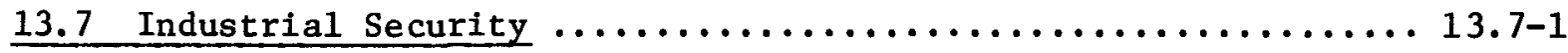

13.7.1 Personnel and P1ant Design $\ldots \ldots \ldots \ldots \ldots \ldots \ldots \ldots \ldots, 13.7-1$

13.7 .2 Security P1an $\ldots \ldots \ldots \ldots \ldots \ldots \ldots \ldots \ldots \ldots \ldots \ldots \ldots \ldots \ldots \ldots \ldots \ldots \ldots, 1$ CHAPTER 14.0 - INITIAL TESTS AND OPERATION

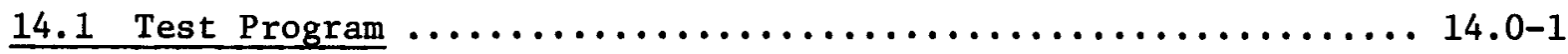

14.1.1 Administrative Procedures (Testing) $\ldots \ldots \ldots \ldots \ldots \ldots, 14.0-1$

14.1.2 Administrative Procedures (Modifications) $\ldots \ldots \ldots \ldots, 14.0-1$

14.1.3 Test Objectives and Procedures $\ldots \ldots \ldots \ldots \ldots \ldots \ldots \ldots . . \ldots \ldots .2-1$

14.1.4 Fuel Loading and Initial Operation $\ldots \ldots \ldots \ldots \ldots \ldots$ 14.2-1

14.1.5 Administrative Procedures (System Operation) $. . \ldots \ldots .14 .2-1$

14.2 Augmentation of Applicant's Staff for Initial Tests

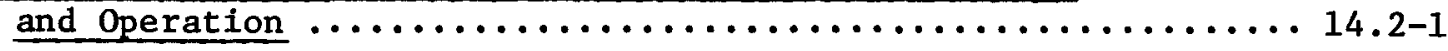


TABLE OF CONTENTS (cont'd)

PAGE NO.

14.2.1 Organizational Functions, Responsibilities and

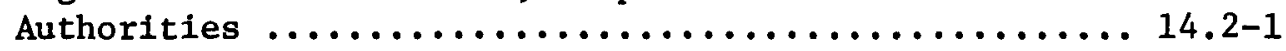

14.2.2 Interrelationships and Interfaces $\ldots \ldots \ldots \ldots \ldots \ldots \ldots .14 .2-1$

14.2.3 Personnel Functions, Responsibilities and Authorities. 14.2-2

14.2.4 Personnel Qualifications .................... 14.2-2

CHAPTER 15.0 - ACCIDENT ANALYSES

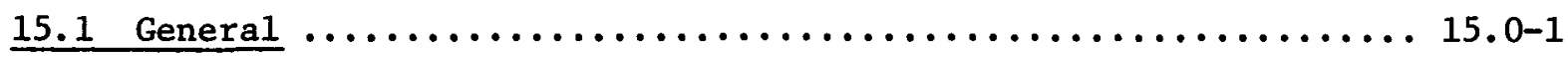

15.1.x Event Evaluation $\ldots \ldots \ldots \ldots \ldots \ldots \ldots \ldots \ldots \ldots \ldots \ldots \ldots \ldots \ldots \ldots \ldots, 1-1$

CHAPTER 16.0 TECHNICAL SPECIFICATIONS

CHAPTER 17.0 - QUALITY AS SURANCE

17.1 Quality Assurance During Design and Construction $\ldots \ldots \ldots \ldots$ 17.0-1

17.1.1 Organization $\ldots \ldots \ldots \ldots \ldots \ldots \ldots \ldots \ldots \ldots \ldots \ldots \ldots \ldots, 17.0-1$

17.1.2 Quality Assurance Program $\ldots \ldots \ldots \ldots \ldots \ldots \ldots \ldots \ldots \ldots \ldots \ldots \ldots \ldots .17$

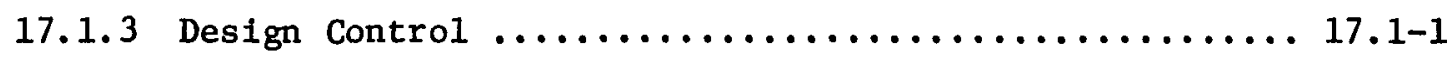

17.1.4 Procurement Document Control $\ldots \ldots \ldots \ldots \ldots \ldots \ldots \ldots \ldots .17 .1$

17.1.5 Instructions, Procedures, and Drawings ........... 17.1-2

17.1.6 Document Contro1 .......................... 17.1-2

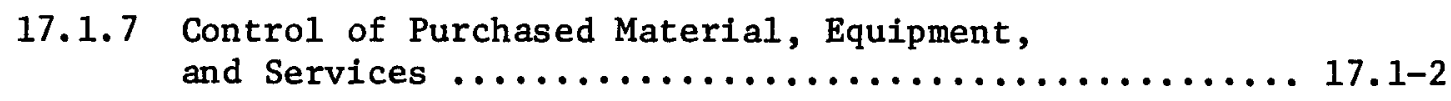

17.1.8 Identification and Control of Materials, Parts and Components .............................. 17.1-2

17.1.9 Control of Special Processes $\ldots \ldots \ldots \ldots \ldots \ldots \ldots \ldots \ldots, 17.1-2$ 
PAGE NO.

17.1 .10 Inspection $\ldots \ldots \ldots \ldots \ldots \ldots \ldots \ldots \ldots \ldots \ldots \ldots \ldots \ldots \ldots \ldots \ldots$

17.1.11 Test Control ...........................17.1-3

17.1.12 Control of Measuring and Test Equipment $\ldots \ldots \ldots \ldots \ldots 17.1-3$

17.1.13 Handling, Storage, and Shipping ..............17.1-3

17.1.14 Inspection, Test and Operating Status ........... 17.2-1

17.1.15 Nonconforming Materials, Parts or Components ....... 17.2-1

17.1.16 Corrective Action ...................... 17.2-1

17.1.17 Quality Assurance Records .................. 17.2-1

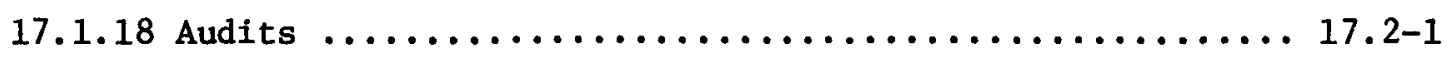

17.2 Quality Assurance Program for Station Operation $\ldots \ldots \ldots \ldots$..... 17. 


\section{INTRODUCTION}

Purpose and Applicability

The Standard Format and Content of Safety Analysis Reports for Nuclear Power Plants (hereinafter "Standard Format") has been prepared by the AEC regulatory staff to provide a uniformity in Safety Analysis Reports (SAR) submitted as part of applications for construction permits and operating licenses for nuclear power plants (plants), and to indicate the information to be provided in the reports. The principal purpose for the preparation and submittal of an SAR is to inform the Commission of the nature of the plant and plans for its use. The information provided in the SAR must be sufficient to permit a review of whether the plant can be built and operated without undue risk to the health and safety of the public. Prior to submission of an SAR an applicant should have evaluated the plant in sufficient detail to conclude that it can be built and operated safely. The SAR is the principal document whereby the applicant provides the information needed to understand the basis upon which this conclusion has been reached.

The required content of an SAR is described in general terms in Section 50.34 of the Commission's regulations (10 CFR Part 50). The Standard Format identifies the principal detailed information that is required by the staff in its evaluation of the application. This format will help assure the completeness of the information provided, will assist the regulatory staff and others in locating the information, and will aid in shortening the time needed for the review process. The Standard Format applies to both a Preliminary Safety Analysis Report (PSAR) and a Final Safety Analysis Report (FSAR), but if a specific criterion applies only to the FSAR, it will be so indicated in the text (FSAR) at the end of the text criterion as guidance of a specific statement. If a certain section is applicable only to a FSAR it may be indicated by including (FSAR) following the heading.

Although the specific information identified in the Standard Format has been prepared with reference to water-cooled power reactors, the general format and content for the presentation of information is also applicable to power reactors of other types.

The information indicated in the Standard Format is a minimum for an SAR. It is recognized that all the information that may be required to complete the staff review (or all the information that has been presented in previous SARs) is not identified explicitly, and the applicant should include additional information in the SAR, as appropriate. In this regard it is the applicant's responsibility to be aware of current areas of concern 
to the regulatory staff and subjects where insufficient information is being provided, as indicated by questions associated with other applications, and to address these in the SAR.

Upon receipt of an application, the regulatory staff will perform a preliminary review to determine if the SAR provides a reasonably complete presentation of the information that is needed to form a basis for the findings required before issuance of a permit or license*. The Standard Format will be used by the staff as a guideline to identify the type of information needed, unless there is good reason for not doing so. If it does not provide a reasonably complete presentation of the necessary information, further review of the application will not be initiated until a reasonably complete presentation is provided. The information provided in the SAR should be up-to-date with respect to the state of technology for nuclear power plants and should take into account recent changes in AEC regulations and guides and in industry codes and standards, the results of recent developments in nuclear reactor safety, and experience in the construction and operation of nuclear power plants.

The design information provided in the SAR should reflect the most advanced state of design at the time of submission. If certain information identified in the Standard Format is not yet available at the time of submission of a PSAR because the design has not progressed sufficiently at the time of writing, the following should be included in the PSAR: the criteria and bases being used to develop the required information, the concepts and/or alternatives under consideration, and the schedule for completion of the design, and submission of the missing information. In general, the PSAR should describe the preliminary design of the plant in sufficient detail to enable a definitive evaluation by the regulatory staff as to whether the plant can be constructed and operated without undue risk to the health and safety of the public. Similarly, the FSAR should describe in detail the final design of the plant as constructed.

Changes from the criteria, designs and bases included in the PSAR, as well as any new criteria, designs and bases, should be identified in the FSAR. The reasons for and safety significance of each change should be discussed.

Use of Standard Format

In the Standard Format, the SAR is divided into seventeen chapters (e.g., Chapter 2.0 Site Characteristics). Within the chapters the material is arranged in sections (e.g., 2.4 Hydrology), subsections (e.g., 2.4.2 Floods), and further subdivisions.

The SAR should follow the numbering system of the Standard Format at least down to the level of subsections. For example, subsection 2.4.2 of the SAR should provide all the information requested within subsection 2.4.2 of the Standard Format.

*See amendments to 10 CFR $\$ 2.101$ published in the Federal Register on Ju1y 28, 1972 (37 FR 15127) to become effective 30 days after publication. 
It is recognized that in many cases the applicant may wish to include appendices to the SAR to provide supplemental information not explicitly identified in the Standard Format. Some examples of such information are: (1) summaries of the manner in which the applicant has treated matters addressed in AEC Safety Guides or proposed regulations, and (2) supplementary information regarding calculational methods or design approaches used by the applicant or its agents.

\section{Style and Composition}

The applicant should strive for clear, concise presentations of the information provided in the SAR. Confusing or ambiguous statements and unnecessarily verbose descriptions do not contribute to expeditious technical review. Claims of adequacy of designs or design methods should be supported by technical bases.

It is not the intent of the Standard Format to require duplication of information. Similar or identical information may be requested in various chapters because it is relevant to more than one portion of the plant; however, this information, if appropriately referenced and identified in the applicable places of the SAR need not be repeated. For example, where piping and instrumentation diagrams for the same system are requested in more than one section in the Standard Format duplicate diagrams need not be submitted provided that all the information requested in all subsections is submitted and appropriately identified and referenced.

Where númerical values are stated, the number of significant figures given should reflect the accuracy or precision to which the number is known. Where possible, estimated limits of error or uncertainty should be given.

Abbreviations should be consistent throughout the SAR, and should be consistent with generally accepted usage. Any abbreviations, symbols or special terms not in general usage or unique to the proposed plant should be defined in each chapter of the SAR where they are used.

Drawings, maps, diagrams, sketches, and charts should be employed where the information can be presented more adequately or conveniently by such means. Due concern should be taken to assure that all information presented in drawings is legible, symbols are defined, and drawings are not reduced to the extent that visual aids are necessary to interpret pertinent items of information presented in the drawings.

Reports or other documents that are referenced in the text of the SAR should be listed at the end of the section in which they are referenced. In cases where proprietary documents are referenced, a non-proprietary 
summary description of the document should also be referenced. Material incorporated into the application by reference should be listed in Chapter 1. (See Section 1.6 of the Standard Format.)

\section{Physica1 Specifications}

All material submitted as part of the Safety Analysis Report should conform to specific standards as to the physical dimensions of page size, quality of paper and inks, and numbering of pages, exhibits and attachments. More specifically:

a. Paper Size (not to exceed)

Textual pages: $81 / 2 \times 11$ inches.

Drawings and graphics: $81 / 2 \times 11$ inches preferred; however, a larger size is acceptable provided:

(1) the bound side does not exceed 11 inches except where required for leg, legality and

(2) the finished copy when folded does not exceed $81 / 2 \times 11$ inches.

b. Paper Stock

Weight or substance: 16 to 20 pound.

Composition: wood chemical sulphite (no groundwood) and a $\mathrm{pH}$ factor of 5.5 .

Color: white is preferred, but color (particularly pastel) is acceptable provided the combination of paper stock and ink is suitable for microfilming.

c. Ink

Color sufficiently dense to record on microfilm or image-copying equipment.

d. Page Margins

A margin of no less than one inch is to be maintained on the top, bottom, and binding side of all pages submitted.

e. Printing

Composition: textual pages should be single spaced.

Type front \& style: must be suitable for microfilming.

Reproduction: may be mechanically or photographically reproduced. All pages of text to be printed on two sides and the image printed head-to-heatr. 
f. Binding

Pages should be punched for loose-leaf ring binding.

g. Page Numbering

Pages should be numbered by chapter and section and sequentially within the section, as is done in the Standard Format. Do not number sequentially the entire report.

\section{Procedure for Updating or Revising Pages}

The updating or revising of data and text should be on a replacement page basis. "Pen and ink" or "cut and paste" changes should not be used.

The changed or revised portion on each page should be highlighted by a "change indicator" mark. This mark should be: (a) a bold line vertically drawn in the margin opposite the binding margin, and (b) only as long as the portion actually changed.

Al1 pages submitted to update, revise, or add pages to the report are to show the date of change and a change or amendment number. The transmittal letter should include a guide page listing the pages to be inserted and pages to be removed. 
STANDARD FORMAT AND CONTENT OF SAFETY ANALYSIS REPORTS

FOR NUCLEAR POWER REACTORS

\subsection{INTRODUCTION AND GENERAL DESCRIPTION OF PLANT}

The first chapter of the SAR should present an introduction and general plant description. This chapter should enable the reader to obtain a basic understanding of the overall facility without having to delve into the subsequent chapters. Review of the detailed chapters which follow can then be accomplished with better perspective and with recognition of the relative safety importance of each individual item to the overall plant design.

\subsection{Introduction}

This section should present briefly the principal aspects of the overall application. For example, the specific information that should be included is as follows: the type of license requested, the number of plant units, a brief description of the proposed location of the plant, the type of the nuclear steam supply system and its designer, the type of containment structure and its designer, the core thermal power levels, both rated and design,* and the corresponding net electrical output for each thermal power leve1, the scheduled completion date and the anticipated commercial operation date for each unit.

\subsection{General Plant Description}

This section should include a summary description of the principal characteristics of the site, and a concise description of the plant. The plant description should include a brief discussion of the principal design criteria, operating characteristics and safety considerations for the nuclear steam supply system, the engineered safety features and emergency systems, instrumentation, control and electrical systems, power conversion system, fuel handling and storage systems, cooling water and other auxiliary systems, and the radioactive waste management system. The general arrangement of major structures and equipment should be indicated by the use of plan and elevation drawings in sufficient number and detail to provide a reasonable understanding of the general layout of the plant. Those features of the plant likely to be of special interest

* Rated power is defined as the power level at which the plant would be operated if licensed. Design power is defined as the highest power level that would be permitted by plant design, and which is used in some safety evaluations. 
because of their relationship to safety should be identified. Such items as unusual site characteristics, solutions to particularly difficult engineering problems, and significant extrapolations in the technology as represented by the design should be highlighted.

\subsection{Comparison Tables}

\subsubsection{Comparisons with Similar Facility Designs}

This subsection should provide a summary of sufficient detail to identify the principal similarities to other nuclear power plants (preferabl plants already designed, constructed, or operated) and principal differences from such plants. Such comparisons may be limited to those plants or portions of plants designed or built by the nuclear steam system supplier, the architect-engineer or the applicant. This information should be provided in tabular form, cross-referencing the appropriate sections of the SAR that fully describe the similarities and differences. This comparison should not be restricted to a comparison of the reactor design parameters, but should include all principal features of the plant such as the engineered safety features, the containment concept, instrumentation and electrical systems, the radioactive waste management system, and other principal systems.

\subsubsection{Comparison of Final and Preliminary Information (FSAR)}

The FSAR should be complete wi thout reliance on the PSAR. In an FSAR, tables should be provided to identify clearly all the significant changes that have been made in the plant since submittal of the PSAR. Each item should be cross-referenced to the appropriate section in the FSAR that describes the changes and the reasons for them.

\subsection{Identification of Agents and Contractors}

This section should identify the prime agents or contractors for the design, construction and operation of the nuclear power plant. The principal consultants and outside service organizations (such as those providing audits of the quality assurance program) should be identified. The division of responsibility between the reactor designer, architectengineer, constructor and plant operator should be delineated.

\subsection{Requirements for Further Technical Information}

In accordance with Section 50.35 of 10 CFR Part 50 , this section of the PSAR should identify, describe, and discuss those safety features or components for which further technical information is required in support 
of the issuance of a construction permit, but which has not been supplied in the PSAR. This section of the PSAR should:

(1) identify and distinguish between those technical information development programs that will be required to determine the adequacy of a new design, and those that will be used to demonstrate the margin of conservatism of a proven design,

(2) describe the specific technical information that must be obtained to demonstrate acceptable resolution of the problems,

(3) describe the program in sufficient detail to show how the information will be obtained,

(4) provide a schedule of completion of the program as related to the projected startup date of the proposed plant, and

(5) discuss the design alternatives or operational restrictions available in the event that the results of the program do not demonstrate acceptable resolution of the problems.

Reference may be made to topical program summary reports filed with the AEC; however, if such references are made, the applicability of each technical information development item to the applicant's plant should be discussed.

In the FSAR this section should include a resume of special technical information development programs undertaken to establish the final design and/or to demonstrate the conservatism of the design, and a discussion of any programs that will be conducted during operation in order to demonstrate the acceptability of contemplated future changes in design or modes of operation.

\subsection{Material Incorporated by Reference}

This section should provide a tabulation of all "topical reports" which are incorporated by reference as part of the application. In this context, "topical reports" are defined as reports that have been prepared by reactor manufacturers or architect-engineers and filed separately with the AEC in support of this application or of other applications or product lines. This tabulation should include for each topical report the title, the report number, the date submitted to the AEC, and the applicable sections of the SAR in which this report is referenced. For any topical 
reports that have been withheld from public disclosure, pursuant to Section 2.790 (b) of 10 CFR Part 2, as proprietary documents, nonproprietary summary descriptions of the general content of such reports should also be referenced. This section should also include a tabulation of any documents submitted to the AEC in other applications that are incorporated in whole or in part in this application by reference.

In appropriate locations within the SAR, summary descriptions should be provided of information incorporated by reference that has been provided in SARs submitted for other applications. 


\subsection{SITE CHARACTERISTICS}

This chapter of the SAR should provide information on the geological, seismological, hydrological, and meteorological characteristics of the site and vicinity, in conjunction with population distribution, land use, and site activities and controls. The purpose is to indicate how these site characteristics have influenced plant design and operating criteria and to show the adequacy of the site characteristics from a safety viewpoint.

\subsection{Geography and Demography}

\subsubsection{Site Location}

The site location should be described by specifying the latitude and longitude of the reactor to the nearest second, and the Universal Transverse Mercator coordinates* to the nearest 100 meters. The state and county in which the site is located should be identified, as well as the location of the site relative to prominent natural and man-made features such as rivers and lakes.

\subsubsection{Site Description}

A map of the site should be included and should be of suitable scale to define clearly the boundary of the site and the distance from significant plant features to the site boundary. The area to be considered as the exclusion area (as defined in 10 CFR Part 100) must be delineated clearly. The application should include a description of the applicant's legal rights with respect to the properties described (ownership, lease, easements, etc.) and/or the nature and source of his authority to "determine all activities."

\subsubsection{Exclusion Area Control - For any activity unrelated to} plant operation conducted within the exclusion area, the applicant should identify the nature of its authority to determine all activities in the exclusion area. Where the exclusion area is traversed by a highway, waterway, or railroad, the applicant should describe the arrangements made or to be made to control traffic in the event of an emergency.

\subsubsection{Boundaries for Establishing Effluent Release Limits - The} site description should define the boundary lines of the restricted area (as defined in 10 CFR Part 20), and describe how access to this area is

*As found on U.S. Geological Survey topographical maps. 
controlled for radiation protection purposes, including how applicant will be made aware of individuals entering the area and will control such access. If it is proposed that limits higher than those established by Part 20.106(a) (and related low as practicable provisions) be set, then the information required by Part 20.106 should be submitted. The site map discussed above may be used to identify this area, or a separate map of the site may be used. Indicate the location of the boundary line with respect to the water's edge of nearby rivers and lakes. Distances from plant effluent release points to the boundary line should be defined clearly.

\subsubsection{Population and Population Distribution}

Population data presented should be based on the 1970 census data and, where available, more recent census data. The following information should be presented on the population and its distribution.

2.1.3.1 Population Within Ten Miles - On a map of suitable scale which identifies places of significant population grouping, such as cities and towns within the 10 mile radius, concentric circles should be drawn, with the reactor at the center point, at distances of $1,2,3$, 4,5 and $10 \mathrm{miles}$. The circles should be divided into 22-1/2 degree segments with each segment centered on one of the 16 cardinal compass points (e.g., north, north-northeast, northeast, etc.). Within each area thus formed by the concentric circles and radial lines, the current resident population should be specified, as well as the projected population by decade for at least four decades. Describe the basis for the projection.

\subsubsection{Population Between 10 and 50 Miles - A map of suitable} scale for these distances should be used in the same manner as described in 2.1.3.1 above to describe the population and its distribution at $10 \mathrm{mile}$ intervals between the 10 and $50 \mathrm{mile}$ radii from the reactor.

\subsubsection{Low Population Zone - The low population zone (as defined} in $10 \mathrm{CFR}$ Part 100) and the basis for its selection should be specified. The population within the zone should be described in a manner similar to that described in 2.1.3.1 and 2.1.3.2, or presented in tabular form.

2.1.3.4 Transient Population - Variations in population on a seasonal basis should be described and, where appropriate, variations in population distribution during the working day should be discussed, particularly where significant shifts in population or population distribution may occur within the low population zone.

2.1.3.5 Population Center - The nearest population center (as defined in 10 CFR Part 100) should be specified and its population, direction, and distance from the reactor provided.

2.1.3.6 Public Facilities and Institutions - Any facilities and institutions such as schools, hospitals, prisons, and parks within ten 
miles of the site should be identified and located with respect to the reactor, and their transient or permanent populations discussed.

\subsubsection{Uses of Adjacent Lands and Waters}

Land uses and uses of nearby bodies of water should be described. Lands devoted to agricultural uses should be described in the context of principal food products, acreage, and yields. The nearest location used for dairying should be identified. The description of water uses should include extent of commercial and sport fishing, species and yields of fish taken and relative abundance, and commercial and recreational uses. Suosections 2.4.1.2 and 2.4.13.1 may be cross-referenced for tabulations of surface and groundwater uses.

Sufficient data should be provided regarding food crops and edible aquatic biota to permit estimates to be made in Chapter 11 of the range of maximum potential annual radiation doses to individuals and to the population resulting from the principal radionuclides in discharged effluents.

\subsection{Nearby Industrial, Transportation and Military Facilities}

The purpose of this section is to establish whether the plant is designed to withstand safely the effects of potential accidents at, or as a result of the presence of, other industrial, transportation, mining, and military installations or operations in the vicinity* of the site which may have a potentially significant effect on the safe operation of the plant.

\subsubsection{Locations and Routes}

Provide a map showing all military bases, missile sites, manufacturing plants, chemical plants and storage facilities, airports, transportation routes (land and water), and oil and gas pipelines and tank farms. Include a description of military firing ranges and nearby airplane low level flight, holding, and landing patterns.

\subsubsection{Descriptions}

A description of products manufactured, stored, or transported should be provided, as should the maximum quantities of hazardous material likely to be processed, stored, or transported.

* All activities within five miles of the site may be considered. Activities at greater distances should be described and evaluated as appropriate to their significance. 


\subsubsection{Evaluations}

Based on the information provided in subsections 2.2.1 and 2.2.2, a safety evaluation should be made for each of the activities including consideration of the following aspects as applicable.

For plants located on navigable waterways, the evaluation should consider the potential effects of impacts on the plant cooling water intake structures by the maximum size and weight of barges or ships that normally pass the site. (If the plant is located in a region in which low temperatures are experienced, discuss the protection provided to the intake structures against ice blockage and/or damage.) The effects of accidental upstream releases of corrosive liquids or oil on the intake structures should be evaluated.

The effects of explosion of chemicals, flammable gases, or munitions should be considered. If large natural gas pipelines cross, or pass close to the plant, explosions from this source should be evaluated. In situations where stone quarries are located near the site, consider the effect of detonation of the maximum amount of explosives that is permitted to be stored.

The potential effects of fires in adjacent oil and gasoline plants or storage facilities, adjacent industries, brush and forest fires and from transportation incidents should be evaluated. Evaluate the potential effects of accidental releases of toxic gases (e.g., chlorine) from onsite storage facilities, nearby industries and transportation accidents. The effect of expected airborne pollutants on important plant components should be evaluated to show the adequacy of the design, materials, construction, and operating procedures.

For sites in the vicinity of airports, evaluate the potential effects of aircraft impacts on the plant, taking into account aircraft size, velocities, weight, and fuel loading.

In the event high natural-draft cooling towers or other tall structures such as discharge stacks are used onsite, evaluate the potential for damage to equipment or structures important to safety in the event of collapse.

\subsection{Meteorology}

This section should provide a meteorological description of the site and its surrounding areas, and sufficient data to describe the meteorological characteristics of the site. The information should be sufficient to permit an independent evaluation by the staff of the meteorological effects. 


\subsubsection{Regional Climatology}

2.3.1.1 Data Sources - Provide references to the climatic at lases and regional climatic summaries used.

2.3.1.2 General Climate - Describe the general climate of the region including the interplay between synoptic scale processes and terrain characteristics of the region.

2.3.1.3 Severe Weather - Provide the intensity and frequency of occurrence of heavy precipitation (rain and snow), hail, ice storms, thunderstorms, tornadoes, strong winds, and high air pollution potential.

\subsubsection{Local Meteorology}

2.3.2.1 Data Sources - Provide onsite data summaries and/or National Weather Service (NOAA) station summaries from nearby locations and other meteorological data which are indicative of site characteristics. These summaries will be used to provide an assessment of the impact of meteorological phenomena on the plant and the impact of the plant on the meteorological phenomena.

\subsubsection{Normal and Extreme Values of Meteorological Parameters -} Provide monthly summaries of wind (direction and speed combined), temperature, atmospheric water vapor (absolute and relative) if cooling towers are planned, precipitation (rain and snow), fog and atmospheric stability (if available). Summaries of the persistence of wind and atmospheric stability (if available) should also be provided.

2.3.2.3 Potential Influence of the Plant and Its Facilities on Local Meteorology - Discuss and provide an evaluation of the potential modification of the normal and extreme values of meteorological parameters described in 2.3.2.2 above as a result of the presence and operation of the plant (e.g., the influence of cooling towers or water impoundment features on meteorological conditions).

2.3.2.4 Topographical Description - Provide a map showing the detailed topographic features (as modified by the plant) within at least a five mile radius of the plant, and topographic cross sections in the 16 compass point sectors radiating from the plant. A map showing general topographic features within at least a fifty mile radius of the plant should also be provided. Include discussion of the effect of topography on short-term and long-term diffusion estimates from all release points, where appropriate. 


\subsubsection{Onsite Meteorological Measurements Programs}

Provide a description of the preoperational and operational programs for meteorological measurements at the plant site, including measurements made, locations and elevations of measurements, description of instruments used, calibration and maintenance of instruments, data output and recording systems, and data analysis procedures. Provide joint frequency distributions of wind direction and speed by atmospheric stability class (derived from currently acceptable parameters) based on appropriate meteorological measurement heights and data reporting periods. If adequate onsite meteorological data are not available, conservative estimates of appropriate atmospheric dilution factors should be used. (Additional guidance on acceptable onsite meteorological measurements programs and duration of onsite measurements is presented in AEC Safety Guide 23.)

\subsubsection{Short Term (Accident) Diffusion Estimates}

2.3.4.1 Objective - Provide conservative and realistic estimates of atmospheric dilution factors at the site boundary (exclusion area) and the outer boundary of the low population zone for appropriate time periods to 30 days after an accident, based on onsite or nearby representative station meteorological data. Onsite data should be used as soon as a one year period of record is completed.

2.3.4.2 Calculations - Provide cumulative frequency distributions of hourly calculated atmospheric dilution factors $(X / Q)$ from onsite data using the minimum site boundary distance (exclusion area) and actual site boundary (exclusion area) distances from the effluent release point(s). Report the $X / Q$ values from each of these distributions that are exceeded $5 \%$ and $50 \%$ (median value) of the time. Provide cumulative frequency distributions of $\times / Q$ estimates for time periods of 8 and 16 hours, and 3 and 26 days at the outer boundary of the low population zone and report the worst condition and the $5 \%$ and $50 \%$ probability level conditions. Guidance on appropriate diffusion models for estimating $X / Q$ values is presented in AEC Safety Guides 3 and 4.

\subsubsection{Long Term (Routine) Diffusion Estimates}

2.3.5.1 Objective - Provide realistic estimates of annual average offsite atmospheric dilution factors for annual average release limit calculations and man-rem estimates based on onsite and/or nearby representative station meteorological data.

\section{$2 \cdot 3-3$}


2.3.5.2 Calculations - Provide a calculation of the maximum annual average $X / Q$ at or beyond the site boundary (exclusion area) utilizing appropriate meteorological data for each routine venting location. Provide estimates of annual average $X / Q$ values for 16 radial sectors to a distance of 50 miles from the plant using appropriate meteorological data. Provide analyses for determining the finite cloud parameters for annual average release calculations of gaseous effluents. Also provide and justify above ground release points (e.g., effective stack height).

\subsection{Hydrologic Engineering}

The following subsections should contain sufficient information to allow an independent hydrologic engineering review to be made of all hydrologically related design bases, performance requirements, bases for design and operating procedures for structures, systems and components important to safety as a result of the following phenomena:

(1) runoff type floods up to and including the probable maximum flood,

(2) surges, seiches and wave action,

(3) tsunamis,

(4) artifical floods due to dam failures or landslides,

(5) Low water and/or drought effects (including set-down due to surges, seiches or tsunamis) on cooling water supplies and their dependability,

(6) ice blockage of cooling water sources and ice jam flooding;

(7) channel diversions of cooling water sources;

(8) dilution and dispersion characteristics of the normal and accidental release hydrosphere relating existing and potential future users of surface and groundwater resources.

\subsubsection{Hydrologic Description}

2.4.1.1 Site and Facilities - Describe the site and a11 safety-related elevations, structures, exterior accesses thereto and safety related equipment and systems from the standpoint of hydrologic considerations. Provide a topographic map of the site and indicate thereon any proposed changes to natural drainage features. 
2.4.1.2 Hydrosphere - Describe the location, size, shape and other hydrologic characteristics of streams, rivers, lakes, shore regions and groundwater environments influencing plant siting. Include a description of upstream and downstream river control structures, and provide a regional topographic map showing the major hydrologic features. List the owner, location, and rate of use of surface water users whose intakes could be adversely affected by accidental or normal releases of contaminants. Refer to subsection 2.4.13.2 for the tabulation of groundwater users.

\section{$\underline{2.4 .2 \quad \text { Floods }}$}

2.4.2.1 Flood History - Provide a synopsis of the flood history (date, level, peak discharge, etc.) in the site region. A "flood" is defined as any abnormally high water stage or overflow from a stream, floodway, lake or coastal area that results in significantly detrimental effects. Include river or stream floods, surges, seiches, tsunamis, dam failures, ice jams, etc.

2.4.2.2 Flood Design Considerations - Discuss the general capability of safety related facilities, systems, and equipment to withstand floods and flood waves. The design flood protection for safety related components and structures of the plant should be based on the highest calculated flood water level elevations and flood wave effects resulting from analysis of several different hypothetical floods. All possible flood conditions up to and including the highest and most critical flood level resulting from any of several different probable maximum events are to be considered as the basis for the design protection level for safety related components and structures of the plant. The probable maximum water level from a stream flood, surge, seiche, combination of surge and stream flood in estuarial areas, wave action or tsunami (whichever is applicable and/or greatest) may cause the highest water level. Other possibilities are the flood level resulting from the most severe flood wave at the plant site caused by an upstream landslide, dam failure or dam breaching, a seismic or foundation disturbance, or a hydrologic or structural design capability that is inadequate for nuclear plants. The effects of coincident wind generated wave action should be superimposed on the applicable flood level. The assumed hypothetical conditions are to be evaluated both statically and dynamically to determine the design flood protection level. Landslides upstream or downstream of the site should also be considered herein. The topical information required is generally outlined in subsections 2.4 .3 through 2.4 .6 , but the type of events considered and the controlling event should be summarized in this subsection. 


\subsubsection{Probable Maximum Flood (PMF) on Streams and Rivers}

Describe the PMF using the Corps of Engineers definition of such an event: the hypothetical flood characteristics (peak discharge, volume, and hydrograph shape) that are considered to be the most severe "reasonably possible" at a particular location, based on relatively comprehensive hydrometeorological analyses of critical runoff-producing precipitation (and snowmelt, if pertinent) and hydrologic factors favorable for maximum flood runoff. PMF determinations are usualiy prepared by estimating "probable maximum" precipitation (PMP) amounts over the subject drainage basin, in critical periods of time, and computing the residual runoff hydrograph likely to result with critical conditions of ground wetness and related factors. Estimates of the PMF are usually based on the observed and deduced characteristics of flood-producing storms and associated hydrologic factors, modified on the basis of hydrometeorological analyses to represent the most severe runoff conditions considered to be "reasonably possible" in the particular drainage basin under study. In addition to determining the PMF for adjacent large rivers or streams, a local PMF should be estimated for each local drainage course which can influence safety related structures, systems, or components. Summarize the locations and associated water levels for which PMF determinations have been made.

2.4.3.1 Probable Maximum Precipitation (PMP) - The PMP is the theoretically greatest precipitation over the applicable drainage area that would produce flood flows that have virtually no risk of being exceeded. These estimates usually involve detailed analyses of actual flood-producing storms in the general region of the drainage basin under study, and certain modifications and extrapolations of historical data to reflect more severe rainfall-runoff relations than actually recorded, insofar as these are deemed "reasonably possible" of occurrence on the basis of hydrometeorological reasoning. Discuss considerations of storm configuration Corientation of areal distribution), maximized precipitation amounts (include a description of maximization procedures and/or studies available in the area such as reference to National Weather Service and Corps of Engineers determinations), time distributions, orographic effects, storm centering, seasonal effects, antecedent storm sequences, antecedent snowpack (depth, moisture content. areal distribution), and any snowmelt mode1. Present the selected maximized storm precipitation distribution (time and space).

2.4.3.2 Precipitation Losses - Describe the absorption capability of the basin including consideration of initial losses, infiltration rates, and antecedent precipitation. Provide verification of these assumptions by reference to regional studies, or by presenting detailed local stormrunoff studies. 
2.4.3.3 Runoff Model - Describe the hydrologic response characteristics of the watershed to precipitation (such as unit hydrographs), verification from historic floods or synthetic procedures, the nonlinearity of the model at high rainfall rates, and provide a description of sub-basin drainage areas (including a map), their sizes and topographic features of watersheds. Include a tabulation of all drainage areas, and runoff, reservoir and channel routing coefficients.

2.4.3.4 Probable Maximum Flood Flow - Present the PMF runoff hydrograph as defined as resulting from the probable maximum precipitation (and snowmelt, if pertinent) which considers the hydrologic characteristics of the potential influence of existing and proposed upstream dams and river structures for regulating or increasing the water level. If such dams or structures are designed to withstand a PMF, their influence on the regulation of water flow and levels shall be considered; however, if they are not designed or constructed to withstand the PMF (or inflow from an upstream dam failure) the maximum water flows and resulting static and dynamic effects from their failure by breaching should be included in the PMF estimate (cross reference para. 2.4.4.2). Discuss the PMF stream-course response mode1 and its ability to compute floods of various magnitudes up to the severity of a PMF. Present any reservoir and channel routing assumptions with appropriate discussions of initial conditions, outlet works (both uncontrolled and controlled), spillways (both uncontrolled and controlled), the ability of any dams to withstand coincident reservoir wind wave action (including discussions of set-up, the significant wave height, the maximum wave height, and runup), the wave protection afforded, and the reservoir design capacity (i.e., the capacity for PMF and coincident wind wave action). Finally, provide the estimated PMF discharge hydrograph at the site and, when available, provide a similar hydrograph without upstream reservoir effects to allow evaluation of reservoir effects and a regional comparison of the PMF estimate to be made.

2.4.3.5 Water Leve1 Determinations - Describe the translation of the estimated peak PMF discharge to elevation using (when applicable) crosssection and profile data, reconstitution of historical floods (with consideration of high water marks and discharge estimates), standard step methods, roughness coefficients, bridge and other losses, verification, extrapolation of coefficients for the PMF, estimates of PMF water surface profiles, and flood outlines.

2.4.3.6 Coincident Wind Wave Activity - Discuss the runup, wave heights, and resultant static and dynamic effects of wave action on each safety related facility from wind generated activity which may occur coincidently with the peak PMF water level. 


\subsubsection{Potential Dam Failures (Seismica1ly Induced)}

Discuss the evaluation of the effects of potential seismically induced dam failures on the upper limit of flood capability for sites along streams and rivers. Consider the potential influence of upstream dams and river structures for regulating or increasing the water level. The maximum water flow and level resulting from failure of a dam or dams by seismically induced breaching under the most severe probable modes of failure should be taken into account, including the potential for subsequent downstream domino-type failures due to flood waves, where such structures cannot be shown sufficient to withstand severe earthquakes. The simultaneous occurrence of the PMF and an earthquake capable of failing the upstream dams is not considered, since each of these events considered singly has a low probability of occurrence. The suggested worst conditions at the dam site may be evaluated by considering (1) a 25-year flood with full reservoirs coincident with an earthquake determined by a procedure similar to that used to determine the characteristics of the Safe Shutdown Earthquake* and (2) a standard-project flood (as defined by the Corps of Engineers), or one-half the probable maximum flood, with full reservoirs coincident with the maximum earthquake determined on the basis of historic seismicity. Where downstream dams also regulate cooling water supplies, their potential seismically induced failures also should be considered, discussed herein, and referred to in para. 2.4.11.6.

2.4.4.1 Reservoir Description - Include a description of the locations of existing or proposed dams (both upstream and downstream) that influence conditions at the site, tabulate drainage areas above reservoirs, provide descriptions of types of structures, a11 appurtenances, ownership, seismic design criteria, and spillway design criteria. Provide the elevationstorage relationships for pertinent reservoirs, and tabulate short and long term storage allocations.

2.4.4.2 Dam Failure Permutations - Discuss the locations of dams (both upstream and downstream), potential modes of failure, and results of seismically induced and other types of dam failures that could cause the most critical conditions (floods or low water) with respect to the site for such an event (see para. 2.4.3.4). Consideration should be given to possible landslides, antecedent reservoir levels and river flows at the coincident flood peak (base flow). Present the determination of the peak flow rate at the site for the worst possible dam failure, and summarize an analysis to show that the presented condition is the worst permutation. Include the description of all coefficients and methods used. Also consider the effects of other related events on plant safety such as blockage of a river, waterborne missiles, etc.

* Refer to 10 CFR Part 100, proposed Appendix A. 
2.4.4.3 Unsteady Flow Analysis of Potential Dam Failures - In determining the effect of dam failures at the site (para. 2.4.4.2), the analytical methods presented should be applicable to artificially large floods with appropriately acceptable coefficients, and should also consider floodwaves through reservoirs downstream of failures. Domino-type failures due to flood waves should be considered where applicable. Discuss estimates of antecedent flow and static and dynamic flood wave effects which are included to attenuate the dam failure flood wave downstream.

2.4.4.4 Water Level at Plant Site - Describe the backwater, unsteady flow, or other computation leading to the water elevation estimate (para. 2.4.4.2) for the most critical upstream dam failure, and discuss its reliability. Superimpose wind wave conditions that may occur simultaneously in a manner similar to that described in subsection 2.4.3.6.

\subsubsection{Probable Maximum Surge and Seiche Flooding}

2.4.5.1 Probable Maximum Winds and Associated Meteorological Parameters The mechanism is defined as a hypothetical hurricane or other cyclonic type wind storm that might result from the most severe combinations of meteorological parameters that are considered reasonably possible in the region involved, if the hurricane or other type wind storm should move along a critical path and at optimum rate of movement. The determination of probable maximum meteorological winds, which involves detailed analyses of actual historical storm events in the general region, and certain modifications and extrapolations of data to reflect a more severe meteorological wind system than actually recorded, insofar as these are deemed "reasonably possible" of occurrence on the basis of meteorological reasoning, should be presented in detail. The probable maximum conditions are the most severe combinations of hydrometeorological parameters (such as the meteorological characteristics of the probable maximum hurricane as reported by the U.S. National Oceanic and Atmospheric Administration in their unpublished report HUR 7-97* for the East and Gulf Coasts, or the most severe combination of meteorological parameters of moving squall lines for the Great Lakes, etc.) considered reasonably possible that would produce a surge or seiche which has virtually no risk of being exceeded. This hypothetical event is postulated along a critical path at an optimal rate of movement from correlations of storm parameters of record. Sufficient bases and information should be provided to assure that the parameters presented are the most severe combination.

* This report, HUR-7-97, "Interim Report - Meteorological Characteristics of the Probable Maximum Hurricane, Atlantic and Gulf Coasts of the United States," is available upon request from the Hydrometeorological Branch, Office of Hydrology, NOAA, 8060 13th Street, Silver Spring, Md. 20910.

$$
2.4-6
$$


2.4.5.2 Surge and Seiche History - Discuss the proximity of the site to large bodies of water for which surge or seiche type flooding can reach safety related facilities. The probable maximum water level (surges) for shore areas adjacent to large water bodies is the peak of the hypothetical surge or seiche stage hydrograph (still water levels), and coincident wave effects. It is based on relatively comprehensive hydrometeorological analyses and the application of probable maximum meteorological criteria (such as hurricanes, moving squal1 lines, or other cyclonic wind storms), in conjunction with the critical hydrological characteristics, to estimate the probable maximum water level at a specific location. The effects of the probable maximum meteorological event are superimposed on the coincidental maximum annual astronomical and ambient tide levels, and associated wave action, to determine the effects of water level and wave action on structures. Provide a description of the surge and/or seiche history in the site region.

2.4.5.3 Surge and Seiche Sources - Discuss considerations of hurricanes, frontal (cyclonic) type wind storms, moving squall lines, and surge mechanisms which are possible and applicable to the site. Include the antecedent water level (with reference to the spring tide for coastal locations, the average monthly recorded high water for lakes, and a forerunner or ambient water level where applicable), the determination of the controlling storm surge or seiche (include the probable maximum meteorological parameters such as the storm track, wind fields, the fetch or direction of approach, bottom effects, and verification with historic events), the method used and results of the computation of the probable maximum surge hydrograph (graphical presentation).

2.4.5.4 Wave Action - Discuss the wind generated activity which can occur coincidentally with a surge or seiche, or independently thereof. Estimates of the wave period, the significant wave height and elevations, and the maximum wave height and elevations, with the coincident water level hydrograph, should be presented. Specific data should be presented on the largest breaking wave height, setup, and runup that can reach each safetyrelated facility.

2.4.5.5 Resonance - Discuss the possibility of oscillations of waves at natural periodicity, such as lake reflection and harbor resonance phenomena, and any resulting effects at the site.

2.4.5.6 Runup - Provide estimates of wave runup on the plant facilities. Include a discussion of the water levels on each affected facility and the protection to be provided against static effects, dynamic effects, and splash. Cross-reference 2.4.5.4. above for breaking waves. 
2.4.5.7 Protective Structures - Discuss the location and design criteria for any special facilities for the protection of intake, effluent and other safety related facilities against surges, seiches, wave reflection and other wave action.

2.4.6 Probable Maximum Tsunami Flooding

For sites adjacent to coastal areas, discuss historical tsunamis, either recorded or translated and inferred, which provide information for use in determining the probable maximum water levels, and the geoseismic generating mechanisms available with appropriate references to section 2.5 .

2.4.6.1 Probable Maximum Tsunami - This event is defined as the most severe tsunami at the site which has virtually no risk of being exceeded. Consideration should be given to the most reasonably severe geoseismic activity possible (such as fractures, faults, land slide potential, volcanism, etc.) in determining the limiting tsunami-producing mechanism. The geoseismic investigations required to identify potential tsunami sources and mechanisms are similar to those necessary for the analysis of surface faulting and vibratory ground motions indicated for section 2.5 , and are summarized herein to define those locations and mechanisms to be investigated that could produce the controlling maximum tsunami at the site from both local and distant generating mechanisms. Such considerations as the orientation of the site relative to the earthquake epicenter or generating mechanism, shape of the coastline, off-shore land areas, hydrography, stability of the coastal area (proneness of sliding), etc., should be factored into the analysis.

2.4.6.2 Historical Tsunami Record - Provide local and regional historical tsunami information.

2.4.6.3 Source Tsunami Wave Height - Provide estimates of the maximum tsunami wave height possible at each major local generating source considered and the maximum offshore deepwater tsunami height from distant generators. Discuss the controlling generators for both locally and distantly generated tsunamis.

2.4.6.4 Tsunami Height Offshore - Provide estimates of the tsunami height in deep water adjacent to the site, or before bottom effects appreciably alter wave configuration, for each major generator.

2.4.6.5 Hydrography and Harbor or Breakwater Influences on Tsunami Present the routing of the controlling tsunami including breaking wave formation, bore formation, and any resonance effects (natural frequencies and successive wave effects), that result in the estimate of the maximum 
tsunami runup on each pertinent safety-related facility. This should include a discussion of the analysis used to translate tsunami waves from offshore generator locations, or in deep water, to the site, and antecedent conditions. Provide, where possible, verification of the techniques and coefficients used by reconstituting tsunamis of record.

\subsubsection{Effects on Safety-Related Facilities - Discuss the effects} on safety-related facilities of the controlling tsunami, and state the design criteria for the tsunami protection to be provided.

\subsubsection{Ice Flooding}

Present design criteria for protection of safety-related facilities from the most severe ice jam flood, wind-driven ice ridges, or ice-produced forces that are reasonably possible and could affect safety-related facilities with respect to adjacent rivers, streams, lakes, etc., and the location and proximity of such facilities to ice generating mechanisms. Describe the regional ice and ice jam formation history.

\subsubsection{Cooling Water Canals and Reservoirs}

2.4.8.1 Canals - Present the design bases for capacity and protection of canals against wind waves with acceptable freeboard, and (where app1icable) the ability to withstand a probable maximum flood, surge, etc.

2.4.8.2 Reservoirs - Provide the design bases for capacity (reference subsection 2.4.11), the PMF design capability including wind wave protection, emergency storage evacuation (low level outlet and emergency spillway), with verified runoff models (unit hydrographs), flood routing, emergency spillway design, and outlet protection.

\subsubsection{Channel Diversions}

Discuss the potential for the upstream diversion or rerouting of the source of cooling water, such as river cutoffs, ice jams, or subsidence, with respect to historical and topographical evidence in the region. Present the history of flow diversions in the region. Describe available alternative cooling water sources in the event diversions are possible.

\subsubsection{Flooding Protection Requirements}

Describe the static and dynamic consequences of all types of flooding on each pertinent safety-related facility. Present the design bases, and reference appropriate discussions in other sections of the SAR where implemented, required to assure that safety-related facilities will be capable of surviving all design flood conditions. 


\subsubsection{Low Water Considerations}

2.4.11.1 Low Flow in Rivers and Streams - Estimate the probable minimum flow rate and level resulting from the most severe drought considered reasonably possible in the region as such conditions may affect the source of cooling water and/or the ability of the ultimate heat sink to perform adequately under severe hydrometeorological conditions.

\subsubsection{Low Water Resulting from Surges, Seiches or Tsunamis -} Determine the surge, seiche, or tsunami caused low water level that could occur from probable maximum meteorological or geoseismic conditions. Include a description of the probable maximum meteorological event producing such conditions, its track, associated parameters, antecedent conditions (see 2.4.5.4 above), and the computed low water level, or tsunami conditions applicable. Also consider, where applicable, ice formation, or ice jams causing low flow, as such conditions may affect the cooling water source.

2.4.11.3 Historical Low Water - Discuss historical low water controls, minimum stream flows or minimum surges and elevations, and probabilities (unadjusted for historical controls and adjusted for historical and future controls and uses) only when statistical methods are used to extrapolate flows and/or levels to probable minimum conditions.

2.4.11.4 Future Control - Provide the estimated flow rate, durations and levels for probable minimum flow conditions considering future uses. Substantiate any provisions for flow augmentation available for plant use.

2.4.11.5 Plant Requirements - Present the required minimum safety related cooling water flow, the sump invert elevation and configuration, the minimum design operating level, pump submergence elevations (operating heads), effluent submergence and mixing and dispersion design bases. Discuss the capability of cooling water pumps to supply sufficient water during periods of extreme low water level. Cross-reference para. 9.2.1, 9.2.5 and 10.4 .5 where applicable.

2.4.11.6 Heat Sink Dependability Requirements - Describe the ability to provide warning of impending low flow to allow switching to alternative sources where applicable. Compare minimum flow and/or level estimates with plant requirements and describe any available low water safety factor (see para. 2.4.4). Cross-reference the SAR sections where design bases are stated, such as para. 9.2.1, 9.2.5 and 10.4.5. Also summarize the requirements and describe the sources of firewater. Where such water is drawn from the ultimate heat sink, include this requirement in the discussion of the design bases for the sink. (For guidance on ultimate heat sink, see Safety Guide 27.) 


\section{$\underline{2.4 .12}$ Environmental Acceptance of Effluents}

Describe the ability of the surface-ground water environment to disperse, dilute and/or concentrate normal and inadvertent or accidental liquid releases of radioactive effluents for the full range of anticipated operating conditions as such releases may relate to existing and/or potential future use of surface or groundwater resources. Present the applicable design bases for effluent facilities to meet design requirements. Refer to subsections 2.4.1.2 and 2.4.13.2 for the locations and users, respectively, of surface and ground waters. Provide, or reference other appropriate para., the ultimate heat sink design bases for both normal and accident operation modes, such as flow rates, heat rejection relationships, heat loads, make-up and blowdown requirements for closed loop systems, etc. Describe any safety related effects of normal or accidental releases of radionuclides and heated water on surface and ground waters, such as any potential for recirculation, sediment concentration, hydraulic short circuiting of cooling ponds, etc. Cross-reference para. 11.2.7.

\section{4 .13 Groundwater}

2.4.13.1 Description and Onsite Use - Describe the regional and local groundwater aquifers, formations, sources, and sinks. Describe the type of groundwater use, well, pump and storage facilities, and flow requirements of the plant by type of use.

2.4.13.2 Sources - Describe present regional use, and projected future use; tabulate existing users (amounts, water levels, location, and drawdown) and piezometric levels; indicate flow directions and gradients; and discuss the reversibility of groundwater flow and the effects of potential future use on the flow rates, gradients and groundwater levels beneath the site. Note any potential groundwater recharge area within influence of the plant. Discuss the cones of influence of existing and potential future wells with respect to groundwater beneath the site.

2.4.13.3 Accident Effects - Provide an evaluation of the dispersion and dilution capability of the groundwater environment with respect to existing users and future users under operating and accident conditions.

2.4.13.4 Monitoring or Safeguard Requirements - Discuss the need for procedures and safeguards to protect groundwater users. Present preliminary plans for any safeguards and monitoring. 


\subsubsection{Technical Specification and Emergency Operation Requirements}

Describe any emergency protective measures designed to minimize the water associated impact of adverse hydrologically related events on safety related facilities. Describe the manner in which these requirements will be incorporated into appropriate Technical Specifications and/or Emergency Procedures. Discuss the need for any Technical Specifications for plant shutdown to minimize the consequences of an accident due to hydrologically associated phenomena. In the event emergency procedures are to be utilized to meet safety requirements due to hydrologically related events, present appropriate water levels, lead times available and indicate what type of action would be taken.

\subsection{Geology and Seismology}

This section of the PSAR should provide information regarding the seismic and geologic characteristics of the site and the region surrounding the site. Proposed Appendix A to $10 \mathrm{CFR}$ Part 100, "Seismic and Geologic Siting Criteria for Nuclear Power Plants" (published for comment and interim guidance in the Federal Register, Vol. 36, No. 228, November 25, 1971), sets forth the principal seismic and geologic considerations that guide the regulatory staff in its evaluation of the acceptability of sites and seismic design bases.

This section should include but not necessarily be limited to the information discussed below. This section should be preceded by a summary that contains a synopsis of subsections 2.5 .1 through 2.5.5. Included should be a brief description of the site, the investigations performed, results of investigations, conclusions, and a statement as to who did the work.

\subsubsection{Basic Geologic and Seismic Information}

Basic geologic and seismic information is required throughout the following subsections as a basis for evaluations appropriate to these subsections. In some cases, this information is germane to more than one subsection. The information may be presented under this subsection, under the following subsections, or as appendices to this section, providing adequate cross-references are made in the appropriate subsection(s).

Information obtained from published reports, maps, private communications, or other sources should be referenced. Information from surveys, geophysical investigations, borings, trenches, or other investigations, should be adequately documented by descriptions of techniques, graphic logs, photographs, laboratory results, identification of principal investigators, and other data necessary to assess the adequacy of the information. 
The following basic information should be included concerning the geology and seismology of the site and the region surrounding the site.

\subsubsection{Regional Geology -}

(1) Describe the regional physiography. The relationship between the regional and the site physiography should be discussed. A regional physiographic map showing site location should be included.

(2) Describe the regional geology, including geologic and tectonic maps of the region surrounding the site.

(3) Discuss the regional geologic setting. Indicate the geologic province and the relation to other geologic provinces. Include regional geologic maps indicating the site location, and showing both surface and bedrock geology.

(4) Discuss the geologic history of the region.

(5) Describe the 1ithologic, stratigraphic, and structural geologic conditions of the region surrounding the site, and relate these conditions to its geologic history. Provide geologic profiles showing the relationship of the regional and local geology to the site location.

(6) Identify and describe tectonic structures underlying the region surrounding the site, such as: folds, faults, basins, domes, etc. Include a discussion of the geologic history of the tectonic features. Include a regional tectonic map showing the site location.

(a) Provide detailed discussions of the regional tectonic structures of significance to the site. The detailed analyses of faults to determine their capacity for generating ground motions at the site and to determine the potential for surface faulting should be included in subsections 2.5 .2 and 2.5.3, respectively.

(b) Identify and describe areas of actual or potential surface or subsurface subsidence, uplift, or collapse resulting from:

(i) Natural features such as tectonic depressions, cavernous conditions or karst terrains, and potential landslides;

(ii) Man's activities, such as withdrawa1 or addition of subsurface fluids, or mineral extraction;

(iii) Regional warping. 
(7) Provide a discussion of the regional groundwater conditions. Crossreference to subsection 2.4 .13 .

2.5.1.2 Site Geology - Material in this section may be included as appropriate in section 2.5 .4 and cross-referenced in this section.

(1) Describe the site physiography discussing the relationship between the regional and site physiography. A site topographic map should be included showing the locations of the principal plant facilities. Describe the configuration of the land forms and relate the history of geologic changes that have occurred. Areas that are significant to the site of actual or potential landsliding, surface or subsurface subsidence, uplift, or collapse resulting from natural features such as tectonic depressions and cavernous or karst terrains should be evaluated.

(2) Describe the lithologic, stratigraphic, and structural geologic conditions of the site, and relate to geologic history and regional geology. Describe the thicknesses, physical characteristics, origin, and degree of consolidation of each lithologic unit. Furnish summary logs of borings and excavations such as trenches used in the geologic evaluation.

(3) Furnish a detailed discussion of the structural geology in the vicinity of the site, with particular attention to specific structural units of significance to the site, such as: folds, faults, synclines, anticlines, domes, basins, etc. Provide a large scale site structural geology map showing bedrock surface contours and including the locations of Category I structures.

(4) Furnish a large scale geologic map of the site area which shows surface geology and which includes the locations of major structures of the nuclear power plant, including all Category I structures. Areas of bedrock outcrop direct observations should be distinguished from areas which are covered and concerning which geologic interpretation has been extrapolated. When the interpretation differs substantially from the published geologic literature on the area, the differences should be noted and documentation for the new conclusions presented.

(5) Discuss the geologic history of the site and relate to a regional geologic history. Include a local geologic stratigraphic column. 
(6) Furnish a plot plan showing the locations of major structures of the nuclear power plant, including all Category I structures, and the locations of all borings, trenches, and excavations along with a description, logs, and maps of the borings, trenches, and excavations, as necessary to indicate the results.

(7) Provide geologic profiles showing the relationship of the major foundations of the nuclear power plant to subsurface materials, including groundwater, and the significant engineering characteristics of the subsurface materials.

(8) Provide plan and profile drawings showing the extent of excavations and backfill planned at the site and compaction criteria for all engineered backfill.

(9) Include an evaluation from an engineering geology standpoint of the local geologic features which affect the plant structures. Geologic conditions underlying all Category I structures, dams, dikes, and pipelines should be described in detail.

(a) Describe physical evidence concerning the behavior during prior earthquakes of the surficial geologic materials and the substrata underlying the site from the lithologic, stratigraphic, and structural geologic studies.

(b) Identify and evaluate deformational zones, such as shears, joints, fractures, and folds, or combinations of these features relative to structural foundations.

(c) Describe and evaluate zones of alteration or irregular weathering profiles, and zones of structural weakness composed of crushed or disturbed materials.

(d) Describe unrelieved residual stresses in bedrock.

(e) Describe all rocks or soils that might be unstable because of their mineralogy, lack of consolidation, water content, or potentially undesirable response to seismic or other events. (Seismic response characteristics to be considered include liquefaction, thixotrophy, differential consolidation, cratering, and fissuring.)

(f) Evaluate the effects of man's activities, such as withdrawal or addition of subsurface fluids, or mineral extraction at the site. 
(10) Define site groundwater conditions and cross-reference to subsection 2.4.13.

(11) Provide profiles and tables showing the results of any geophysical surveys (seismic refraction, seismic reflection, acoustic, aeromagnetic, etc.) conducted to evaluate the stratigraphic structure and bedrock, and subsurface material characteristics of the site. Provide results of compressional and shear wave velocity surveys, and cross hole and uphole velocity surveys, where performed.

(12) Furnish static and dynamic soil and rock properties of the site including grain-size classification, Atterberg limits, water content, unit weight, shear strength, relative density, shear modulus, Poisson's ratio, bulk modulus, damping, consolidation characteristics, and strength under cyclic loading. These properties should be substantiated with appropriate representative laboratory test records.

(13) Discuss the detailed safety-related criteria, analysis techniques to be used, and the factors of safety for the materials underlying the foundations for all Category I nuclear power plant structures and for all Category I embankments under dynamic conditions combined with adverse hydrologic conditions.

\subsubsection{Vibratory Ground Motion}

Information should be presented to describe how the design basis for vibratory ground motion (Safe Shutdown Earthquake) was determined. The following specific information and determinations should also be included to the extent necessary to clearly establish the design basis for vibratory ground motion. Information presented in other sections may be crossreferenced and need not be repeated.

2.5.2.1 Geologic Conditions of the Site - Describe the 1ithologic, stratigraphic, and structural geologic conditions of the site and the region surrounding the site, including its geologic history.

2.5.2.2 Underlying Tectonic Structures - Identify tectonic structures underlying the site and the region surrounding the site.

2.5.2.3 Behavior During Prior Earthquakes - Describe physical evidence concerning the behavior during prior earthquakes of the surficial geologic materials and the substrata underlying the site from the lithologic, stratigraphic, and structural geologic studies. 
2.5.2.4 Engineering Properties of Materials Underlying the Site Describe the static and dynamic engineering properties of the materials underlying the site. Included should be properties needed to determine the behavior of the underlying material during earthquakes and the characteristics of the underlying material in transmitting earthquake-induced motions to the foundations of the plant, such as seismic wave velocities, density, water content, porosity, and strength.

2.5.2.5 Earthquake History - List all historically reported earthquakes which have affected or which could be reasonably expected to have affected the site, including the date of occurrence and the following measured or estimated data: magnitude or highest intensity, and a plot of the epicenter or region of highest intensity. Where historically reported earthquakes could have caused a maximum ground acceleration of at least one-tenth the acceleration of gravity $(0.1 \mathrm{~g})$ at the foundations of the proposed nuclear power plant structures, the acceleration or intensity and duration of ground shaking at these foundations should also be estimated. Since earthquakes have been reported in terms of various parameters, such as magnitude, intensity at a given location, and effect on ground, structures, and people at a specific location, some of these data may have to be estimated by use of appropriate empirical relationships. Where appropriate, the comparative characteristics of the material underlying the epicentral location or region of highest intensity and of the material underlying the site in transmitting earthquake vibratory motion should be considered.

2.5.2.6 Correlation of Epicenters with Geologic Structures - Provide a correlation of epicenters or regions of highest intensity of historically reported earthquakes, where possible, with tectonic structures, any part of which is located within 200 miles of the site. Epicenters or regions of highest intensity which cannot be reasonably correlated with tectonic structures should be identified with tectonic provinces, any part of which is located within 200 miles of the site.

2.5.2.7 Identification of Active Faults - For faults, any part of which is within 200 miles of the site and which may be of significance in establishing the Safe Shutdown Earthquake, determine whether these faults should be considered as active faults. 
2.5.2.8 Description of Active Faults - For faults, any part of which are within 200 miles of the site which may be of significance in establishing the Safe Shutdown Earthquake and which are considered as active faults, determine: the length of the fault; the relationship of the fault to regional tectonic structures; and the nature, amount, and geologic history of the maximum Quaternary displacement related to any one earthquake along the fault.

2.5.2.9 Maximum Earthquake - Determine the historic earthquakes of greatest magnitude or intensity which have been correlated with tectonic structures. For active faults, the earthquake of greatest magnitude related to the faults should be determined, taking into account geologic evidence. The vibratory ground motion at the site should be determined assuming the epicenters of the earthquakes are situated at the point on the structures closest to the site.

Where eplcenters or regions of highest intensity of historically reported earthquakes cannot be related to tectonic structures but are identified with tectonic provinces in which the site is located, determine the accelerations at the site assuming that these earthquakes occur adjacent to the site.

Where epicenters or regions of highest intensity of historically reported earthquakes cannot be related to tectonic structures but are identified with tectonic provinces in which the site is located, determine the accelerations at the site assuming that the epicenters or regions of highest intensity of these earthquakes are located at the closest point to the site on the boundary of the tectonic province.

$2,5,2,10$ Safe Shutdown Earthquake - The earthquake producing the maximum vibratory accelerations at the site should be designated the Safe Shutdown Earthquake for vibratory ground motion. The Safe Shutdown Earthquake should be defined by response spectra corresponding to the maximum vibratory accelerations.

2.5.2.11 Operating Basis Earthquake - The Operating Basis Earthquake, when one is selected by the applicant, should also be defined by response spectra.

\subsubsection{Surface Faulting}

Information should be presented which describes whether and to what extent the nuclear power plant need be designed for surface faulting. The following specific information and determinations should also be included to the extent necessary to clearly establish the design basis for surface faulting. Information presented in 2.5.1 may be crossreferenced and need not be repeated. 
2.5.3.1 Geologic Conditions of the Site - Describe the 11thologic, stratigraphic, and structural geologic conditions of the site and the area surrounding the site, including its geologic history.

2.5.3.2 Evidence of Fault Offset - Determine the geologic evidence of fault offset at or near the ground surface at or near the site.

2.5.3.3 Identification of Active Faults - For faults greater than 1,000 feet long, any part of which is within 5 miles of the site, determine whether these faults should be considered as active faults.

2.5.3.4 Earthquakes Associated With Active Faults - List all historically reported earthquakes which can be reasonably associated with active faults greater than 1,000 feet long, any part of which is within 5 miles of the site, including the date of occurrence and the following measured or estimated data: Magnitude or highest intensity, and a plot of the epicenter or region of highest intensity.

2.5.3.5. Correlation of Epicenters With Active Faults - Provide a correlation of epicenters or regions of highest intensity of historically reported earthquakes with active faults greater than 1,000 feet long, any part of which is located within 5 miles of the site.

2.5.3.6 Description of Active Faults - For active faults greater than 1,000 feet long, any part of which is within 5 miles of the site, determine: the length of the fault; the relationship of the fault to regional tectonic structures; the nature, amount, and geologic history of displacements along the fault; and the outer limits of the fault established by mapping fault traces for 10 miles along its trend in both directions from the point of its nearest approach to the site.

2.5.3.7 Zone Requiring Detailed Faulting Investigation - Determine the zone requiring detailed faulting investigation.

2.5.3.8 Results of Faulting Investigation - Where the site is located within a zone requiring detailed faulting investigation, present details and results of this investigation, to determine the need to take into account surface faulting in the design of the nuclear power plant.

Where it is determined that surface faulting need not be taken into account, present sufficient data to justify the determination clearly. 
2.5.3.9 Design Basis for Surface Faulting - Where it is determined that surface faulting needs to be taken into account, present the design basis for surface faulting.

\subsubsection{Stability of Subsurface Materials}

Information should be presented concerning the stability of soils and rock underneath the nuclear power plant foundations during the vibratory motion associated with the Safe Shutdown Earthquake. Evaluation of the following geologic features which could affect the foundations should be presented: (Information presented in other sections may be crossreferenced and need not be repeated.)

\subsubsection{Geologic Features - Describe:}

(1) Areas of actual or potential surface or subsurface subsidence, uplift, or collapse resulting from:

(a) Natural features such as tectonic depressions and cavernous or karst terrains, particularly those underlain by calcareous or other soluble deposits;

(b) Man's actvities, such as withdrawal or addition of subsurface fluids, or mineral extraction;

(c) Regional warping.

(2) Deformational zones, such as shears, joints, fractures and folds, or combinations of these features.

(3) Zones of alteration or irregular weathering profiles, and zones of structural weakness composed of crushed or disturbed materials.

(4) Unrelieved residual stresses in bedrock.

(5) Rocks or soils that might be unstable because of their mineralogy, lack of consolidation, water content, or potentially undesirable response to seismic or other events. (Seismic response characteristícs to be considered include liquefication, thixotrophy, differential consolidation, cratering, and fissuring.)

2.5.4.2 Properties of Underlying Materials - Describe in detail the static and dynamic engineering properties of the materials underlying the site. Furnish the physical properties of foundation materials such as: grain-size classification, consolidation characteristics, water 
content, Attenberg limits, unit weight, shear strength, relative density, shear modulus, damping, Poisson's ratio, bulk modulus, strength under cyclic loading, seismic wave velocities, density, porosity, and strength characteristics. These data should be substantiated with appropriate representative laboratory test records.

2.5.4.3. Plot Plan - Provide a plot plan or plans showing the locations of all borings, trenches, seismic lines, piezometers, geologic profiles, and excavations and superimpose the locations of all Class I structures of the nuclear power plant. Furnish profiles showing the relationship of the foundations of Class I structures to subsurface materials, including groundwater and significant engineering characteristics of the subsurface materials.

2.5.4.4 Soil and Rock Characteristics - Provide the results by means of table and profiles of compressional and shear wave velocity surveys performed to evaluate the characteristics of the foundation soils and rocks. Provide graphic core boring logs and the logs of trenches or other excavations.

2.5.4.5 Excavations and Backfill - Furnish plan and profile drawings showing the extent of excavations and backfill planned at the site and compaction criteria for all engineered backfill. The criteria should be substantiated with representative laboratory or field test records. (Where possible those plans and profiles may be combined with profiles 2.5 .4 .3 or 2.5 .4 .4$.

\subsubsection{Groundwater Conditions - Provide a history of groundwater} fluctuations beneath the site and a discussion of groundwater conditions during construction of the nuclear power plant and during plant life.

2.5.4.7 Response of Soil and Rock to Dynamic Loading - Furnish analyses of the responses of soil and rock to dynamic loading.

2.5.4.8 Liquefaction Potential - Provide a discussion of the liquefaction potential of material beneath the site. Either demonstrate that there are no liquefaction susceptible soils beneath the site or provide the following information regarding soil zones where the possibility for liquefaction exists: relative density, void ratio, ratio of shear stress to initial effective stress, number of load cycles, grain size distribution, degrees of cementation and cohesion, and groundwater elevation fluctuations.

2.5.4.9 Earthquake Design Basis - Provide the earthquake design basis on which these analyses are based. 
2.5.4.10 Static Analyses - Discuss the static analyses, such as settlement analyses (with appropriate representative laboratory data), lateral pressures (with backup data), etc.

2.5.4.11 Criteria and Design Methods - List and furnish a brief discussion of the criteria, references, or methods of design employed (or to be employed), and factors of safety (documented by test data).

2.5.4.12 Techniques to Improve Subsurface Conditions - Discuss and provide specifications for required techniques to improve subsurface conditions such as: grouting, vibrafloration, dental work, rock bolting, anchors, etc.

\subsubsection{Slope Stability}

Information and appropriate substantiation should be presented concerning the stability of all slopes, both natural and manmade (both cut and fill), the failure of which could adversely affect the nuclear power plant.

2.5.5.1 Slope Characteristics - Cross sections of the slopes should be provided along with a summary of the static and dynamic properties of embankment and foundation soil and rock underlying the slope, substantiated with representative laboratory test data.

2.5.5.2 Design Criteria and Analyses - The design criteria and analyses used to determine slope stability should be described, including factors of safety, along with the adverse conditions considered in the analyses, such as sudden drawdown, earthquake, steady seepage at anticipated pool levels, etc.

2.5.5.3 Logs of Core Borings - Furnish logs of core borings or test pits taken in proposed borrow areas.

2.5.5.4 Compaction Specifications - Provide compaction specifications along with representative lab data on which they are based. 


\subsection{DESIGN OF STRUCTURES, COMPONENTS, EQUIPMENT AND SYSTEMS}

This chapter of the SAR should identify, describe and discuss the principal architectural and engineering design of those structures, components, equipment, and systems important to safety.

\subsection{Conformance with AEC General Design Criteria}

This section should briefly discuss the extent to which the design criteria for the plant structures, systems and components important to safety meet the AEC "General Design Criteria for Nuclear Power Plants" specified in Appendix A to 10 CFR Part 50. For each criterion, a summary should be provided to show how the principal design features meet the criterion. Any exceptions to criteria should be identified and the justification for each exception should be discussed. In the discussion of each criterion, the sections of the SAR where more detailed information is presented to demonstrate compliance with or exceptions to the criterion should be referenced.

\subsection{Classification of Structures, Components, and Systems}

\subsubsection{Seismic Classification}

This subsection should identify those structures, systems and components important to safety that are designed to withstand the effects of a Safe Shutdown Earthquake (see Section 2.5) and remain functional. These plant features are those necessary to assure:

(1) the integrity of the reactor coolant pressure boundary,

(2) the capability to shutdown the reactor and maintain it in a safe condition, or

(3) the capability to prevent or mitigate the consequences of accidents which could result in potential offsite exposures comparable to the guideline exposures of 10 CFR Part 100.

Guidance for determining the seismic classification of structures, systems, and components is provided in Safety Guide 29. These plant features, including their foundations and supports, designed to remain functional in the event of a Safe Shutdown Earthquake are designated as Category I. The subsection should indicate if compliance with Safety Guide 29 is intended and provide a 1ist of all Category I items. If only portions of structures and systems are Category $I$, they should be listed and, where necessary for clarity, the boundaries of the Category I 
portions should be shown on Piping and Instrumentation Diagrams. Where there are differences with Safety Guide 29, they should be identified and a discussion of the proposed classification should be included.

All structures, systems, and components or portions thereof, which are intended to be designed for an Operating Basis Earthquake (OBE), should be listed or otherwise clearly identified.

\subsubsection{System Quality Group Classifications}

This subsection should identify those fluid systems or portions of fluid systems important to safety and the industry codes and standards applicable to each pressure-containing component in the systems.

Section $50.55 a$ of $10 \mathrm{CFR} 50$ specifies quality requirements for the reactor coolant pressure boundary, and Safety Guide 26 describes a quality group classification system and relates it to industry codes for water and steam containing fluid systems. The subsection should indicate if compliance with Safety Guide 26 is intended. Where there are differences, they should be identified and a discussion included justifying each proposed Quality Group classification in terms of the reliance placed on these systems:

(1) to prevent or mitigate the consequences of accidents and ma1functions originating within the reactor coolant pressure boundary,

(2) to permit shutdown of the reactor and maintenance in the safe shutdown condition, and

(3) to contain radioactive material.

In such cases, the proposed design features and measures that would be applied to attain a quality level equivalent to the level of the above classifications should be specified, including the quality assurance programs that would be implemented. The subsection should contain Piping and Instrumentation Diagrams which identify the system quality group classification boundaries of each safety-related system. The classifications should be noted at valves or other appropriate locations in each fluid system where the respective classification changes in terms of the AEC Group Classification letters, for example, from A to B, B to $C, C$ to $D$ as well as other combinations, or alternately, in terms of corresponding classification notations which can be cross-referenced with those Classification Groups in Safety Guide 26. 


\subsection{Wind and Tornado Loadings}

\subsubsection{Wind Loadings}

This section should describe the wind loadings for Category I structures . The description should include the following information:

3.3.1.1 Design Wind Velocity - The design wind velocity and recurrence interval should be presented.

3.3.1.2 Basis for Wind Velocity Selection - The basis for the wind velocity selection that was made to include wind histories and supporting data should be discussed.

3.3.1.3 Vertical Velocity Distribution and Gust Factor - The specific vertical velocity distribution and the gust factor employed for the selected design wind velocity should be submitted.

3.3.1.4 Determination of Applied Forces - Describe the procedure used to translate the wind velocity into applied forces on the structures including the wind force distribution and drag coefficients being applied. The applied force magnitude and distribution which is calculated for each Category I structure should be specified.

\subsubsection{Tornado Loadings}

This section should discuss the tornado loadings for Category I structures including the following information.

3.3.2.1 Applicable Design Parameters - The design parameters app1icable to the design tornado such as translational velocity, rotational velocity and the design pressure differential and its associated time interval should be specified.

3.3.2.2 Determination of Forces on Structures - Describe the methods used to convert the tornado loadings into forces on Category I structures including the distribution across the structures and the combination of applied loads. If factor loads are used, then the basis for selection of the load factor used for tornado loading should be furnished.

3.3.2.3 Ability of Category I Structures to Perform Despite Failure of Structures not Designed for Tornado Loads - Information to show that the failure of any structures not being designed for tornado loads will not affect the ability of other Category I structures or systems to perform their intended design functions should be presented. 


\subsection{Water Leve1 (Flood) Design}

This section should discuss the flood design for Category I structures and components. It should include the following information.

\subsubsection{Flood Elevations}

The flood elevations that will be used in the design of each structure for bouyancy and static water force effects should be provided.

\subsubsection{Phenomena Considered in Design Load Calculations}

The phenomena, such as flood current, wind wave, hurricane, or tsunami, that is being considered if dynamic water force is a design load for any structure should be identified and discussed.

\subsubsection{Flood Force Application}

The manner in which the forces and other effects resultant from flood loadings are applied should be described.

\subsubsection{Flood Protection}

The flood protection measures for Category I systems and components which are located below grade or below flood level should be described.

\subsection{Missile Protection}

This section should describe the design bases with respect to internal and external missile protection for Category I structures and components. This discussion should include the following information.

\subsubsection{Missile Barriers and Loadings}

Present a tabulation of the structures, shields, and barriers that will be designed to withstand missile effects. Possible missile loadings that should be considered include accident/incident generated missiles, environmental load generated missiles, and site proximity missiles (e.g., aircraft and guided missiles installations).

\subsubsection{Missile Selection}

The missiles that have been selected for each structure and the basis for their selection should be discussed. 


\subsubsection{Selected Missiles}

For each selected missile, specify the origin, weight, and dimensions, the impact velocity and orientation, the material composition, and any other parameters required to determine missile penetration.

\subsubsection{Barrier Design Procedures}

Discuss the procedures by which each barrier will be designed to resist the missile hazards previously described.

\subsubsection{Missile Barrier Features}

Present engineering sketches showing the layout and principal design features of all structures intended primarily as missile barriers.

\subsection{Protection Against Dynamic Effects Associated with the Postulated Rupture of Piping}

This section should describe design bases and design measures to assure that the containment vessel and all essential equipment within or outside of the containment, including components of the reactor coolant pressure boundary, and other safety related components have been adequately protected against the effects of blowdown jet and reactive forces, and pipe whip resulting from postulated rupture of piping located either inside or outside of containment. The following specific information should be included.

\subsubsection{Systems in which Design Basis Piping Breaks Occur}

Identify the systems (or portions of systems) in which design basis piping breaks are postulated to occur.

\subsubsection{Design Basis Piping Break Criteria}

Discuss the design basis piping break criteria with respect to location in the piping systems, the pipe break sizes and orientations (e.g., circumferential, longitudinal) postulated to occur at the break locations.

\subsubsection{Design Loading Combinations}

Design loading combinations and criteria including the associated design stress limits applicable to the postulated rupture of unrestrained piping and pipe whip restraints should be presented. 


\subsubsection{Dynamic Analyses}

Present a summary of the dynamic analyses applicable to Category 1 piping and associated supports which determine the resulting loadings as a result of a postulated pipe break including:

(1) the locations and number of design basis breaks on which the dynamic analyses are based (FSAR).

(2) the postulated rupture orientation, such as a circumferential and/or longitudinal break(s), for each postulated design bas is break location (FSAR).

(3) a description of the forcing functions to be used for the pipe whip dynamic analyses. Include in the description, direction, rise time, magnitude, duration and initial conditions that adequately represent the jet stream dynamics and the system pressure differences (FSAR).

(4) diagrams of typical mathematical models used for the dynamic analys is (FSAR).

(5) a summary of the analyses which demonstrates that unrestrained motion of ruptured lines will not damage to an unacceptable degree structures, systems, or components important to safety, such as the containment or its liner (FSAR).

\subsubsection{Protective Measures}

Discuss the measures, as applicable, to protect against pipe whip, blowdown jet and reactive forces including:

(1) pipe restraint design criteria to prevent pipe whip impact,

(2) protective provisions for vital equipment against pipe whip and blowdown jet and reactive forces,

(3) criteria for separation of redundant features,

(4) provisions to separate physically piping and other components of redundant features (FSAR),

(5) a description of the typical pipe whip restraints and a summary of number and location of all restraints in each system (FSAR). 


\subsection{Seismic Design}

\subsubsection{Seismic Input}

\subsubsection{Design Response Spectra - Design response spectra (1/2 SSE}

and SSE) should be provided. If applicable, design response spectra for the OBE should be submitted. A discussion of effects of the following parameters should also be included:

(1) earthquake duration.

(2) earthquake distance and depths between the seismic disturbances and the site.

(3) existing earthquake records and the associated amplification response range where the amplification factor is greater than one.

3.7.1.2 Design Response Spectra Derivation - The response spectra which envelopes the design response spectra derived from the actual or synthetic earthquake time motion records should be provided. A comparison, for all the damping values that are used in the design, of the response spectra derived from the time history and the design response spectra should be submitted. The system period intervals at which the spectra values were calculated should be identified.

3.7.1.3 Critical Damping Values - The specific percentage of critica1 damping values used for Category I structures, systems, components and soil should be provided, (e.g., damping values for the type of construction or fabrication, such as prestressed concrete and welded pipe, and the applicable allowable design stress levels for these plant features should be submitted).

3.7.1.4 Bases for Site Dependent Analysis - The bases for a site dependent analysis, if used to develop the shape of the design response spectra from bedrock time history or response spectra input, should be provided. Specifically, the bases for use of in situ soil measurements, soil layer location and bedrock earthquake records should be provided. If the analytical approach used to determine the shape of the design response spectra neglects vertical amplification and possible slanted soil layers, then these assumptions as well as the influence of the effect of possible predominant thin soil layers on the analytical results should be discussed.

\subsubsection{Soil-Supported Category I Structures - A 1ist of all soil-} supported Category I structures should be provided including the depth of soil over bedrock for each structure listed. 
3.7.1.6 Soil-Structure Interaction - The use of a simplified lumped mass and soil spring approach to characterize soil-structure interaction, for soil sensitive sites should be identified. The basis for the use of a lumped parameter mathematical model with equivalent soil springs should be provided.

\subsubsection{Seismic System Analysis}

This subsection should discuss the seismic system analyses applicable to Category I structures and systems. The following specific information should be included.

\subsubsection{Seismic Analysis Methods - For all Category I structures,} systems, and components identified in section 3.2.1, including any items to be designed for an $\mathrm{OBE}$, the applicable methods of seismic analysis (modal analysis response spectra, modal analysis time history, equivalent static load, etc.) should be identified in the PSAR. Applicable stress or deformation criteria and descriptions (sketches) of typical mathematical models used to determine the response should be specified. If empirical methods (tests) are used in lieu of analysis, the testing procedure, load levels and acceptance bases for structures, systems, components and equipment should also be provided (FSAR). All seismic methods of analyses used should be described (FSAR).

\subsubsection{Natural Frequencies and Response Loads (FSAR) - A summary} of natural frequencies and response loads (e.g., in the form of critical mode shapes and modal responses) determined by the seismic system analysis should be provided. In addition, the response spectra at critical plant equipment elevations and points of support should be specified.

\subsubsection{Procedures Used to Lump Masses (FSAR) - A description of} the procedure used to lump masses for the seismic system analyses (ratio of system mass and compliance to component mass and compliance, and the ratio of floor mass and compliance to supported equipment mass and compliance) should be provided.

\subsubsection{Rocking and Translational Response Summary (FSAR) - If a} fixed base in the mathematical models for the dynamic system analyses is assumed, a summary of the rocking and translational responses should be provided. A brief description should be included of the method, mathematical model and damping values (rocking vertical, translation and torsion) that have been used to consider the soil-structure interaction. 


\subsubsection{Methods Used to Couple Soil With Seismic-System Structures -} A description of the methods and procedures used to couple the soil and the seismic-system structures and components in the eyent a finite element analysis for the layered site is used should be provided.

3.7.2.6 Development of Floor Response Spectra - If a modal response spectra multi-mass method of analysis is used to develop floor response spectra, a discussion of the conservatism of this method should be presented. The discussion should address equivalency to a multi-mass time history method or identify other equivalent theoretical or experimental methods.

\subsubsection{Differential Seismic Movement of Interconnected Components -} The stress and deformation criteria that will be used to consider the differential seismic movement of inter-connected components between floors should be provided.

\subsubsection{Effects of Variations on Floor Response Spectra - Consideration} in the analyses of the effects on floor response spectra (e.g., peak width and period coordinates) of expected variations of structural properties, dampings, soil properties, and soil-structure interactions should be described.

3.7.2.9 Use of Constant Vertical Load Factors - The use of constant vertical load factors as vertical response loads for the seismic design of all Category I structures, systems, and components in lieu of the use of a vertical seismic-system multi-mass dynamic analysis method should be identified.

3.7.2.10 Method Used to Account for Torsional Effects - The method employed to consider the torsional modes of vibration in the seismic analysis of the Category I structures should be described. The use of static factors to account for torsional accelerations in the seismic design of Category I structures, or in lieu of the use of a combined vertical, horizontal, and torsional multi-mass system dynamic analysis should be indicated.

3.7.2.11 Comparison of Responses (FSAR) - Where applicable, the responses obtained from both modal analysis response spectrum and time history methods at selected points in the Category I structure should be submitted.

3.7.2.12 Methods for Seismic Analysis of Dams - A description of the analytical methods and procedures that will be used for the seismic system analysis of dams that impound bodies of water to serve as heat sinks should be provided.

$$
3.7-3
$$


3.7.2.13 Methods to Determine Category I Structure Overturning Moments - A description of the dynamic methods and procedures used to determine Category I structure oyerturning moments should be provided including a description of the procedures used to account for soil reactions and vertical earthquake effects.

3.7.2.14 Analysis Procedure for Damping - The analysis procedure followed to account for the damping in different elements of the model of a coupled system should be described including the criteria used to account for composite damping in a coupled system with different elements.

\subsubsection{Seismic Subsystem Analysis}

The discussion of the seismic subsystem analysis should include the following specific information:

\subsubsection{Determination of Number of Earthquake Cycles - Procedures} should be described that are used to determine the number of earthquake cycles during one seismic event. The number of maximum amplitude loading cycles for which Category I structures, systems, and components are designed should be specified.

3.7.3.2 Basis for Selection of Forcing Frequencies- The basis should be provided for the selection of forcing frequencies to preclude res onance (e.g., the earthquake specified for the site, and the structure and component response characteristics produce forcing frequencies that are removed from the natural frequencies.)

3.7.3.3 Root Mean Square Basis - The term "root-mean-square basis," if used in describing the procedure for the combination of modal responses, should be mathematically defined.

3.7.3.4 Procedure for Combining Modal Responses - A description of the procedure for combining modal responses (shears, moments, stresses, deflections, and/or accelerations) should be provided if a response spectrum modal analysis method is used and modal frequencies are closely spaced.

3.7.3.5 Siguificant Dynamic Response Modes - A discussion should be provided addressing the inclusion of all significant dynamic modes of response under seismic excitation if static loads equivalent to the peak of the floor spectrum curve are used for the seimic design of components, structures and equipment. 


\subsubsection{Design Criteria and Analytical Procedures for Piping - The}

design criteria and a description of the analytical procedures applicable to piping that accounts for the relative displacements between piping and support points, i.e., floors and components, at different elevations within a building and between buildings should be provided.

\subsubsection{Basis for Computing Combined Response - The basis for the} methods used to determine the possible combined (two component) horizontal and vertical amplified response loading for the seismic design of piping and equipment, including the effect of the seismic response of the supports, equipment, structures and components should be submitted.

\subsubsection{Amplified Seismic Responses - If a constant load factor is} used as the vertical floor response load for the seismic design of Category I structures, components, and equipment, a discussion should be provided addressing the following considerations:

(1) The possible combined (two component) horizontal and vertical amplified input loading for the seismic design of equipment and components due to the amplified response of the structures and floors.

(2) The possible combined (two component) horizontal and vertical amplified input loading for the seismic design of piping and equipment due to the amplified response of structures, floors, supports, and components.

\subsubsection{Use of Simplified Dynamic Analysis - If a simplified} (e.g., other than a multi mass modal analysis) dynamic analysis is used for Category I piping, the magnitude by which the resonant periods of a selected piping span are removed from the predominant supporting building and component periods should be indicated (FSAR). A summary of typical results comparing the simplified dynamic methods and response spectra modal analysis methods should be submitted (FSAR). The basis for simplified (e.g., other than a multi-mass modal analysis) dynamic analyses methods and procedures that will be used for seismic design of structures, systems, and components should be provided. In addition, the criteria that will be used to avoid the predominant input frequencies produced by the response of structures, supports, and components to the earthquake input should also be presented.

3.7.3.10 Modal Period Variation - The procedures used to account for modal period variation in the mathematical models for Category I structures due to variations in material properties should be specified. 
3.7.3.11 Torsional Effects of Eccentric Masses - The criteria that will be employed to account for the torsional effects of valves and other eccentric masses (e.g., valve operators) in the seismic piping analyses should be provided.

3.7.3.12 Piping Outside Containment Structure - With respect to Category I piping buried or otherwise located outside of the containment structure, the seismic design criteria and methods employed to ascertain that allowable piping and structural stresses are not exceeded due to differential movement at support points, at containment penetrations, and at entry points into other structures should be described.

3.7.3.13 Interaction of Other Piping With Category I Piping - The design criteria to account for the seismic motion of piping systems not Category $I$ in the seismic design of Category $I$ piping and the interfaces between Category $I$ and other piping should be described.

3.7.3.14 Field Location of Supports and Restraints (FSAR) - The criteria employed to determine the field location of seismic supports and restraints for Category I piping, piping system components, and equipment, including placement of snubbers and dampers should be provided. The procedures followed to assure that the field location and the seismic design of these supports and restraining devices are consistent with the assumptions made in the dynamic seismic analysis should be described.

3.7.3.15 Seismic Analyses for Fuel Elements, Control Rod Assemblies and Control Rod Drives - The seismic subsystem analyses that will be applied in establishing seismic design adequacy of reactor fuel elements, control rod assemblies and control rod drives should be described.

\subsubsection{Seismic Instrumentation Program}

With respect to the seismic instrumentation program, the following information should be provided:

3.7.4.1 Comparison with AEC Safety Guide 12 - The seismic instrumentation provided should be discussed and compared with the seismic instrumentation program described in AEC Safety Guide 12, "Instrumentation for Earthquakes." The basis for elements of the proposed program that differ from Safety Guide 12 should be submitted.

3.7.4.2 Location and Description of Instrumentation (FSAR) - Seismic instrumentation such as peak recording accelerographs and peak deflection recorders that will be installed in selected Category I structures 
and on selected Category I components should be described. The basis for selection of these structures and components and the location of instrumentation, as well as the extent to which this instrumentation will be employed to verify the seismic analyses following a seismic event should be specified.

\subsubsection{Control Room Operator Notification - The provisions that} will be utilized to inform the control room operator of the value of the peak acceleration level experienced in the basement of the reactor containment structure within a few minutes after the earthquake should be described. The basis for establishing predetermined values for activating the readout of the seismic instrument to the control room operator should be included.

3.7.4.4 Comparison of Measured and Predicted Responses - The criteria and procedures that will be used to compare measured responses of Category I structures and selected components in the event of an earthquake with the results of the system dynamic analyses should be provided.

\subsubsection{Seismic Design Control}

This section should describe the design control measures (as specified in Appendix B of 10 CFR Part 50, "Quality Assurance Criteria for Nuclear Power Plants") which will be implemented to assure that appropriate seismic input data derived from seismic system and subsystem analyses are correctly specified to the manufacturer of Category I components and equipment and to constructors of other Category I structures and systems. The responsible design groups or organizations that will verify the adequacy and validity of the analyses and tests employed by manufacturers of Category I structures and systems should be identified. A description of the review procedures to be employed by each group or organization should be included. The applicable information contained in chapter 17 may be referenced in this section.

\subsection{Design of Category I Structures}

\subsubsection{Concrete Containment}

This section should provide information for concrete containments concerning:

(1) the physical descriptions,

(2) the applicable codes, standards, specifications, regulations, safety guides and industry standard practices,

\section{$3.8-1$}


(3) the loading criteria, including the loading and load combinations,

(4) the computational techniques and analytical procedures,

(5) the structural design acceptance criteria such as stress allowables, strain allowables, deformation limits, strength capabilities and other behavior or response criteria and the design comparisons to these criteria,

(6) the material, quality control measures and construction techniques, and

(7) the testing and surveillance requirements.

The following information should be provided.

3.8.1.1 Description of the Containment - A physical description of the containment should be provided, and supplemented with sketches or diagrams as necessary. Unique or new features of the containment should be identified. The descriptions should be sufficient to provide the complete geometry of the structure.

The tendon system including the embedded sheaths should be described. The arrangement of the prestressing tendons or the reinforcing steel, especially at penetrations, splices, anchorage zones, connections, joints and other discontinuities should be provided.

3.8.1.2 Applicable Codes, Standards, and Specifications - The design codes, standards, specifications, regulations, genera1 design criteria, safety guides and other industry standard practices that are applied should be identified with respect to the containment. The specific edition, date, or addenda of the applicable documents should be identified including any exceptions taken, and their justification, and/or application of substitute provisions. The limitations and assumptions made in the referenced documents should be discussed in relation to the procedures outlined for the design of the facility. A summary of plant principal specifications as prepared by the structural designer should be furnished.

Applicable AEC Safety Guides should be listed. In addition, it should be indicated which of the safety guides the applicant chose to comply with. The provisions of ACI 318-71 including Chapters 18 and 19 as we 11 as Appendix A that are utilized should be identified. Portions of documents or entire documents such as the ACI 349 Committee Report, "Criteria for Reinforced Concrete Nuclear Power Containment Structures," and/or the 
ACI-ASME (ACI 359) document, "Proposed Standard Code for Concrete Reactor Vessels and Containments," that are utilized should be identified and discussed. The various specifications and standards such as the various ASTM standards that are utilized should be identified and any deviations identified.

For prestressed concrete containments the application of Section 18.2.1 of ACI 318-71 and Sections 202 (d) and (e) of ACI Committee 334 Report should be described. The use of documents such as the ACI Standard designated ACI 307-69 should be described as it is applied to the concrete containment.

3.8.1.3 Loads and Loading Combinations - The loads and loading combinations which the containment is subjected to should be defined including the load factors selected for each load component where a factored load approach is used. The design approach used with the loading combinations and any load factors should be specified. The effects of the induced strains on the liner should be described. The loads acting on the containment such as dead loads, live loads, and earth pressure loads as well as the design basis accident loads, loads resulting from natural phenomena such as earthquakes, floods, tornadoes, hurricanes, and missile effects unique for the site should be described. The design loading combinations utilized to examine the effects on localized areas such as penetrations, shell discontinuities, prestressing tendon anchor zones, crane girder brackets, and local areas of high thermal gradients, etc. should be provided together with time dependent loading such as the thermal effects, effects of creep, shrinkage, and other related effects.

Explanation should be provided of the use of an ultimate strength approach with a load factor of 1.0 .

3.8.1.4 Design and Analysis Procedures - The design and analyses procedures that will be used in designing the containment should be described including the assumptions made and the boundary conditions used. The expected behavior under load, where the loads include those that may be nonaxisymmetric, localized, or transient should be provided. If several analytical techniques are used on a containment for local areas or if specific studies are made, information should be provided on the compatibility of results and the initial assumptions. A description should be provided which presents information regarding the manner in which creep, shrinkage and cracking of the concrete are addressed in the analysis and design. Computer programs that are utilized should be referenced to permit identification with available published programs. Proprietary computer programs should be described in sufficient detail to establish the applicability of the program and the measures taken to validate the program with solutions derived from other acceptable programs. 
For prestressed concrete containments the considerations made for the analysis and design of the tendon anchorage zones, including all loads and effects expected during the life of the containment, should be provided. For conventionally reinforced concrete containments the provisions for analysis and design of shear effects should be described.

Information permitting an evaluation of the effect of the variations in assumptions, materials, etc., on the analysis results should be provided. The effect of the buttress on a typical prestressed concrete containment should be addressed along with its manner of altering the assumption of axisymmetry. In containments where an analysis has been performed by plane strain theory for items such as a buttress, liner anchors, etc., a discussion should be provided addressing the omission of strains in the orthogonal direction. The method of analyzing the effect of penetrations, the thickening, the reinforcements, the embedments, etc., at the various locations should be specifically described.

The method of providing reinforcing steel in the critical areas should be provided. The design for the leak-tight liner barrier should be described including the configuration of the anchorage system.

\subsubsection{Structural Acceptance Criteria - The acceptance criteria} relating stresses, strains, gross deformations, factors of safety and other parameters that identify quantitatively the margins of safety should be specified. The material provided should address the containment as an entire structure, but it should also address the margins of safety related to the major, important local areas of the containment, including openings, hatch penetrations, anchorage zones, and other areas important to the safety function. The criteria addressing the various loading combinations as well as the conditions that will exist at the end of the structure's service life should be provided. Information should also be provided on the effects of repeated reactor shutdowns and startups during the plant's life and whether this degrades the margins of safety.

The effect of two and three-dimensional stress/strain fields on the behavior of the structure and the local areas within the structure should be furnished. The adequacy of the connections and joints of the various elements of the containment should be evaluated.

3.8.1.6 Materials, Quality Control and Special Construction Techniques The materials, quality control procedures, and the special construction techniques used for the containment should be identified. A summary of the material specifications to provide information on the engineering properties of the materials and the quality control procedures that will be used to maintain quality should be submitted. Special construction 
techniques such as post-tensioning or providing Cadweld splicing should be described as well as the related quality control standards.

The tonnage of reinforcing steel of a given size and grade to be represented by a given number of test specimens should be specified. The quantity of prestressing steel to be represented by a given number of specimens should be presented with the origin of the samples being defined. The testing requirements for evaluating the quality of materials and machined end anchorage hardware should be presented when prestressing systems are used. The assurance procedures which include a means to ascertain the suitability of steel plate material to transmit orthogonal loads such as is the case in areas of a steel liner should be submitted. The materials, standards and quality control procedures used for the liner and penetrations should be provided. Criteria for construction tolerances such as dimensional limitations for liner erection should be given. A comparison of the actual materials used, results of the quality control program and results of the construction techniques should be provided (FSAR).

3.8.1.7 Testing and Inservice Surveillance Requirements - The testing and inservice surveillance requirements for the containment should be defined. Discussion of the initial structural and leakage rate testing as well as those tests related to the inservice surveillance programs and requirements should be provided (FSAR). The objectives of the tests as well as the acceptance criteria for the results should be defined. If new or previously untried design approaches are used the extent of additional testing and inservice surveillance should be discussed. Proposed Appendix J to $10 \mathrm{CFR}$ Part 50 provides interim guidance for containment testing.

\subsubsection{Steel Containment System (ASME Class MC Components)}

This section should discuss the design criteria and analytical techniques upon which the design of ASME Code Class MC steel containment components are based including the applicable information specified under 3.8.1, "Concrete Containment," for items 3.8.1.1 through 3.8.1.5. The equivalent paragraphs in this section should be numbered 3.8.2.1 through 3.8.2.5, respectively. In addition, the following specific information should be included.

3.8.2.6 Design Loading Combination Stress Limits - The combination of loadings used for design should be categorized with respect to the design stress limits defined in ASME Section III, Subsection NE. Deformation criteria associated with each of the design loading combinations should also be specified. 
3.8.3 Concrete and Structural Steel Internal Structures of Steel or Concrete Containments

This section should provide information in accordance with that requested under Section 3.8.1, but in reference to the internal structures of the containment. The outlined items, 3.8.1.1 through 3.8.1.7, of that section give guidance on content.

The typical containment encloses numerous structures and structural components that are necessary for the functioning of the containment, including such items as the reactor cavity and primary shield, the secondary shield, equipment compartments, various floors, and fuel pool and others.

The following information should be submitted:

3.8.3.1 Description of the Internal Structures - A physical description of the internal structures should be provided and supplemented with sketches or diagrams as necessary. Unique or new features of the containment internal structures should be presented. The descriptions should be sufficient to provide information on the structural configuration of the internals being used as well as identifying the various materials.

Descriptions should be provided for the barrier floor and its connection to the containment along with the detail at the downcomer vents for the over-and-under type BWR. For the PWR ice condenser type containment, the arrangement and connections, joints, etc., between the various compartments should be presented. The reactor cavity area should be described as well as the secondary shield structures and equipment compartments.

The locations where removable slabs, block partitions, etc., are utilized should be specified.

\subsubsection{Applicable Codes, Standards and Specifications - Information} should be provided as requested in section 3.8 .1 , but as applied to the internal structures of the containment.

3.8.3.3 Loads and Loading Combinations - The loads and loading combinations which the internal compartments and structures are subjected to should be defined including the load factors selected for each of the load components. The loadings on the internal structures that are required for containment function, such as the barrier floor in the BWR over-and-under concept and the compartmentalized containment concepts, should be provided. Typical loads acting on the internal structures such as dead and live loads, the loads resulting from natural phenomena such 
as earthquakes, the loads resulting from internal missiles, the loads from the design basis accident including jet impingement loads on structures and the loads transferred from support structures that generally influence localized areas should also be included together with the time dependent loads such as thermal effects, effects of creep, shrinkage, and other related effects.

3.8.3.4 Design and Analysis Procedures - The design and analysis procedures that will be used in designing the internal structures should be described, including the assumptions made and the identification of boundary conditions. The expected behavior under load, the mechanisms for load transfer to these structures and then to the containment base $\mathrm{slab}$ and the range of design variables that influence the results of the analyses should be provided. Computer programs that are utilized should be referenced to permit identification with available published programs. Proprietary computer programs should be described to the maximum extent practical to establish the applicability of the program and the measures taken to validate the program with solutions derived from other acceptable programs.

A discussion should be provided of the design and analysis procedures used for internal structures such as the reactor cavity, the barrier floor and sacrificial shield of a BWR type containment, the compartments of PWR type containments including the ice condenser containment, the fuel pool complex and other vital internal structures. The method used to evaluate the effect of radiation-generated heat on the structure should be provided. The manner in which the design of the various structural components within the containment is executed should be presented. A description should be included of the procedures used to proportion the various amounts of reinforcing steel, to define the geometry of the reinforcing pattern and to define the bond and anchorage requirements for reinforced concrete, etc. For structural components made up of structural steel elements the method of designing the various sections, connections, etc., should be defined.

3.8.3.5 Structural Acceptance Criteria - The design criteria relating to stresses, strain, gross deformations, factors of safety and other parameters that identify quantitatively the margins of safety should be specified.

The criteria for the stresses, strains or deformations resulting from the response induced by the design earthquakes should be fully defined and related to the requirements of any components, systems or equipment that 
are attached to the internal structures. The limiting parameters that control the shear response of the internal structures should be defined and the basis for the limits should be established. If empirically derived limits are used, the experimental programs that adequately represent the actual physical conditions should be discussed.

3.8.3.6 Materials, Quality Control and Special Construction Techniques The materials, quality control procedures and the special construction techniques should be described as outlined in Section 3.8.1.6. The effect of various amounts of radiation on the structure should be discussed. Special construction techniques, such items as post-tensioning a prestressing system, grouting of various components, using special anchorage devices or connectors and other similar procedures should be specified.

\subsubsection{Testing and Inservice Surveillance Requirements - The testing} and inservice surveillance requirements for the internal structures should be defined. Test or analys is requirements for internal structures related directly to the functioning of the containment concept, such as the barrier floor in the BWR type containment or the barriers and compartments in the PWR ice condenser type containment, should be specified. Inservice surveillance requirements, when needed, should also be described (FSAR).

\subsubsection{Other Category I Structures}

The information provided in this section should be in accordance with that requested under Section 3.8.1, but for all Category I structures not defined in either Sections $3.8 .1,3.8 .2,3.8 .3$ or 3.8 .5 .

The following information should be submitted:

3.8.4.1 Description of the Structures - A physical description of these structures should be provided, and supplemented with sketches or diagrams as necessary. Unique or new features for these structures should be presented. The description should be sufficient to provide information on the structural configuration being utilized for the structure in general as well as the provisions being made in special areas such as crane girder components, etc. For the major plant structures information should be provided that defines the location, separation and any ties between buildings.

3.8.4.2 Applicable Codes, Standards and Specifications - Information should be provided as requested in Section 3.8.1.2, but as applied to the other structures. If local building codes are utilized sufficient supporting information should be provided to allow an evaluation as to the applicability of the document and its degree of conservatism. 
3.8.4.3 Loads and Loading Combinations - The loads and loading combinations should be defined including the load factors selected for each of the load components. The type of loads acting on these structures such as dead, live, and earth pressure loads, loads resulting from natural phenomena such as earthquakes, floods, tornadoes, hurricanes, and other time dependent loads unique to the site or a particular structure should be identified.

3.8.4.4 Design and Analysis Procedures - The design and analys is procedures should be described, including the assumptions made and the identification of boundary conditions. The expected behavior under load, the mechanisms of load transfer to the foundations and the range of design variables that influence the results of the analyses should be provided. Computer programs that are utilized should be referenced to permit identification with available published programs. Proprietary computer programs should be described to the maximum extent practical to establish the applicability of the program and the measures taken to validate the program with solutions derived from other acceptable programs.

3.8.4.5 Structural Acceptance Criteria - The design criteria relating to stresses, strains, gross deformations, factors of safety and other parameters that identify quantitatively the margins of safety should be specified and addressed as outlined in Section 3.8.1.5.

3.8.4.6 Materials, Quality Contro1 and Special Construction Techniques The materials, quality control procedures and special construction techniques should be addressed as outlined in Section 3.8.1.6.

\subsubsection{Testing and Inservice Surveillance Requirements - The testing} and inservice surveillance requirements, if any, should be specified.

\subsubsection{Foundations and Concrete Supports}

The information provided in this section should be in accordance with that requested under Section 3.8.1, but in reference to the foundations and concrete supports. The outlined items, 3.8.1.1 through 3.8.1.7, of that section give guidance on content.

The information furnished should address all foundations for Category I structures constructed of other than soil materials for the purpose of transferring loads, forces and deformations to the basic supporting earth media. The concrete supports include all of the reinforced concrete configurations associated with Category I structures that provide a structural system for the transfer of load, forces and deformations to structures or foundations either beneath or adjacent to the system. 
The following information should be provided.

3.8.5.1 Description of the Foundations and Supports - A physical description of the foundations and support structures should be provided and supplemented with sketches or diagrams as necessary, to indicate the locations and relationships of the various Category I foundations. Unique features of the foundations or concrete supports should be described including information on the concept of load transfer for the various types of foundations and support configurations being utilized. Information defining the local conditions and their local interaction effects on Category I structures should also be included.

A typical detail illustrating the manner in which the large equipment such as steam generators and reactor coolant pumps are anchored to the containment internal structures' and base slab should be provided.

A sketch of the reinforcing pattern at the junction of reinforced concrete vertical structural elements and the foundation structure should be provided.

If a foundation concept utilizes piling, an illustration should be provided to indicate the configuration and the mechanisms for load transfer from the pile cap to the piling.

3.8.5.2 Applicable Codes, Standards and Specifications - Information should be provided as requested in Section 3.8 .1 .2 , but as applied to the foundations and concrete supports.

The degree of conformance with the related AEC Safety Guides, should be discussed.

A list of the various material specifications that are used to produce the concrete for the Category I foundations and concrete supports should be provided.

3.8.5.3 Loads and Loading Combinations - The loads and loading combinations which the Category I foundations and supports are subjected to should be defined including the load factors selected for each load component. The design approach used with the loading combinations and load factors should be specified including the manner by which gross settlement and differential settlement are taken into account. The design bases applied to loads transferred from supported systems and components to foundations including consideration of elastic properties of the connections should be discussed. The type of loads acting on the foundations should be identified such as dead, live and earth pressure loads, the 
design basis accident loads, loads resulting from natural phenomena such as earthquakes, flood, tornadoes, hurricanes, and other loads unique to the site. The various effects such as base shear, gross overturning moment and torsional moment produced by these loading combinations should be provided.

If load factors of 1.0 or less are used, an explanation and discussion should be provided.

3.8.5.4 Design and Analysis Procedures - The design and analysis procedures that will be used in designing the structural foundations or elements thereof and the various supports should be described including the assumptions made and boundary conditions used. The expected behavior under load, the mechanisms for load transfer to the soil materials or support structures and the range of design variables that influence the results of the analysis for the model representative of the structural foundation or support system should be discussed. Computer programs that are utilized should be referenced to permit identification with available published programs. Proprietary computer programs should be described to the extent practical to establish the applicability of the program and the measures taken to validate the program with solutions derived from other acceptable programs.

The design analysis and method of load transfer for piles supporting the containment to resist uplift and lateral loads should be provided, including whether skin friction or point bearing vertical load transfer is the principal support mechanism under both static and dynamic loads.

For a major concrete support structure such as the reactor concrete support, the design analysis used that takes into account the loadings from seismic and blowdown effects from a postulated break in piping connected to the reactor vessel should be described.

3.8.5.5 Structural Acceptance Criteria - The acceptance criteria relating to stresses, strains, gross deformations, differential settlements, factors of safety against shear failure and overturning moments, and other parameters that identify quantitatively the margins of safety should be specified. Comparisons of design results to the acceptance criteria should be provided.

The limiting conditions of stresses, strains, deformations, etc., for the foundations, including the effects of soil structure interaction, and the comparable allowable limits should be provided and discussed. 
3.8.5.6 Materials, Quality Contro1 and Special Construction Techniques The materials, quality control procedures, and the special construction techniques used for the foundations and supports should be identified. The material specifications should be summarized to provide information on the engineering properties of the materials and the quality control procedures that will be used to maintain quality. Special construction techniques such as post-tensioning or providing Cadwelds should be described as well as the related quality control standards.

The quality control procedures for the concrete including the type of tests required, the frequency and location of sampling, and the test requirements should be presented. A description of the quality control of the structural steel materials should be provided. The results of the quality control program should be discussed (FSAR).

3.8.5.7 Testing and Inservice Surveillance Requirements - The testing and inservice surveillance requirements, if any, for the foundations and concrete supports should be defined. A discussion of special programs or procedures for initial testing and/or inservice surveillance should be provided, including objectives and acceptance criteria.

The program of load tests to be carried out on the foundation piles to determine their response under load, including the lower bound of permissible loads, lateral and vertical deflections and the maximum limits of vertical and lateral deflection should be described. The results should also be provided.

If programs for continued surveillance of foundations are required, a discussion to define the various aspects of the programs should be provided (FSAR).

\subsection{Mechanical Systems and Components}

\subsubsection{Dynamic System Analysis and Testing}

This subsection should provide, as a minimum, the following specific information:

3.9.1.1 Vibration Operational Test Program (FSAR) - The vibration operational test program required by $\mathrm{NB}-3622.3, \mathrm{NC}-3622$, and $\mathrm{ND}-3611$ of ASME Section III Code which verifies that the piping and piping restraints have been designed to withstand dynamic effects due to valve closures, pump trips, etc. and that piping vibrations are within acceptable levels should be described. A description of the testing actions (pump trips, valve actuations, etc) that will be applied in the vibration operational test program should be included. 
3.9.1.2 Dynamic Testing Procedures (FSAR) - A description of the dynamic testing procedures used in the design of Category I mechanical equipment such as fans, pump drives, valve operators, heat exchanger tube bundles, to withstand seismic, accident and operational vibratory loading conditions should be provided. The methods and procedures employed which consider the frequency spectra and amplitudes calculated to exist at the equipment supports should also be described. If analyses and/or testing procedures do not include evaluation of the equipment in the operating mode, a description of the bases for assuring that this equipment will function when subjected to seismic accident loadings and vibratory loadings should be provided.

3.9.1.3 Dynamic System Analysis Methods for Reactor Internals (FSAR) The dynamic system analysis methods and procedures which have been used to determine dynamic responses of reactor internals and associated $\mathrm{Class} \mathrm{I}$ components of the reactor coolant pressure boundary which have effect on the responses (e.g., analyses and tests) should be briefly described. The preoperational test program as related to Safety Guide 20, Vibration Measurements on Reactor Internals, should be described. If elements of the test program differ substantially from the requirements of Safety Guide 20, the basis for these differences should be submitted.

\subsubsection{Correlation of Test and Analytical Results (FSAR) - A dis-} cussion should be provided which describes the correlation of the results from the reactor internals preoperational vibration testing program with the analytical responses derived from the mathematical model used for the dynamic analysis of the reactor internals under LOCA loadings.

3.9.1.5 Analysis Methods Under LOCA Loadings - The following information should be included in the discussion of the dynamic system analysis methods and procedures used to confirm the structural design adequacy of the reactor coolant system (unaffected 1oop) and the reactor internals (including fuel element assemblies, control rod assemblies and drives) under the LOCA loadings:

(1) Typical diagrams of the dynamic system mathematical modeling of piping, pipe supports, and reactor internal structures that will be used in the analysis, including a discussion of the bases for any structural partitioning and directional decoupling of components (FSAR).

(2) A description of the forcing functions that will be used for the LOCA dynamic analysis including system pressure differentials, direction, rise time, magnitude, duration and initial conditions (FSAR). 
(3) A description of the methods and procedures that will be used to compute dynamic responses.

(4) A summary of the results of the dynamic analysis including loading combinations which govern the design of the system (FSAR).

3.9.1.6 Analytical Methods for ASME Code C1ass 1 Components (FSAR) The analytical methods used to evaluate stresses for ASME Code Class 1 components (e.g., elastic or inelastic) should be described including a discussion of their compatibility with the type of dynamic system analysis used. If inelastic component stress analyses and inelastic design stress limits are used in conjunction with an elastic dynamic system analysis, the bases upon which these procedures are used should be discussed.

\subsubsection{ASME Code Class 2 and 3 Components}

The following information should be provided for ASME Code Class 2 and 3 that are to be constructed in accordance with the ASME Boiler and Pressure Vesse1 Code, Section III Subsections NC and ND respectively:

\subsubsection{Plant Conditions and Design Loading Combinations - The plant} conditions and design loading combinations (e.g., normal service or operating loads, seismic loads, etc.) that provide the bases for design of components (or systems) should be listed for each system.

3.9.2.2 Design Loading Combination - The combinations of design loadings should be categorized (as applicable) with respect to plant conditions identified as Normal, Upset, Emergency or Faulted. The design stress limits and deformation criterla associated with each of the plant conditions should be specified.

3.9.2.3 Design Stress Limits - Design stress limits which allow inelastic deformation (or are comparable to the faulted design limits defined in ASME Section III for Class I components) should be identified. A brief description of the design procedures that will be used in such cases should be provided.

3.9.2.4 Analytical and Empirical Methods For Design of Pumps and Valves - A description of the analytical methods, design standards and design limits to be employed to assure that pumps required to function and valves required to open or close during or following the specified plant condition will operate as designed should be provided. If empirical methods are to be employed based on tests, a summary description of test procedures, imposed test loadings and results obtained including the 
basis for extrapolations to components larger or smaller than those tested should be provided in the FSAR. The above information should also be provided for all other ASME Code Class 2 and 3 pumps and valves.

\subsubsection{Design and Installation Criteria, Pressure-Relieving Devices -} The design and installation criteria applicable to the mounting of the pressure-relieving devices (safety valves and relief valves) for the overpressure protection of Class 2 system components should be described. In particular, the design criteria that account for full discharge loadings (i.e., thrust, bending, torsion) on valves and on connected piping in the event all valves for a system are required to discharge should be described including the provisions made to accommodate these loads.

\subsubsection{Stress Levels for Category I Components (FSAR) - The stress} levels (e.g. seismic, dead weight plus pressure) for Category I system components at all points of high changes in flexibility should be provided under the specified plant condition. Sketches of each system configuration should be included.

3.9.2.7 Field Run Piping Systems - The nominal pipe sizes which determine whether piping is field run should be specified. Those Category I piping systems which are field run should be identified and any special or simplified procedures for designing and installing this piping should be described (FSAR).

\subsubsection{Components Not Covered by ASME Code}

For safety related mechanical components not covered by the ASME Boiler and Pressure Vessel Code, the design criteria and applicable codes and standards should be identified. A summary of the stress and dynamic calculations or experimental testing performed to confirm their structural integrity or functional capability should be submitted (FSAR). Details of the mechanical design and analytical procedures for the design of the fuel assemblies should be also included (FSAR). (See Chapter 4.0 of the Standard Format and Content of the SAR.)

The stress and dynamic criteria, methods, and procedures which have been used to determine the operability of the control rod drives and control rod insertability under LOCA and seismic loadings should be provided. (See also Chapter 4.0 of the Standard Format and Content of the SAR.)

\subsection{Seismic Design of Category I Instrumentation and Electrica1} Equipment

The following information should be provided for the seismic design of 
Category I instrumentation and electrical equipment.

3.10.1 Seismic Design Criteria

All Category I instrumentation and electrical equipment requiring seismic qualification should be identified. The seismic design criteria applicable to the reactor protection system, engineered safety feature circuits, and the emergency power system should be provided. The criteria should address :

(1) the capability to initiate a protective action during the safe shutdown earthquake, and

(2) the capability of the engineered safety feature circuits and the standby power system to withstand seismic disturbances during post-accident operation.

The extent of compliance with the seismic qualification procedures and documentation requirements of IEEE Std 344-1971, "Seismic Qualification of Class I Electric Equipment for Nuclear Power Generating Stations," should be indicated.

\subsubsection{Seismic Analyses, Testing Procedures and Restraint Measures}

A description of the analyses, testing procedures, and seismic restraint measures employed to establish the seismic design adequacy of Category I electrical equipment supports such as cable trays, battery racks, instrument racks, and control consoles under the conditions of possible seismic loading amplification of floors to which frames and racks that support electrical equipment are attached should be provided (FSAR). The criteria and verification procedure employed to account for the possible amplified design loads (frequency and amplitude) for vendor-supplied components, should be specified.

\subsection{Environmental Design of Mechanical and Electrical Equipment}

The purpose of this section is to provide information on the environmental conditions and design bases for which the mechanical, instrumentation and electrical portions of the engineered safety features and reactor protection systems are designed to assure acceptable performance in all environments (e.g., normal, test, and accident).

The following specific information should be included concerning the design bases related to the capability of the mechanical, instrumentation, 
and electrical portions of the engineered safety features, and reactor protection system to perform their intended functions in the combined post-accident environment of temperature, pressure, humidity, chemical and radiation:

\subsubsection{Equipment Identification}

A11 safety related equipment and components (e.g., motors, cables, filters, pump seals, shielding) located in the primary containment and elsewhere that are required to function during and subsequent to any of the design basis accidents should be identified.

\subsubsection{Qualification Tests and Analyses}

A description of the qualification tests and analyses that have been or will be performed on each of these items to assure that it will perform in the combined temperature, pressure, humidity, chemical and radiation environment should be provided. The specific values of temperature, pressure, humidity, chemicals and radiation, should be included. The extent of compliance to IEEE Std 334-1971, "IEEE Trial-Use Guide for Type Tests of Continuous-Duty Class I Motors Installed Inside the Containment of Nuclear Power Generating Stations," should be indicated.

\subsubsection{Qualification Test Resu1ts (FSAR)}

The results of the qualification tests for each type of equipment should be provided.

\section{$\underline{3.11 .4 \text { Loss of Ventilation }}$}

The bases should be provided which assure that loss of the air conditioning and/or ventilation system will not adversely affect the operability of safety related control and electrical equipment located in the control room and other areas. The analyses performed to identify the worst case environment (e.g., temperature, humidity) should be described, including identification and determination of the limiting condition with regard to temperature that would require reactor shutdown. Any testing (factory and/or onsite) that has been or will be performed to confirm satisfactory operability of control and electrical equipment under extreme environmental conditions should be described. The documentation of the successful completion of qualification tests for each type of equipment should be specified in the PSAR and supplied in the FSAR. 


\section{$4.0 \quad$ REACTOR}

In this chapter of the SAR, the applicant should provide an evaluation and supporting information to establish the capability of the reactor to perform its safety functions throughout its design lifetime under all normal operational modes, including both transient and steady state, and accident conditions. This chapter should also include information to support the analyses presented in Chapter 15.0, Accident Analyses.

\subsection{Summary Description}

A summary description of the mechanical, nuclear, and thermal and hydraulic designs of the various reactor components including the fuel, reactor vessel internals, and reactivity control systems should be given. The description should indicate the independent and interrelated performance and safety functions of each component. A summary table of the important design and performance characteristics should be included. A tabulation of analysis techniques used and load conditions considered including computer code names should also be included.

\subsection{Mechanical Design}

\subsubsection{Fue1}

The design bases for the mechanical design of the fuel components should be presented including mechanical limits such as maximum allowable stresses, deflection, cycling and fatigue limits, capacity for fuel fission gas inventory, maximum internal gas pressure, material selection, radiation damage, and shock and seismic loadings. Details of the dynamic analysis, input forcing functions, vibration, and seismic response loadings should be presented in Sections 3.7 and 3.9 of the SAR.

4.2.1.1 Design Bases - The applicant should explain and substantiate the selection of design bases from the viewpoint of safety considerations. Where the limits selected are consistent with proven practice, a referenced statement to that effect will suffice; where the limits extend beyond present practice, an evaluation and an explanation based upon developmental work and/or analysis should be provided. These bases may be expressed as explicit numbers or as general conditions. The discussion of design bases should include consideration of:

(1) the physical properties of the cladding and the effects of design temperature and irradiation on the properties;

(2) stress-strain limits;

(3) the effects of fuel swelling;

(4) variations of melting point and fuel conductivity with burnup; and

$$
\text { 4. 0-1 }
$$


(5) the requirements for surveillance and testing of irradiated fuel rods.

4.2.1.2 Description and Design Drawings - A description and preliminary (PSAR) or final (FSAR) design drawings of the fuel assemblies and fuel elements showing arrangement, dimensions, critical tolerances, sealing and handling features, methods of support, fission gas spaces, burnable poison content, and internal components should be provided. A discussion of design features which prevent improper orientation or placement of a fuel assembly within the core should be included.

4.2.1.3 Design Evaluation - An evaluation of the fuel design should be provided including considerations such as materials adequacy throughout lifetime, a summary of results of a vibration analysis, fuel element internal pressure and cladding stresses during normal and accident conditions with particular emphasis upon temperature transients or depressurization accidents; potential for a waterlogging rupture; potential for a chemical reaction, including hydriding effects; fretting corrosion; cycling and fatigue; and dimensional stability of the fuel and critical components during design lifetime. The evaluation should include discussions of failure and burnup experience, and the thermal conditions for which the experience was obtained for the type of fuel to be used, and the results of long term irradiation testing of production fuel and test specimens.

4.2.1.4 Testing and Inspection Plan - The testing and inspections to be performed to verify the mechanical characteristics of the fuel components should be described including clad integrity, verification of fuel enrichment, burnable poison concentration, fuel pellet characteristics, radiographic inspections, destructive tests, fuel assembly dimensional checks, and the program for inspection of new fuel assemblies, new control rods, and new reactor internals to assure mechanical integrity after shipment. Where testing and inspection programs are essentially the same as for previously accepted plants, a referenced statement to that effect with an identification of the fabricator and a summary table of the important design and performance characteristics should be provided.

\subsubsection{Reactor Vessel Internals}

4.2.2.1 Design Bases- The design bases for the mechanical design of the reactor vessel internal components should be presented including mechanical limits such as maximum allowable stresses, deflection, cycling and fatigue limits, fuel assembly restraints (positioning and holddown), material selection, radiation damage, and shock loadings. Details of the dynamic analyses, input forcing functions, and response loadings should be presented in Section 3.9 of the SAR.

4.2.2.2 Description and Drawings - The reactor vessel internals should be described and general assembly drawings provided showing the arrangement of the important components, positioning and support of the fuel assemblies, 
control rod, shim and burnable poison arrangement and support, and location of in-core instrumentation and reactor vessel surveillance specimen capsules.

4.2.2.3 Design Loading Conditions - The design loading conditions that provide the basis for the design of the reactor internals to sustain normal operation, anticipated operational occurrences, postulated accidents, and seismic events should be specified, All combinations of design loadings should be listed (e.g., operating pressure differences and thermal effects, seismic and transient pressure loads associated with postulated loss-of-coolant accidents) that are accounted for in design of the core support structure.

4.2.2.4 Design Loading Categories - Each combination of design loadings should be categorized with respect to either the Normal, Upset, Emergency or Faulted Condition (defined in the ASME Section III Code) and the associated design stress intensity or deformation 1imits should be stipulated. Design loadings should include Safe Shutdown Earthquake, one-half Safe Shutdown Earthquake and Operating Basis Earthquake if applicable. If these data are provided in Chapter 3.0, appropriate reference is adequate.

4.2.2.5 Design Criteria Bases - The bases for the proposed design stress and deformation criteria should be identified (for consideration see the January 1971 draft of the ASME Code for Core Support Structures Subsection NG).

\subsubsection{Reactivity Control Systems}

4.2.3.1 Design Bases - The design bases for the mechanical design of each of the reactivity control systems should be presented including control rod clearances, mechanical insertion requirements, material selection, radiation damage, and positioning requirements. Details of the dynamic analysis and testing, stress and deformation, and fatigue limits should be discussed in Section 3.9 of the SAR.

4.2.3.2 Description and Drawings - A description of each of the reactivity control systems should be provided including Preliminary (PSAR) or final (FSAR) design drawings of the control rods and followers, rod drives, latching mechanisms, and assembly within the reactor; design drawings and flow diagrams for chemical injection systems; and design drawings for temporary reactivity control devices for the initial core.

4.2.3.3 System Evaluation - An evaluation of the reactivity control systems should be provided which includes considerations such as materials 
adequacy throughout design lifetime; results of a dimensional and tolerance analys is of the systems as a whole, including points of support in the vessel, core structure and channels, control rods and followers, extension shafts and drive shafts; thermal analysis to determine tendencies to warp; analysis of pressure forces which could eject rods or temporary reactivity control devices from the core; potential for functional failure of critical components; analysis of the ability to preclude excessive rates of reactivity addition; possible effect of violent fuel rod failures and blowdown loads on control rod channel clearances; assessment of the sensitivity of the systems to mechanical damage as regards the capability to continuously provide reactivity control; and previous experience and/or developmental work with similar systems and materials.

4.2.3.4 Testing and Inspection Plan - The testing and inspections to be performed to verify the mechanical characteristics of the reactivity control systems should be described including test and surveillance programs to demonstrate proper functioning during initial start-up and throughout design lifetime.

4.2.3.5 Instrumentation - The instrumentation to be employed in connection with mechanical and chemical reactivity control systems and reactivity monitoring should be discussed in terms of functional requirements. Details of the design and logic of the instrumentation should be discussed in Chapter 7.0 of the SAR. .

\subsection{Nuclear Design}

\subsubsection{Design Bases}

The design bases for the nuclear design of the fuel and reactivity control systems should be provided and discussed including nuclear and reactivity control limits such as excess reactivity, fuel burnup, negative reactivity feedback, core design lifetime, fuel replacement program, reactivity coefficients, stability criteria, maximum controlled reactivity insertion rates, control of power distribution, shutdown margins, stuck rod criteria, maximum rod speeds, chemical and mechanical shim control, burnable poison requirements, and backup and emergency shutdown provisions. Describe the degree to which the design of backup systems such as the standby liquid control system considers the effects of anticipated transients with failure to scram.

\subsubsection{Description}

A description of the nuclear characteristics of the design should be provided including the following information: 
4.3.2.1 Nuclear Design Description - List, describe or illustrate for appropriate times in the fuel cycle features of the nuclear design not discussed in specific subsections. These should include such areas as fuel enrichments distributions, burnable poison distributions, and the physics of the burnout process, other physical features of the lattice or assemblies relevant to nuclear design parameters, delayed neutron fraction and neutron lifetimes, core lifetime and burnup, plutonium buildup, soluble poison insertion rates and the relationship to cooldown or xenon burnout or other transient requirements.

4,3,2.2 Power Distribution - Present ful1 quantitative information on calculated "normal" power distributions including distributions within typical assemblies, axial distributions, gross radial distributions (XY assembly patterns), and non-separable aspects of radial and axial distributions.

A full range should be covered of both representative and limiting power density patterns related to representative and limiting permitted conditions or relevant parameters such as power, flow, flow distribution, rod patterns, time in cycle (burnup and possible burnup distributions), cycle, burnable poison, xenon, etc., in sufficient detail to assure normally anticipated distributions are fully described and that the effects of all parameters important in affecting distributions are displayed. This should include details of transient power shapes and magnitudes accompanying normal transients such as load following, xenon buildup, decay or redistribution, xenon oscillation control, etc.

Discuss and assign specific magnitudes to errors or uncertainties which may be associated with these calculated distributions and present the experimental data, including results from both critical experiments and operating reactors, which back up the analysis, likely distribution limits and assigned uncertainty magnitudes. Discuss experimental checks to be made on this reactor and the criteria for satisfactory results.

Give in detail, including all relevant components and such variables as maximum allowable peaking factors vs axial position or changes over the fuel cycle, the design power distributions (shapes and magnitudes) and design peaking factors to be used in steady state limit statements and transient analysis initial conditions and justify the selections via a discussion of the relationship of these design assumptions to the previously presented expected and limiting distributions and uncertainty analys is.

Describe the relationship of these distributions to the monitoring instrumentations, discussing in detail the adequacy of instrument numbers and spatial deployment (including allowed failures), required correlations between readings 
and peaking factors, calibrations and errors, operational procedures and specific operational limits, axial and azimuthal asymmetry limits, limits for alarms, rod blocks, scrams, etc., to demonstrate that sufficient information is available to determine, monitor and limit distributions associated with normal operation to within proper limits.

4.3.2.3 Reactivity Coefficients - Present full quantitative information on calculated reactivity coefficients, including fuel-Doppler coefficient, moderator coefficients (density, temperature, pressure, void) and power coefficient.

State the precise definitions or assumptions relating to parameters involved such as effective fuel temperature for Doppler, distinction between intra and inter assembly moderator coefficients, parameters held constant in power coefficient, spatial variation of parameter and flux weighting used.

The information should be primarily in the form of curves covering the full applicable range of the parameters (density, temperature, pressure, void, power) from cold startup through limiting values used in accident analyses.

The information should include quantitative discussion of both spatially uniform parameter changes and these nonuniform parameter and flux weighting changes appropriate to operational and accident analyses and the methods used to treat nonuniform changes in transient analysis.

Sufficient information should be presented to illustrate the normal and limiting values of parameters appropriate to operational and accident states considering cycle, time in cycle, control rod insertions, boron content, burnable poisons, power distribution, moderator density, etc.

Discuss potential uncertainties in the results of the calculations and experimental results which back up the analysis and assigned uncertainty magnitudes and experimental checks to be made in this reactor. Where limits on coefficients are especially important, such as positive moderator coefficients in the power range, experimental checks on these limits should be fully detailed.

Present the coefficients actually used in transient analyses and show by reference to the previously discussed information and uncertainty analysis that suitably conservative values are used (a) for both beginning of life (BOL) and end of life (EOL) analyses, (b) where most negative or most positive (or least negative) coefficients are appropriate, (c) where spatially nonuniform changes are involved.

4.3.2.4 Contro1 Requirements - Provide tables and discussion relating to core reactivity blancès for BOL, EOL, and, where appropriate, intermediate 
conditions. This should include consideration of such reactivity influences as: control bank requirements and expected and minimum worths, burnable poison worths, soluble boron amounts and unit worths for various operating states, "stuck rod" allowance, moderator and fuel temperature and void defects, burnup and fission products, xenon and samarium poisoning, $\mathrm{pH}$ effects, permitted rod insertions at power, error allowances. Present and discuss required and expected shutdown margin as a function of time in cycle. Discuss uncertainties in the shutdown margin and experimental confirmations from operating reactors.

4.3.2.5 Control - Describe fully methods, paths and limits for normal operational control involving such areas as soluble poison concentration and changes, control rod motion, power shaping rod (e.g., part length rod) motion, flow change. This should include consideration of cold, hot and peak xenon startup, load following and xenon reactivity control, power shaping (e.g., xenon redistribution or oscillation control), burnup.

\subsubsection{Control Rod Patterns and Reactivity Worths - Present full} information on control rod patterns expected to be used throughout a fuel cycle. This should include details on separation into groups or banks if applicable, order and extent of withdrawal of individual rods or banks, limits, with justification, to be imposed on rod or bank positions as a function of power level and/or time in cycle or for any other reason, expected positions of rods or banks for cold critical, hot standby critical and for full power for both BOL and EOL. Describe allowable deviations from these patterns due to misaligned or stuck rods or for any other reason such as special power shaping. For the allowable patterns, including allowable deviations, indicate for various power and EOL, BOL conditions, the maximum worth of rods which might be postulated to be removed from the core in an ejection or drop accident and rods or rod banks which could be removed in rod withdrawal accidents and give the worths of these rods as a function of position. Describe any experimental confirmation of these worths. Present maximum reactivity increase rates associated with these withdrawals. Describe fully and give the methods for calculating the scram reactivity as a function of time after scram signal including consideration for Technical Specification scram times, stuck rod(s), power level and shape, time in cycle and any other parameter important for bank reactivity worth and axial reactivity shape functions. For BWRs provide criteria for control rod velocity limiters and control rod worth minimizers.

\subsubsection{Criticality of Fuel Assemblies - State wet and dry $k$ ff for} single and groups of adjacent fuel assemblies up to the number required for criticality.

$$
4.3-4
$$




\subsubsection{Stability}

(1) Xenon Stability - Provide information defining the degree of predicted stability for xenon oscillations in both the axial direction and in the horizontal plane. If any form of xenon instability is predicted, include evaluations of higher mode oscillations. Indicate in detail the analytic and experimental bases for the predictions. Include an assessment of potential error in the predictions. Also, show how unexpected oscillations would be detectable before safety limits are exceeded.

Provide unambiguous positions regarding stability or lack thereof. That is, where stability is claimed, provide corroborating data from sufficiently similar power plants, or provide commitments to demonstrate stability. Indicate criteria for determining whether the reactor will be stable or not. Where instability or marginal stability is predicted, provide details of how oscillations will be detected and controlled and provisions for protection against exceeding safety limits.

(2) Reactor Stability - Provide analys is of the overall reactor stability against power oscillations (other than xenon).

4.3.2.9 Vessel Irradiation - Provide the neutron flux distribution and spectrum in the core, at core boundaries and at the pressure vessel wall for appropriate times in the reactor life for NVT determinations.

\subsubsection{Analytical Methods}

Provide a detailed description of the analytical methods used in the nuclear design including those for predicting criticality, reactivity coefficients and burnup effects. Computer codes used should be described in detail as to the name and the type of code, how it is used and its validity based on critical experiments and/or confirmed predictions of operating plants. Code descriptions should include methods of obtaining parameters such as cross sections. Estimates of the accuracy of the analytical methods should be included.

\subsubsection{Changes}

List any changes in reactor core design features, calculational methods, data or information relevant to determining important nuclear design parameters which depart from prior practice of the reactor designs and list affected parameters. Details of the nature and effects of the changes should be treated in appropriate subsections. 


\subsection{Thermal and Hydraulic Design}

4.4.1 Design Bases

The design bases for the thermal and hydraulic design of the reactor should be provided including such items as maximum fuel and clad temperatures and cladding to fuel gap characteristics as a function of burnup (at rated power, design overpower and during transients), critical heat flux ratio (at rated power, design overpower, and during transients), flow velocities and distribution control, coolant and moderator voids, hydraulic stability, transient limits, fuel cladding integrity criteria, and fuel assembly integrity criteria.

\subsubsection{Description}

A description of the thermal and hydraulic characteristics of the reactor design should be provided including the following:

4.4.2.1 Summary Comparison - Provide a summary comparison of the thermal and hydraulic design parameters of the reactor with previously approved reactors of similar design. Include, for example, primary coolant temperatures, fuel temperatures, critical heat flux ratio, critical heat flux correlations used, coolant velocities, surface heat fluxes, power densities, specific powers, surface areas, and flow areas.

4.4.2.2 Fuel Cladding Temperatures - Discuss and provide fuel cladding temperatures, both local and gross, with an indication of the correlation used for thermal conductivity and the method of employing peaking factors.

4.4.2.3 Critical Heat Flux Ratio - Provide the critical heat flux ratios for both the hot spot and the core average with an indication of the critical heat flux correlation used, analysis techniques, method of use, method of employing peaking factors, and comparison with other correlations.

4.4.2.4 Flux Tilt Considerations - Discuss the margin provided in the peaking factor employed to account for flux tilts, to assure that flux limits are not exceeded during operation. Describe plans for power the event of flux tilts.

4.4.2.5 Void Fraction Distribution - Give the predicted c and maximum void fraction and distribution.

4.4.2.6 Core Coolant Flow Distribution - Describe and discuss core coolant flow distribution and orificing, and the basis on which orificing is designed relating to shifts in power production during core life.

$$
\text { 4. 4-1 }
$$


4.4.2.7 Core Pressure Drops and Hydraulic Loads - Proyide core pressure drops and hydraulic loads during normal and accident conditions.

4.4.2.8 Correlation and Physical Data - Discuss the correlations and physical data employed in determining important characteristics such as heat transfer coefficients and pressure drop.

4.4.2.9 Thermal Effects of Operational Transients - Evaluate the capability of the core to withstand the thermal effects resulting from anticipated operational transients.

4.4.2.10 Uncertainties in Estimates - Discuss the uncertainties associated with estimating the peak or limiting conditions for thermal and hydraulic analysis (e.g., fuel temperature, clad temperature, pressure drops, and orificing effects).

4.4.2.11 Plant Configuration Data - Provide the following information in regard to plant configuration and operation:

(1) total coolant flow through each flow path, i.e, core flow, bypass flow, etc.

(2) total volume of each plant component including ECCS components with sufficient detail in reactor vessel and (for PWR) steam generator to define each part, i.e., downcomer, lower plenum, upper head, etc.

(3) the flow path length through each volume.

(4) the height and liquid level of each volume.

(5) the elevation of the bottom of each volume with respect to some reference elevations, preferably the centerline of the outlet piping.

(6) the line lengths and sizes of all safety injection lines.

(7) minimum flow areas of each component.

(8) steady state pressure and temperature distribution through the system.

\subsubsection{Evaluation}

An evaluation of the thermal and hydraulic design of the reactor should be provided including the following specific information.

$$
\text { 4. 4-2 }
$$


4.4.3.1 Core Hydraulics - With respect to core hydraulics, the evaluation should include, (1) a discussion of the results of flow model tests (with respect to pressure drop for the various flow paths through the reactor and flow distributions at the core inlet), (2) the empirical correlation selected for use in analyses for both single-phase and two-phase flow conditions and the applicability over the range of anticipated reactor conditions, and (3) the effect of partial or total isolation of a loop.

4.4.3.2 Influence of Power Distribution - The influence of axial and radial power distributions on the thermal and hydraulic design should be discussed, including an analysis to determine which fuel rods control the thermal limits of the reactor.

4.4.3.3 Core Thermal Response - The thermal response of the core should be evaluated at rated power, design overpower, and for expected transient conditions.

4.4.3.4 Analytical Techniques - A comprehensive discussion of the analytical techniques used in evaluating the core thermal-hydraulics should be provided, including estimates of uncertainties. Parameters not included in $4.4 .2(3), 4.4 .2(8)$, and $4.4 .2(10)$ should be discussed.

4.4.3.5 Hydraulic Instability Analysis - Provide the results of an analys is of hydraulic instability over the intended range of coolant flow.

4.4.3.6 Temperature Transient Effects Analysis - Provide an analysis of the potential for and effect of sudden temperature transients on waterlogged elements or elements with high internal gas pressure.

4.4.3.7 Potentially Damaging Temperature Effects During Transients Provide an analysis of temperature effects during anticipated operational transients that may cause bowing or other damage to fuel, control rods or structure.

4.4.3.8 Energy Release During Fuel Element Burnout - Evaluate the energy release and potential for a chemical reaction should physical burnout of fuel elements occur.

4.4.3.9 Energy Release or Rupture of Waterlogged Fuel Elements Evaluate the energy release and resulting pressure pulse should waterlogged elements rupture and spill fuel into the coolant.

\subsubsection{Fuel Rod Behavior Effects From Coolant Flow Blockage -} Discuss the behavior of fuel rods in the event of coolant flow blockage. 
4.4.4 Testing and Verification

The testing and verification techniques to be used to assure that the planned thermal and hydraulic design characteristics of the core have been provided and will remain within required limits throughout core lifetime should be discussed.

\subsubsection{Instrumentation Requirements}

Discussion of the functional requirements for the instrumentation to be employed in monitoring and measuring those thermal-hydraulic parameters important to safety should be provided. Include, for example, the requirements for in-core instrumentation to confirm predicted power density distribution and moderator temperature distributions. Details of the instrumentation design and logic should be discussed in Chapter 7.0 of the SAR. 


\subsection{REACTOR COOLANT SYSTEM AND CONNECTED SYSTEMS}

This chapter of the SAR should provide information regarding the reactor coolant system and systems connected to it. Special consideration should be given to the reactor coolant system and pressure-containing appendages out to and including isolation valving which is the "reactor coolant pressure boundary" (RCPB), as defined in Section 50.2(v) of 10 CFR Part 50.

Evaluations, together with the necessary supporting material, should be submitted to show that the reactor coolant system is adequate to accomplish its intended objective and to maintain its integrity under conditions imposed by all foreseeable reactor behavior, either normal or accident conditions. The information should permit a determination of the adequacy of the evaluations; that is, assurance that the evaluations included are correct and complete and all the evaluations needed have been made. Evaluations included in other chapters that have a bearing on the reactor coolant system should be referenced.

\section{$\underline{5.1}$ Summary Description}

A summary description of the reactor coolant system and its various components should be provided. The description should indicate the independent and interrelated performance and safety functions of each component. Include a tabulation of important design and performance characteristics.

\subsubsection{Schematic Flow Diagram}

A schematic flow diagram of the reactor coolant system denoting all major components, principal pressures, temperatures, flow rates, and coolant volume under normal steady state full power operating conditions should be provided.

\subsubsection{Piping and Instrumentation Diagram}

Provide a piping and instrumentation diagram of the reactor coolant system and connected systems delineating:

(1) The extent of the systems located within the containment,

(2) The points of separation between the reactor coolant (heat transport) system and the secondary (heat utilization or removal) system, and

$$
5 \cdot 0-1
$$


(3) The extent of isolability of any fluid system as provided by the use of isolation valves between the radioactive and nonradioactive sections of the system, isolation valves between the RCPB and connected systems, and passive barriers between the RCPB and other systems.

\subsubsection{Elevation Drawing}

Provide an elevation drawing showing principal dimensions of the reactor coolant system in relation to the supporting or surrounding concrete structures from which a measure of the protection afforded by the arrangement and the safety considerations incorporated in the layout can be gained.

\subsection{Integrity of Reactor Coolant Pressure Boundary}

This section should present discussions of the measures to be employed to provide and maintain the integrity of the reactor coolant pressure boundary (RCPB) for the plant design lifetime.

\subsubsection{Design of Reactor Coolant Pressure Boundary Components}

The design methods and procedures to be used for the components of the RCPB should be stated. They should include the following information:

5.2.1.1 Performance Objectives - State the performance objectives of the system and its components from which the design parameters are derived in the normal, upset, emergency, and faulted conditions considered.

5.2.1.2 Design Parameters - State the design pressure, temperature, seismic loads, and maximum system and component test pressures for the system and individual components.

5.2.1.3 Compliance With 10 CFR Part 50, Section 50.55a - Provide a table which shows compliance with the rules of 10 CFR Part 50, Section 50.55a, "Codes and Standards." In the event there are cases wherein conformance to the rules of Section $50.55 a$ would result in hardships or unusual difficulties without a compensating increase in the level of safety and quality, provide a complete description of the circumstances resulting in such cases and the basis for proposed alternative requirements. Describe how an acceptable level of safety and quality will be provided by the proposed alternative requirements. 
5.2.1.4 Applicable Code Cases - Provide a list of the ASME and ANSI code case interpretations that will be applied to components within the reactor coolant pressure boundary.

5.2.1.5 Design Transients - Provide a complete list of transients to be used in the design and fatigue analysis of all the applicable components within the reactor coolant pressure boundary discussed in Sections 5.4 and 5.5. Specify all design transients and their number of cycles such as startup and shutdown operations, power level changes, emergency and recovery conditions, switching operations (i.e., startup or shutdown of one or more coolant loops), control system or other system malfunctions, component malfunctions, transients resulting from single operator errors, inservice hydrostatic tests, seismic events, etc., that are contained in the ASME Code-required "Design Specifications" for the components of the reactor coolant pressure boundary. Categorize all transients or combinations of transients with respect to the conditions identified as "normal," upset," "emergency" or "faulted" as defined in the ASME Section III Nuclear Component Code. In addition, provide the design loading combinations and the associated stress or deformation limits specified. The information should include sufficient detail to provide the bases for the design of all classes of components intended to conform to the rules of section III of the ASME Code.

\subsubsection{Identification of Active Pumps and Valves - Provide a list} which classifies pumps and valves (including check valves) within the reactor coolant pressure boundary as either active or inactive components. Describe the design methods and procedures employed to assure that active components will function as designed in the event of a postulated pipe rupture (faulted condition) in the reactor coolant pressure boundary, e.g., allowable stress limits established at or near the yield stress calculated on an elastic basis. Describe the isolation signal, the closure time, and the leak-tight integrity criteria for all active valves. Where empirical methods (tests) are employed, provide a summary description of test methods, loading techniques and results including the bases for extrapolations to components larger or smaller than those tested (FSAR).

5.2.1.7 Design of Active Pumps and Valves - A description of the analytical methods and identification of design limits to be employed to assure that pumps required to function and valves required to open or close during or following the specified plant condition, will operate as designed should be provided. If empirical methods will be employed 
based on tests, a summary description of test procedures, imposed test loadings and results obtained including the basis for extrapolations to components larger or smaller than those tested should be provided.

5.2.1.8 Inadvertent Operation of Valves - A discussion should be included for valves not relied upon for performing action during transients or events considered in the respective operating condition categories but which, if operated inadvertently, could compound the consequences of such transients.

5.2.1.9 Stress and Pressure Limits - If stress and pressure limits other than those specified in Paragraphs NB-3655 and NB-3656 of Section III, of the ASME Boiler and Pressure Vesse1 Code (1971) or ANSI B31.7 Code Case 70 are proposed for inactive components, provide the basis for their application.

5.2.1.10 Stress Analysis for Structural Adequacy - The type of stress analysis (simplified, discontinuity, etc.) and a description of methods that will be used to determine the structural adequacy of the components under the normal, upset, emergency and faulted operating condition categories should be provided.

5.2.1.11 Analysis Method for Faulted Condition - The use of the plastic instability and limit analysis methods of design specified in the ASME Code - Section III for the faulted condition category may be nonconservative and incompatible when used in conjunction with dynamic system analysis. Justification for the use of inelastic stress analysis methods in conjunction with elastic system dynamic analysis should be provided, or the selected method of analyses and associated design limit of Appendix F of ASME Code Section III for faulted condition that will be used should be identified.

5.2.1.12 Protection Against Environmental Factors - Protection provided for the principal components of the reactor coolant system against environmental factors (e.g., fires, flooding, missiles effects) to which the system may be subjected should be discussed.

5.2.1.13 Compliance with Code Requirements - For components that are to be constructed in accordance with Section III of the ASME Code, Subsection NB, the analytical calculations or experimental testing performed to assure compliance with the Code should be provided. A brief description should be submitted in the FSAR of the mathematical or test 
models, the methods of calculation or test including any simplifying assumptions, and a summary of results which include the stresses obtained by calculation or test, cumulative usage factors and design margins. The information provided should be sufficiently detailed to show the validity of the structural design to sustain and meet in every respect the provisions of the Certified Design Specifications and the requirements of Section III of the ASME Code (FSAR).

5.2.1.14 Stress Analysis for Emergency and Faulted Condition Loadings The type of stress analyses to be used for emergency and faulted condition loadings should be provided.

5.2.1.15 Stress Levels in Category I Systems - A 1ist of Category I systems and the associated stress levels (i.e., seismic, dead weight plus pressure, LOCA, etc.) at all points of high changes in flexibility under the faulted condition should be provided. Include sketches of each system configuration (FSAR).

5.2.1.16 Analytical Methods for Stresses in Pumps and Valves - List the analytical methods used to evaluate stresses in all pumps and valves including safety and relief valves. For design conditions other than those explicitly addressed by the ASME Section III Code (e.g., design condition categories for which code limits have not been developed, geometries not included, etc.), provide a summary of each analytical method and the associated design limits. Where empirical relationships and methods determine the design, the bases for extrapolating these methods or experience to all loading conditions should be specified for each component.

5.2.1.17 Ana1ytica1 Methods for Evaluation of Pump Speed and Bearing Integrity - Provide the methods used to evaluate critical speed problems in pumps, and to assure the integrity of the bearings for the transient conditions encountered during service.

5.2.1.18 Operation of Active Valves Under Transient Loadings Describe the program to assure that active valves will operate under the transient loadings experienced during the service life.

5.2.1.19 Field Run Piping - The nominal pipe sizes which determine whether piping is field run should be specified. Those Category I piping systems which are field run should be identified and any special or simplified procedures for designing and installing this piping should be described. (FSAR) 


\subsubsection{Overpressurization Protection}

Provide the following information regarding the provisions taken to protect the RCPB against overpressurization:

5.2.2.1 Location of Pressure-Relief Devices - Identify and show the location on $\mathrm{P}$ and $\mathrm{I}$ diagrams of all pressure-relieving devices for:

(1) the reactor coolant system,

(2) the primary side of the auxiliary or emergency systems interconnected with the primary system, and

(3) any blowdown or heat dissipation system connected to the discharge side of the pressure-relieving devices.

5.2.2.2 Mounting of Pressure-Relief Devices - Describe the design and installation details for the mounting of the pressure-relieving devices (safety valves and relief valves) within the reactor coolant pressure boundary. In particular, specify the design bases which will be used to take into account full discharge loads (i.e., thrust, bending, torsion) imposed on valves and on connected piping in the event all the valves are required to discharge. Indicate the provisions made to accommodate these loads.

5.2.2.3 Report on Overpressure Protection - To facilitate review of the bases for the pressure relieving capacity of the reactor coolant pressure boundary, submit the "Report on Overpressure Protection" that has been prepared in accordance with the requirements of the ASME Section III Nuclear Power Plant Components Code or, if the report is not available at the time the PSAR is submitted, indicate the approximate date for submission. In the event the report is not expected to be available until either the Operating License review or late in the construction schedule for the plant, provide in the PSAR the bases and analytical approach (e.g., preliminary analyses) being utilized to establish the overpressure relieving capacity required for the reactor coolant pressure boundary.

\subsubsection{General Material Considerations}

With respect to materials which will be used in the reactor coolant pressure boundary, provide the following information: 
5.2.3.1 Material Specifications - Provide a list of specifications for the principal pressure retaining ferritic materials and austenitic stainless steels, including weld materials, intended to be used for each component (e.g., vessels, piping, pumps and valves) that is part of the reactor coolant pressure boundary. With respect to ferritic materials (including welds) of the reactor pressure vessel beltline, the information regarding these specifications should include any additionally imposed limits on residual elements (reportable and nonreportable) by specification requirements which are intended to reduce sensitivity to irradiation embrittlement in service. Any additional or special requirements by the purchaser should also be indicated.

\subsubsection{Compatibility With Reactor Coolant - Provide a list of the} materials of construction exposed to the reactor coolant and a description of their compatibility with the coolant and contaminants or radiolytic products to which the system may be exposed.

5.2.3.3 Compatibility With External Insulation and Environmental Atmosphere - Provide a list of the materials of construction of reactor coolant pressure boundary and a description of their compatibility with external insulation or the environmental atmosphere in the event of coolant leakage.

5.2.3.4 Chemistry of Reactor Coolant - Provide a description of the chemistry of the reactor coolant and the additives (such as inhibitors) whose principal function is directed toward corrosion control within the system. Describe water chemistry including maximum allowable content of chloride, fluoride, oxygen, hydrogen and soluble poisons. Discuss controls to be used to control the water chemistry including $\mathrm{pH}$.

\subsubsection{Fracture Toughness}

To allow evaluation of the adequacy of the proposed heatup and cooldown limits for this plant, as dictated by fracture toughness of the ferritic materials, the following information should be provided.

5.2.4.1 Compliance with Code Requirements - Indicate the degree of compliance with the test methods and acceptance criteria of the recently revised ASME Code Section III fracture toughness rules (Code Case 1514), as applied to the fracture toughness data to be obtained for the ferritic materials of the reactor coolant pressure boundary. These rules require determination of the following for the reactor vessels, pumps, valves, and piping with nominal thickness over $2-1 / 2$ inches: 
(1) NDT temperatures obtained from dropweight (DWT) tests, and

(2) Temperatures at which "weak" direction Charpy V-notch specimens exhibit at least $35 \mathrm{mils}$ lateral expansion and not less than $50 \mathrm{ft}-1 \mathrm{bs}$ absorbed energy.

5.2.4.2 Acceptable Fracture Energy Levels - Identify criteria by which the initial upper shelf fracture energy levels for the materials of the reactor vessel beltline (including welds), as determined by Charpy V-notch tests on specimens oriented in the "weak" direction of the material will be established.

5.2.4.3 Operating Limitations During Startup and Shutdown - Indicate any proposed operating limitations on heating and cooling rates during startup and shutdown of the reactor coolant system. Indicate the extent to which these limitations will use as a guide Appendix G, "Protection Against Non-Ductile Failure," of the recently revised ASME Code Section III fracture toughness rules (Code Case 1514) and explain a11 deviations from this guide.

5.2.4.4 Compliance with "Reactor Vessel Material Surveillance Program Requirements" - Provide a description of the reactor vesse 1 material surveillance program to indicate the degree of compliance with the AEC proposed, "Reactor Vessel Material Surveillance Program Requirements" 10 CFR Part 50, Appendix H, published in the Federal Register on July 3, 1971. State the degree of conformance particularly with respect to the following:

(1) number of capsules,

(2) number and type of specimens,

(3) withdrawal schedule,

(4) retention of archive material.

5.2.4.5 Reactor Vessel Annealing - Indicate the extent to which the design of affected systems and components has been reviewed to determine that annealing of the reactor vessel will be feasible should it be necessary because of radiation embrittlement after several years of operation. State the maximum reactor vessel temperature that can be obtained using an in-place annealing procedure. 


\subsubsection{Austenitic Stainless Steel}

For unstabilized stainless steel material of the austenitic type series $3 \times x$ used for components that are part of

(1) the reactor coolant pressure boundary,

(2) systems required for reactor shutdown,

(3) systems required for emergency core cooling,

(4) reactor vessel internals which are required for emergency core cooling, and

(5) reactor vessel internals which are relied upon to permit adequate core cooling for any mode of normal operation or under postulated accident conditions, the following information should be provided.

5.2.5.1 Cleaning and Contamination Protection Procedures - Describe the procedures that will be used to assure that the material is suitably cleaned and suitably protected against contaminants capable of causing stress corrosion cracking throughout the fabrication, shipment, storage, construction, testing, and operation of components and systems.

5.2.5.2 Solution Heat Treatment Requirements - Requirements for solution heat treatment of such material before fabrication or assembly into components and systems should be presented.

5.2.5.3 Material Inspection Program - Provide a description of the material inspection program that will be used to verify the nonsusceptibility of unstabilized austenitic stainless steels to intergranular attack. If the procedures of ASTM A-262, Practice E are not employed, furnish a description of your proposed test procedures.

5.2.5.4 Unstabilized Austenitic Stainless Steels - Provide a 1ist of al1 unstabilized grades of austenitic stainless steels (AISI Type 3xx series) with a carbon content greater than $0.03 \%$, that will be used for components of the reactor coolant pressure boundary and state the criteria that will be met in terms of heat treatment after welding or water chemistry control. 
5.2.5.5 Avoidance of Sensitization - Include a description of plans which will be followed to avoid partial or local severe sensitization of austenitic stainless steel during heat treatments and welding operations for core structural load bearing members and component parts of the reactor coolant pressure boundary. Describe welding methods, heat input, interpass temperature, and the quality controls that will be employed in welding austenitic stainless steel components.

\subsubsection{Retesting Unstabilized Austenitic Stainless Steels Exposed} to Sensitizing Temperatures - Describe plans for retesting unstabilized austenitic stainless steels which have been exposed to the sensitization heat range of $800-1500^{\circ} \mathrm{F}$ as a result of welding, heat treatment, or other operations. Indicate whether these materials will be retested for susceptibility to intergranular attack using the methods prescribed in the American Society for Testing and Materials Specification A-262, Practice E.

5.2.5.7 Control of Delta Ferrite - Indicate the procedures and requirements to be employed for control of delta ferrite in austenitic stainless steel welds, to avoid microfissuring in welds, especially as regards filler materials, welding procedure qualification, and the methods for determining delta ferrite content of the completed welds.

\subsubsection{Pump F1ywhee1s}

With respect to reactor coolant pump flywheels, provide the following information.

5.2.6.1 Compliance With AEC Safety Guide 14 - Indicate your degree of compliance with AEC Safety Guide 14 relating to material properties, design, inservice inspection, and testing.

5.2.6.2 Additional Data and Analyses - Additional data or analyses demonstrating adequate margins of safety for operation of flywheels which are not in accordance with the recommendations of Safety Guide 14 should be presented.

\subsubsection{Reactor Coolant Pressure Boundary Leakage Detection Systems}

To demonstrate compliance with AEC Genera1 Design Criteria 30, which requires that means be provided for detecting and, to the extent practical, identifying the location of the source of reactor coolant leakage, the following information should be provided. 
5.2.7.1 Leakage Detection Methods - Describe the methods that will be used to determine coolant leakage from the reactor coolant pressure boundary in sufficient detail to indicate the subsystems to be provided and their operating principles.

5.2.7.2 Indication in Control Room - Describe the methods that will be used for positive indication in the control room of leakage of coolant from the reactor coolant system to the containment.

5.2.7.3 Limits for Reactor Coolant Leakage - Indicate the limits for the reactor coolant leakage rates; both total leakage and unidentified leakage.

5.2.7.4 Unidentified Leakage - With reference to the proposed maximum allowable unidentified leakage rate from the reactor coolant pressure boundary to the containment area, discuss:

(1) The normally expected leakage rate,

(2) The sensitivity and response time of the subsystems to the departure from the normal leakage rate,

(3) The length of a through-wall flow that would produce a detectable increase in the normal leakage rate,

(4) The margins of safety for a detectable flaw to assume a critical size and the associated leakage increase,

(5) Criteria to evaluate the adequacy and margin included in the proposed leak detection system.

5.2.7.5 Maximum Allowable Total Leakage - With reference to the proposed maximum allowable total leakage rate for the reactor coolant pressure boundary during normal operation, furnish the ratio of the proposed limit to the normal capacity of the reactor coolant makeup system, and to the normal capacity of the containment water removal sys tem.

5.2.7.6 Differentiation Between Identified and Unidentified Leaks Provide a description of the adequacy of the proposed leakage detection systems to differentiate between identified and unidentified leaks from 
the reactor coolant pressure boundary to the containment atmosphere and to other systems and indicate which of these systems provide a means for locating the general area of a leak.

5.2.7.7 Sensitivity and Operability Tests - Provide a description of the tests proposed to demonstrate sensitivities and operability of the leakage detection systems.

\subsubsection{Inservice Inspection Program}

To demonstrate compliance with Section XI of the ASME Boiler and Pressure Vessel Code, "Rules for Inservice Inspection of Nuclear Reactor Coolant Systems," the following information should be provided.

5.2.8.1 Provisions for Access to Reactor Coolant Pressure Boundary Provide a description of the design and arrangement provisions made for access to the reactor coolant pressure boundary as required by Section IS-141 and IS-142 of Section XI. Indicate the specific provisions made for access to the reactor vessel for examination of the welds and other components.

5.2.8.2 Equipment for Inservice Inspections - Provide a description of the equipment that will be used, or is under development for use, in performing the reactor vessel and nozzle inservice inspections.

5.2.8.3 Recording and Comparing Data - A description of the system to be used to record and compare the data from the baseline inspection with the data that will be obtained from subsequent inservice inspections should be provided.

5.2.8.4 Reactor Vessel Acceptance Standards - Present the acceptance standards that will be used to establish acceptability of the vessel for service during preoperational mapping of the reactor vessel by ultrasonic examination, to meet the requirements of IS-232 of Section XI of the ASME Code.

5.2.8.5 Coordination of Inspection Equipment with Access Provisions Describe the procedures to be followed to coordinate the development of the remote inservice inspection equipment with the access provisions for inservice inspection afforded by the plant design. 


\subsection{Thermal Hydraulic System Design}

The thermal hydraulic design of the reactor coolant system should be described in this section. The following specific information should be included.

\subsubsection{Analytical Methods and Data}

Describe the analytical methods, thermodynamic data, and hydrodynamics data used to determine the thermal and hydraulic characteristics of the reactor coolant system.

\subsubsection{Operating Restrictions on Pumps}

State the operating restrictions that will be imposed on the coolant pumps to meet net positive suction head requirements.

\subsubsection{Powex-Flow Operating Map (BWR)}

For boiling water reactors, provide a power-flow operating map indicating the limits of reactor coolant systems operation. This map should indicate the permissible operating range as bounded by minimum flow, design flow, maximum pump speed, and natural circulation.

\subsubsection{Temperature-Power Operating Map (PWR)}

For pressurized water reactors, provide a temperature-power operating map indicating the effects of reduced core flow due to inoperative pumps including system capability during natural circulation conditions.

\subsubsection{Load Following Characteristics}

Describe the load following characteristics of the reactor coolant system and the techniques employed to provide this capability.

\subsubsection{Transient Effects}

Discuss the transient effects on the reactor coolant pressure boundary of such events as loss of full or partial coolant flow, coolant pump speed changes, load changes, and start-up of an inactive loop.

\subsubsection{Thermal and Hydraulic Characteristics Summary Table}

Provide a table summarizing the thermal and hydraulic characteristics of the reactor coolant system.

\section{$5 \cdot 3-1$}




\subsection{Reactor Vessel and Appurtenances}

The discussion in this section should present the design bases, description, evaluation, and necessary tests and inspections for the reactor vessel and its appurtenances.

The following specific information should be provided as a minimum.

\subsubsection{Protection of Closure Studs}

Describe the means provided to prevent exposure of the reactor closure studs to vapor or moisture from borated water or other potentially corrosive media when the reactor vessel head is removed.

\subsubsection{Special Processes for Fabrication and Inspection}

Identify and discuss any special processes to be used for the fabrication and inspection of the vessel.

\subsubsection{Features for Improved Reliability}

Describe any special design and fabrication features incorporated in the reactor vessel to improve further its reliability and reduce its potential for failure.

\subsubsection{Quality Assurance Surveillance}

Identify the reactor vessel fabricator and the extent of quality assurance surveillance to be provided by the applicant or its representative (particularly if the vessel is to be fabricated outside the U.S.).

\subsubsection{Materials and Inspections}

State the reactor vessel materials and inspections to be carried out during fabrication.

\subsubsection{Reactor Vesse1 Design Data}

Provide reactor vessel design data in tabular form.

\subsubsection{Reactor Vessel Schematic (BWR)}

Provide a schematic of the reactor vessel relating nozzle locations, and various reactor coolant level limits to the vessel datum. Show relation of vessel to biological shield and safe-end locations.

$$
\text { 5. 4-1 }
$$




\subsection{Component and Subsystem Design}

This section should present discussions of the performance requirements and design features to assure overall safety of the various components within the reactor coolant system and subsystems closely allied with the reactor coolant system.

Because these components and subsystems differ for various types and designs of reactors, the Standard Format does not assign specific subsection numbers to each of these components or subsystems. The applicant should provide separate subsections (numbered 5.5.1 through 5.5.x) for each principal component or subsystem. The discussion in each subsection should present the design bases, description, evaluation, and necessary tests and inspections for the component or subsystem, including a discussion of the radiological considerations for each subsystem from a viewpoint of how radiation affects the operation of the subsystem and from a viewpoint of how radiation levels affect the operators and capabilities of operation and maintenance. Appropriate details of the mechanical design should be described in Sections $3.7,3.9$, and 5.2 .

The following paragraphs provide examples of components and subsystems that should be discussed as appropriate to the individual plant, and identify some specific information that should be provided in addition to the items identified above.

\subsubsection{Reactor Coolant Pumps}

In addition to the discussion of design bases, description, evaluations, and tests and inspections, discuss the provisions taken to preclude rotor overspeeding of the reactor coolant pumps in the event of a design basis LOCA.

\subsubsection{Steam Generators (PWR)}

The information provided should include estimates of the radioactivity levels anticipated in the secondary side of the steam generators during normal operation, and the bases for the estimate. The potential effects of tube ruptures should be discussed. Proposed secondary side water chemistry and corrosion control measures should be discussed.

Provide the steam generator design criteria employed to assure that flow induced vibration and cavitation effects will not result in degradation of the primary or secondary side, due to tube thinning and corrosion and erosion mechanisms, during the service lifetime of the equipment. Include the following specific information: 
(1) Identify the design conditions and transients which will be specified in the design of the steam generator tubes, and the operating condition category selected (e.g., upset, emergency, or faulted) which defines the allowable stress intensity limits to be used. Justify the basis for the selected operating condition category.

(2) Indicate the margin of tube-wall thinning which could be tolerated without exceeding the allowable stress limits identified in (1) above, under the postulated condition of a design basis pipe break in the reactor coolant pressure boundary during reactor operation.

(3) The inservice inspection program to recognize progressive deterioration.

\subsubsection{Reactor Coolant Piping}

The subsection on reactor coolant piping should present an overall description of this system, making appropriate references to detailed information on criteria, methods, and materials provided in Chapter 3 . The discussion should include the provisions taken during design, fabrication, and operation to control those factors that contribute to stress corrosion cracking. Describe the provisions made for inservice inspection of the reactor coolant piping and associated components.

\subsubsection{Main Steam Line Flow Restrictions}

\subsubsection{Main Steam Line Isolation System}

Include discussion of provisions, such as seal systems, taken to reduce the potential leakage of radioactivity to the environment in the event of a main steam line break.

\subsubsection{Reactor Core Isolation Cooling System}

Include requirements for RCIC operation following a loss of offsite power, and discuss provisions against failure and isolation of the RCIC turbine steam lines outside containment.

\subsubsection{Residua1 Heat Removal System}

Include requirements for RHR operation following prolonged loss of offsite power, and discuss provisions against failure and isolation of steam 1ines to RHR heat exchangers for operation in condensing shutdown mode.

\subsubsection{Reactor Coolant Cleanup System}

The radiological considerations of the reactor coolant cleanup system should be summarized here and derived and justified in Chapters 11 and 12 . 
5.5.9 Main Steam Line and Feed Water Piping

$\underline{5.5 .10}$ Pressurizer

5.5.11 Pressurizer Relief Tank

5.5.12 Valves

5.5.13 Safety and Relief Valves

5.5.14 Component Supports

5.6 Instrumentation Requirements

The instrumentation to be provided in connection with the reactor coolant system and its appendages should be discussed with respect to functional requirements. Provide discussion of the plant operating limits with offspeed differences between recirculating loops for direct-cycle plants. Details of the design and logic of the instrumentation should be discussed in Chapter 7.0. 


\subsection{ENGINEERED SAFETY FEATURES}

Engineered safety features are provided to mitigate the consequence of postulated accidents, in spite of the fact that these accidents are very unlikely. This chapter of the SAR should present information on the engineered safety features provided in the plant in sufficient detail to permit an adequate evaluation of the performance capability of these features. The information should include, for example:

(1) descriptions of the experience, tests at simulated accident conditions or conservative extrapolations from existing knowledge that supports the concept selection upon which the operation of the feature is based;

(2) considerations of component reliability, system interdependency, redundancy and separation of components or portions of systems, etc., associated with assuring that the feature will accomplish its intended purpose and will function for the period required;

(3) provisions for test, inspection, and surveillance to assure that the feature will be dependable and effective upon demand;

(4) evidence that the material used will withstand the postulated accident environment including radiation levels, and that radiolytic decomposition products which may occur will not interfere with it or other engineered safety features.

The engineered safety features included in plant designs vary. The engineered safety features explicitly discussed in the sections of this chapter are those that are commonly used to limit the consequences of postulated accidents in light water-cooled power reactors. They should be treated as illustrative of the engineered safety features that should be treated in this chapter of the SAR, and of the kind of informative material that is needed. Where additional or different types of engineered safety features are used, they should be covered in a similar manner in separate added sections (see Section 6.X).

\subsection{General}

This section should identify and provide a brief summary of the types of engineered safety features provided in the plant. List each system of the plant that is considered to be an engineered safety feature. 


\subsection{Containment Systems}

This section should provide information in sufficient detail to permit the regulatory staff to evaluate the performance capability of the containment system. Structural design criteria for the containment system should be provided in Chapter 3. The containment system is considered as composed of the containment structure or structures including penetrations (e.g., secondary containment or confinement building) and the directly associated systems upon which the containment function depends (e.g., the system of isolation valves installed to maintain or re-establish containment system integrity when required, the filtered ventilation system of a double or secondary containment, and the monitoring system required to provide information on containment conditions).

\subsubsection{Containment Functional Design}

6.2.1.1 Design Bases - This section should provide the bases upon which the functional design of the containment system was established, including, for example, the following information:

(1) The postulated accident conditions and the extent of simultaneous occurrences that determine the containment design requirements should be discussed.

(2) The assumptions regarding the sources and amounts of energy and material that might be released into the containment structure, and the post-accident time-dependency associated with these releases should be presented and discussed.

(3) The assumed contribution of other engineered safety features in limiting the maximum value of the energy released in the containment structure in the event of an accident should be specified.

(4) Discuss subcompartment differential pressure considerations and capability including the theoretical mass and energy input that might result from design basis accidents, particularly for those vital subcompartments that can not be pressure tested. (The structural design of the vital subcompartments with respect to accommodating this mass and energy input should be discussed in Sections 3.8 .1 and 3.8.2.

(5) Discuss parameters affecting the assumed capability for postaccident pressure reduction.

(6) Discuss parameters affecting the assumed capability to reject energy to the outside environment.

$$
6.2-1
$$


6.2.1.2 System Design - This section should provide a description of the design features of the containment system, including, for example, a description of:

(1) the containment and its compartments and components,

(2) adequate backup information to demonstrate that the containment and its compartments and components can perform their intended functions,

(3) the design methods that will be used to assure integrity of the containment internal structures and subcompartments from pressures, temperatures, and dynamic effects (missiles, pipe whip, and jet forces) that could occur following a loss-of-coolant accident,

(4) materials compatibility considerations under normal reactor operating and accident conditions, and

(5) provisions for redundancy and independence of components (e.g., valves).

6.2.1.3 Design Evaluation - This section should provide an evaluation of the functional design of the containment system. The following information* and that listed in Tables $6-1,6-2,6-3$, and $6-4$ should be provided:

(1) Present a discussion of the extent to which assurance of containment leak-tightness at any time depends upon the operation of a system, such as a continuous leakage monitoring system, a continuous leakage surveillance system, a continuous leakage surveillance system for containment penetrations and seals or a pumpback compressor system or ventilation system which maintains a negative pressure between dual barriers of a containment system.

(2) Present an analysis of the capability of these system to perform their functions reliably and accurately during operating periods and under conditions of operating interruptions (e.g., the performance margin, if any, in a pumpback compressor system that might allow it to sustain an operational failure and still function adequately).

(3) A description of the required containment pressure and leak rate analysis to establish the performance capability for a spectrum of reactor coolant break sizes up to and including rupture of the largest pipe in the reactor coolant pressure boundary should be presented. Where confirmatory tests have been performed to demonstrate the applicability of the analysis, the types of tests and the results should be discussed. Final analysis should be provided in the FSAR.

*Where information is included in Chapter 15.0 , cross reference is acceptable. $6.2-2$ 
(4) Present a description of the analytical mode1, including assumptions and the methods used to verify the correctness of the mathematical formulation, and the applicability of the model to the plant design.

(5) For pressure suppression containment concepts, the effects of steam bypass on the capability of the containment to perform its design function for a complete spectrum of reactor coolant break sizes should be discussed. Criteria for acceptability should be provided. Substantiation through analyses or tests should be provided (FSAR).

(6) The long term performance of the containment upon completion of blowdown and initial depressurization of the containment should be evaluated and the capability of the containment system to maintain low, long term pressure levels should be described. A description of the analytical mode1, the assumptions used, the validity of the model and the results should be provided.

(7) For the design basis loss-of-coolant accident, provide an accident chronology to indicate the time of occurrence in seconds (assuming time equals zero is when the design break occurs) of events such as, initiation of the ECCS injection phase, the time containment reaches peak pressure, the end of blowdown, the end of the injection phase, initiation of the ECCS reflooding phase (assuming no offsite power), initiation of the quench containment spray, the time at which the refueling water storage tank (or condensate storage tank) empties, and where applicable, when the containment pressure becomes subatmospheric.

(8) An energy balance table that lists how the energy is stored prior to the design basis loss-of-coolant accident, how much energy is generated and absorbed from time equals zero to the time of the peak pressure, and how the energy is distributed at the time of the peak pressure should be provided. Continue the mass and energy inventory into the recirculation phase and show how the energy is distributed (and how much energy rejected) one day after initiation of the recirculation phase including consideration of energy input due to decay heat, pump work, etc. Provide justification for heat transfer coefficients used.

(9) Assuming a design basis loss-of-coolant accident and minimum engineered safety feature performance, and considering a time scale commencing just prior to and continuing for at least one day into the recirculation phase, provide curves showing the behavior as a function of time of: the sump temperature, the heat generation rate from core decay heat and other sources (e.g., hot meta1 and structures), the heat removal rate from the containment spray system heat exchanger, from the fan recirculation heat exchanger, and from the residual heat removal heat exchanger, and the containment total pressure, vapor pressure and temperature. 
(10) Where applicable, with respect to the containment subcompartments enclosing such components as the reactor vessel (reactor cavity), the pressurizrr, and steam generators, provide the assumptions and results of analyses to show the capability of these compartments to withstand energy releases (expressed in terms of equivalent pipe rupture area - or other applicable unit) that might result from design basis accidents. The structural design aspects of the subcompartments should be discussed in Sections 3.8.1 and 3.8.2.

6.2.1.4 Testing and Inspection - This section should provide information about the program of testing and inspection applicable to: (1) preoperational testing of the containment system, and (2) in-service surveillance to assure continued integrity.

Emphasis should be given to those tests and inspections considered essential to a determination that performance objectives have been achieved and a performance capability maintained throughout the plant lifetime above some pre-established 11mits. Such tests could include for example: integrated leak rate tests of the containment structure, local leak detection tests of penetrations and isolation valves, inspection and testing to identify potential bypass paths, and operability tests of isolation valves. The information provided in this section should include, for example:

(1) the planned tests and their purpose;

(2) the considerations that led to periodic testing and the selected test frequency;

(3) the test methods to be used, including a sensitivity analysis;

(4) the requirements for acceptability of observed performance and the bases for them;

(5) the action to be taken in the event acceptability requirements are not met;

(6) information to show the extent of testing to be performed for reactor containment leakage. In this respect proposed Appendix $J$ to 10 CFR Part 50, "Reactor Containment Leakage Testing of Water Cooled Power Reactors", provides guidance.

(7) a discussion of the design provisions to assure that the containment structure will have the capability of being pressurized to the calculated peak accident pressure at any time during plant life in order to perform integrated leakage rate tests, as may be required. 
Particular emphasis should be given to those surveillance type tests that are of such importance to safety that they may become a part of the technical specifications of an operating 1icense. The bases for such surveillance requirements should be described.

\subsubsection{Instrumentation Requirements - This section should discuss} the instrumentation to be employed for monitoring the containment system and actuating those components and subsystems of the containment system that initiate the safety function. Design details and logic of the instrumentation should be discussed in Chapter 7.0 of the SAR.

6.2.1.6 Materials - List by commercial name, quantity (estimate where necessary) and chemical composition the materials used in or on the safety feature system. Show that the radiolytic or pyrolytic decomposition products, if any, of each material will not interfere with the safe operation of this or any other engineered safety feature.

\subsubsection{Containment Heat Removal Systems}

The components and the systems for heat removal following blowdown from a loss-of-coolant accident under post-accident conditions should be considered in this section. Since the components and systems vary depending on reactor type and plant, the information to be included in this section as outlined below is only illustrative of the type of information that should be provided for each component or system.

6.2.2.1 Design Bases - Provide the bases upon which the designs of the heat removal systems were established including, for example:

(1) the sources and amounts of energy that must be considered in sizing each heat removal system,

(2) the extent to which the operation of each heat removal system is relied upon to attenuate the post-accident conditions imposed upon the containment system, and

(3) the design parameters for the portions of each heat removal system located outside the containment.

6.2.2.2 System Design - The design features of the heat removal systems (e.g., containment spray system or fan cooler systems) should be provided in this section including, for example:

(1) a description of each component and system; 
(2) the major design parameters for each component and system (e.g., design head of pumps, flow rate, heat removal capacity, etc.) with adequate backup information to demonstrate that the system designed to these specifications can perform its intended function;

(3) material compatibility, particularly for those systems in contact with borated water or water with other chemical additives;

(4) the provisions for redundancy and independence of the components and systems;

(5) the design of the recirculation piping (preliminary piping and instrumentation diagrams in PSAR and final in FSAR) leading from the containment sump to the recirculation pumps (e.g., the residual or decay heat removal pumps) and the means provided to detect and further reduce the potential for containment and component leakage as a possible result of component deterioration during the post-accident recirculation period (e.g., use of guard pipes surrounding the recirculation piping and the protective chambers enclosing the isolation valves);

(6) the net positive suction head requirements for the recirculation pumps with supportive design information to show the margin between the required and available net positive suction head (see AEC Safety Guide No. 1). Supportive testing if required should be provided (FSAR);

(7) consideration given to the potential for surface fouling of containment spray system heat exchangers in the design, and the manner in which such fouling could affect the performance requirements;

(8) with respect to the containment spray and/or residua1 heat removal system heat exchangers, the basis for the selection of the tube side and shell side inlet temperatures and the effect on performance of the heat removal capability of the containment spray system;

(9) with respect to the intake system for the spray and residial heat removal pumps describe the preliminary design of the intake screens and sump dimensions. Provide final design (FSAR);

(10) describe the flow distribution within the intake system; and

(11) describe the flow path which potentially harmful debris would have to follow in order to reach the intake system.

6.2.2.3 Design Evaluation - This section should provide evaluations of each heat removal system. A description should be provided of the analytical methods and models used to assess the performance capability of each heat removal system with sufficient information to show the validity

$$
6.2-6
$$


of the models. Provide results of tests performed (FSAR). Summarize the results of failure analyses for all components of each heat removal system to show that the failure of any single component will not prevent fulfilling the design function. Provide curves showing the calculated performance of the following variables as functions of time following occurrence of a design basis loss-of-coolant accident, assuming minimum engineered safety feature performance (cover a time range beginning just prior to, and continuing for at least one day into, the recirculation phase): sump temperature, heat generation rate from core decay heat and other sources (e.g., hot metal and structures), heat removal rate from the containment spray system heat exchanger, from the fan recirculation system heat exchanger, and from the residual heat removal heat exchanger, and the containment total pressure, vapor pressure and temperature.

6.2.2.4 Testing and Inspections - This section should describe the program for preoperational performance tests and in-place testing after installation of each heat removal system. The description should make clear the scope and limitation of the tests. This section should also describe the inspection program for the systems, particularly for those components which will be unable to be tested after installation or periodically during operation. In addition, periodic surveillance inspections and performance tests proposed for each containment heat removal system over the life of the plant should be described. Results of tests performed and a detailed, updated program should be provided (FSAR).

\subsubsection{Instrumentation Requirements - This section should describe} the instrumentation to be employed for the monitoring and actuation of each containment heat removal system. Details of the design and logic of the instrumentation should be discussed in Chapter 7.0 of the SAR.

6.2.2.6 Materials - List by commercial name, quantity (estimate where necessary) and chemical composition the materials used in or on the safety feature system. Show that the radiolytic and pyrolytic decomposition products, if any, of each material will not interfere with the safe operation of this or any other engineered safety feature.

\subsubsection{Containment Air Purification and Cleanup Systems}

The safety related systems for ventilation of the containment systems (including secondary or confinement buildings) and for other air purification or cleanup systems (e.g., containment spray system and internal and external filters) servicing the containment systems should be considered as part of the containment system and discussed in this section of the SAR. (Reference should be made to Chapter 15.0, "Safety Analyses", where these containment functions become essential in describing the consequences of accidents.) The type of information outlined below should be provided for each of the systems. 
6.2.3.1 Design Bases - This section should provide the design bases for each safety related ventilation and air purification system, including, for example:

(1) the conditions which establish the need for ventilation or purging of the containment structure,

(2) the bases employed for sizing the ventilation, purging, and air cleanup systems and components, and

(3) the bases for the fission product removal capability and component sizing of the containment spray system and/or filtration system (where credit is taken for limiting the radiological offsite consequences resulting from the accidents discussed in Chapter 15.0 of the SAR).

6.2.3.2 System Design - This section should discuss the design features and fission product removal capability of each system, including, for example: (1) preliminary piping and instrumentation diagrams of the ventilation and other cleanup systems. Final diagrams should be provided (FSAR); (2) performance objectives (e.g., ventilation flow rates, temperature, humidity, the limits of radioactivity levels to be maintained within the containment structure, and at the site boundary and exclusion zone); and (3) provisions to exhaust, monitor, and filter the ventilation and purging air and the provisions for safe disposal of the effluent to the outside atmosphere (e.g., systems discharging the effluent through stacks).

The following specific information should be included:

(1) The description of the preliminary design of the external charcoal filter systems should include flow parameters; charcoal type, weight, distribution, test specifications, and acceptance criteria; HEPA filter type and specifications; any additional components; humidity controls; system test and surveillance requirements; and expected efficiencies for iodine removal for each of the expected forms of iodine. The same information as above should be included in describing the internal charcoal filter systems, and in addition pressure surge and humidity control data should be included. The final design with details should be provided (FSAR).

(2) Where building recirculation systems are provided the system description should include a discussion of the mode(s) of operation and mixing behavior. Layout drawings of system equipment and air flow guidance ducts should be provided (FSAR). Provide the expected initial and final exhaust flow rates and the rate of change between initial and final flow rates; the recirculation rate; and the mixing volume. 
If charcoal filters are included in the system, information similar to that noted in the preceding paragraph should be provided.

(3) For redundant emergency ventilation systems containing charcoal filters, describe and evaluate the design provisions for maintaining a flow of cooling air in the isolated filter train or for alternate cooling to prevent substantial fission product desorption or ignition of the charcoal. In the evaluation, assume the filter contains the maximum decay heat load, using as a basis the source terms indicated in Safety Guide No. 4 for Pressurized Water Reactors and Safety Guide No. 3 for Boiling Water Reactors.

(4) The important system parameters of each containment spray system that should be described and justified include flow rate through the spray nozzles, fall height (area averaged), effective containment volume and fractional volume spray coverage, the type(s) of nozzles and associated spray drop size spectrum, and also the type of spray additive along with its concentration in storage and during and following delivery. Also describe the measures which preclude spray nozzle clogging and which assure adequate delivery pressure at the spray nozzle. The system description should include a discussion of the operating modes, reliability, reproducibility, and testability of the spray system.

(5) With respect to materials compatibility, an inventory should be provided of all materials which may adversely affect, or be adversely affected by, the spray solution during storage or under post-accident conditions.

(6) List by type (epoxy, phenolic, zinc, etc.) and manufacturer's designation all known paints used in the containment. In addition list the dry density and surface area covered by each paint. List the total surface area and estimated volume covered by unknown paints. Explicitly state the curing procedures applied or to be applied for each paint. A quality assurance program for paint applications should be detailed in Chapter 17.

6.2.3.3 Design Evaluation - This section should provide evaluations of the ventilation and cleanup systems to demonstrate their capability to reduce accident doses and maintain offsite effluent concentrations during normal operation within established guidelines.

6.2.3.4 Tests and Inspections - This section should provide information concerning the program of testing and inspection applicable to preoperational testing and in-service surveillance to assure a continued state of readiness to perform for those ventilation and cleanup systems required to reduce the radiological consequences of an accident. Results of tests performed and a detailed, updated program should be provided (FSAR). 
6.2.3.5 Instrumentation Requirements - This section should describe the instrumentation to be employed for the monitoring and actuation of the ventilation and cleanup systems. Design details and logic of the instrumentation should be discussed in Chapter 7.0 of the SAR.

6.2.3.6 Materials - List by commercial name, quantity (estimate where necessary) and chemical composition the materials used in or on the safety feature system. Show that the radiolytic or pyrolytic decomposition products, if any, of each product will not interfere with the safe operation of this or any other engineered safety feature.

\subsubsection{Containment Isolation Systems}

The system intended to monitor the development of gross leakages in the containment or measurement of leakages within allowable limits in the containment system (leakage pumpback systems which monitor containment barrier leakages may be included under this category) should be considered as part of the containment system.

The following type of information concerning containment isolation systems should be included:

6.2.4.1 Design Bases - Discuss the bases established for the design of the isolation valving required for fluid lines, including, for example: mandatory;

(1) the governing conditions under which containment isolation becomes

(2) the criteria applied with respect to the number and location (inside or outside of containment) of independent isolation valves provided for each fluid system penetrating the containment and the basis therof, and the degree of conformance to AEC General Design Criteria 54, 55, 56 and 57 ;

(3) the design bases for isolation of the fluid instrument lines and the degree of conformance to AEC Safety Guide 11 or other criteria that provide an equivalent degree of protection.

6.2.4.2 System Design - Describe and evaluate the design features of the isolation valving system, including, for example:

(1) a preliminary piping and instrumentation diagram of the isolation valving system indicating the location with respect to the containment barrier of a11 isolation valves and fluid systems penetrating the containment wall, including instrument lines, or systems communicating directly with the outside atmosphere, (e.g., vacuum relief valves). Final diagrams should be provided (FSAR);

$$
\text { 6. 2-10 }
$$


(2) a summary table of the types of isolation valves provided, including: (a) open or closed status under normal operating conditions, shutdown or accident situations; (b) the primary and secondary modes of actuation provided for the isolation valves, (e.g., valve operators, manual remote or automatic); (c) the number of parameters sensed and their values which are required to effect closure of isolation valves; and (d) the closure time and sequence of timing for the principal isolation valves to secure containment isolation;

(3) the protection to be provided for isolation valves, actuators, and controls against damage from missiles;

(4) the provisions to assure operability of isolation valve systems under accident environment, (e.g., imposed pressures and temperatures of the steam-laden atmosphere in the event of an accident);

(5) the provisions to assure integrity of the isolation valve system and connecting lines under the dynamic forces resulting from inadvertent closure under operating conditions (e.g., inadvertent closure of steamline isolation valves under full steaming rate); and

(6) the preliminary design of isolation valves. Final design should be provided (FSAR).

6.2.4.3 Design Evaluation - Provide an evaluation of the containment isolation system to demonstrate its capability to perform its intended function.

6.2.4.4 Tests and Inspections - Provide information concerning the program of testing and inspection that is required to assure a continued state of readiness of the system to perform its safety function. Results of tests performed and a detailed, updated program should be provided (FSAR).

6.2.4.5 Materials - List by commercial name, quantity (estimate where necessary) and chemical composition the materials used in or on the safety feature system. Show that the radiolytic or pyrolytic decomposition products, if any, of each material will not interfere with the safe operation of this or any other engineered safety feature.

\subsubsection{Combustible Gas Control in Containment}

General Design Criterion 41 requires that systems to control hydrogen, oxygen, and other substances that may be released into the reactor containment be provided as necessary to control their concentrations following postulated accidents to assure that containment integrity is 
maintained. This subsection of the report should provide information on the design features to be provided for controlling combustible gas concentrations in containment following an accident.

6.2.5.1 Design Bases - Discuss the bases for the design of the system and components provided to control combustible gas mixtures in the containment following a design basis loss-of-coolant accident, including, for example:

(1) the design criteria as compared to guidance set forth in AEC Safety Guide No. 7, "Control of Combustible Gas Concentrations in Containment Following a Loss-of-Coolant Accident;"

(2) the design criteria applicable to the containment purge system as a backup system for the control of combustible gases in containment following an accident. Included should be an identification of potential additional combustible gas sources including, for example, sources from coatings and corrosion.

(3) the governing conditions under which containment combustible gas control measures become necessary.

6.2.5.2 System Design - Describe the design features of the combustible gas control system, including, for example:

(1) a preliminary piping and instrumentation diagram of the system delineating the extent of the system located inside or outside containment. Final diagrams should be provided (FSAR);

(2) the concept upon which the operation of the system is predicated;

(3) the design features of the systems for mixing, sampling, and monitoring the containment atmosphere to effect control of combustible gases following a loss-of-coolant accident; and

(4) the requirements for redundancy and independence and the interdependency between the system and other engineered safety features.

6.2.5.3 Design Evaluation - Provide evaluations to demonstrate the functional requirements of the system. Provide an analysis of hydrogen generation following a loss-of-coolant accident using the assumptions set forth in AEC Safety Guide No. 7, and an analysis of the predicted thyroid and whole body doses at the site boundary (exclusion area) and the low population zone boundary that would result from containment purging in the event of a design basis loss-of-coolant accident, using the assumptions set forth in Safety Guides No. 3 or 4 , as applicable to the plant site, and Safety Guide No. 7. 
6.2.5.4 Testing and Inspections - The program for preoperational performance tests and in place testing to be performed after installation should be described. The description should make clear the scope and limitation of the tests. Describe the inspection program for the system, particularly if the system or significant components are not testable after installation or periodically during operation. Results of tests performed and a detailed, updated program should be provided (FSAR).

6.2.5.5 Instrumentation Requirements - Discuss the instrumentation provisions for the methods of actuation (e.g., automatic, manual, different locations). The conditions requiring system actuation and the bases for the selection should be included. The design details and logic of the instrumentation should be discussed in Chapter 7 .

6.2.5.6 Materials - List by commercial name, quantity (estimate where necessary) and chemical composition the materials used in or on the safety feature system. Show that the radiolytic or pyrolytic decomposition products, if any, of each material will not interfere with the safe operation of this or any other engineered safety feature.

\subsection{Emergency Core Cooling System}

The emergency core cooling system (ECCS) is included in a plant to furnish cooling water to the core to compensate for loss of normal cooling capability resulting from postulated loss-of-coolant accidents.

The ECCS generally consists of subsystems for storing sources of water, delivering and distributing coolant to the core, transport of heat to a sink and the associated instrumentation.

The specific design requirements of an emergency core cooling system will depend upon the reactor design. Such matters as the time available following coolant loss, cooling capacity required, and the length of time during which cooling must be sustained vary. The functional requirements for the system and an explanation of why these were established should be a fundamental part of this section of the SAR.

When discussing the factors of dependability and effectiveness, specific attention should be directed to such things as system starting, adequate coolant delivery, availability of coolant, period of time the system must operate, the effects of external forces, the state of the art and proposed research and development to assure proper flow distribution to adequately cool the core, the testing program to assure dependable operation, and the reliance placed on the system for overall plant safety. 
The ability to initiate system operation and to deliver the required cooling capacity is fundamental. Considerations should include the design, operation, and testing that are associated with system dependability from the sensing of an accident, through the availability and response of emergency power, to the assurance of adequate cooling of the core.

The potential for damage to the system from external forces, such as missiles and forces causing movement or vibration should be evaluated; e.g., since parts of the ECCS are connected to the reactor coolant system, assurance should be provided that an accidental rupture of the reactor coolant system will not cause movement that would negate or reduce the effectiveness of the emergency core cooling system to an unacceptable level.

Evaluations to show that there will be adequate and proper flow distribution through the core are important. Such matters as the number of channels, the effect of channel length, the phase change of the cooling water, potential metal-water reactions, and the lag time associated with system operation should be considered.

On June 19, 1971, the AEC issued an Interim Policy Statement containing interim acceptance criteria for the performance of emergency core cooling systems in 11ght-water nuclear power plants. The Statement, and an Amendment issued December 18, 1971, also included a description of acceptable assumptions and analytical procedures that may be used in evaluating the performance of emergency core cooling systems for pressurized water reactors and boiling water reactors (evaluation models). The performance evaluations included in the SAR should be conducted in accordance with the latest AEC policy statement and amendments thereto that are in effect when the SAR is submitted. The use of alternative reduction models is permitted if the degree of safety provided is equivalent and provided that their use is justified in detail.

Since the system does not operate in its entirety except following an accident, a measure of its dependability must be assured through testing.

Information concerning the proposed initial tests and subsequent periodic tests and inspections should be included.

The following subsections identify information that should be included in this section.

\subsubsection{Design Bases}

The design of the ECCS is based on the assumption of a pipe break in the reactor coolant system and the manner in which this might affect the core, and the environment in which the system w111 operate. The ability of a system to satisfactorily accommodate a break of a certain size does not

$$
6 \cdot 3-2
$$


necessarily mean it can accommodate all breaks. Therefore, the bases for setting the functional requirements of the ECCS should be identified and explained. The design bases should include, for example:

6.3.1.1 Range of Coolant Ruptures and Leaks - Discuss the range of reactor coolant system ruptures and coolant leaks (from the smallest up to and including the double-ended rupture of the largest pipe in the reactor coolant system) that the ECCS (and subsystems) is designed to accommodate and the analyses supporting the selection.

6.3.1.2 Fission Product Decay Heat - The fission product decay heat that the ECCS is designed to remove and the analyses supporting this selection should be presented.

6.3.1.3 Reactivity Required for Cold Shutdown - Indicate the reactivity required for cold shutdown and the analyses supporting this.

6.3.1.4 Capability to Meet Functional Requirements - Discuss the system capability to meet functional performance and reliability requirements over both the short and long term duration of the accident including specific features (e.g., a switch over to different coolant delivery paths) provided to meet such requirements.

\section{$\underline{6.3 .2}$ System Design}

This section should describe how the ECCS design meets the functional requirements established from the safety analyses. The information on an emergency core cooling system should include the following specific items.

6.3.2.1 Schematic Piping and Instrumentation Diagrams - Provide preliminary piping and instrumentation diagrams for the system showing the location of all components, piping, storage facilities, points where connecting systems and subsystems tie together and into the reactor system, and instrumentation and controls associated with subsystem and component actuation. Final diagrams should be provided (FSAR).

6.3.2.2 Equipment and Component Descriptions - Equipment and components to be installed to satisfy the functional requirements should be described. Identify the significant design parameters for each component within the system. For the range of pipe break sizes considered in the design of the ECCS, specify the components required and demonstrate that adequate coverage of the break spectrum is achieved.

6.3.2.3 Applicable Codes and Classifications - Identify the applicable industry codes and classifications for the system design. 
6.3.2.4 Materials Specifications and Compatibility - Identify the material specifications for ECCS and discuss materials compatibility and chemical effects of all sorts.

6.3.2.5 Design Pressures and Temperatures - State the design pressure and temperature of components for various portions of the system and explain the bases for their selection.

6.3.2.6 Coolant Quantity - State the quantity of coolant available (e.g., in each accumulator, refueling water storage tank, condensate storage tank, torus).

6.3.2.7 Pump Characteristics - Provide pump characteristic curves (FSAR) and pump power requirements.

6.3.2.8 Heat Exchanger Characteristics - Describe the heat exchanger characteristics including design flow rates, inlet and outlet temperatures for the cooling fluid and the fluid being cooled, the overall heat transfer coefficient and the heat transfer area.

6.3.2.9 ECCS Flow Diagrams - Provide flow diagrams for the ECCS, showing flow rates and pressures for loss-of-coolant accident and test conditions.

6.3.2.10 Relief Valves and Vents - State the relief valve capacity and settings or venting provisions included in the system.

6.3.2.11 System Reliability - Discuss the reliability considerations incorporated in the design to assure the system will start when needed and will deliver the required quantity of coolant (e.g., redundancy and separation of components, transmission lines, and power sources). A distinction should be made between true redundancy incorporated in a system and multiple components (e.g., a system that is designed to perform its function with only one of two pumps operating has increased reliability by redundancy; whereas, a system that has two pumps both of which must operate to perform its function does not have redundancy).

6.3.2.12 Protection Provisions - Describe the provisions to protect the system (including connections to the reactor coolant system or other connecting systems) against damage that might result from movement (between components within the system and connecting systems), from missiles, from thermal stresses, or from other causes (LOCA, seismic).

6.3.2.13 Provisions for Performance Testing - Describe the provisions to facilitate performance testing of components (e.g., bypasses around pumps, sampling lines, etc.).

$$
6.3-4
$$


6.3.2.14 Net Positive Suction Head - Specify the available and required net positive suction head for the ECCS pumps and justify any exceptions to the regulatory position stated in AEC Safety Guide No. 1.

\subsubsection{Control for Motor-Operated Isolation Valves (PWR) - For PWRs,} describe the provisions with respect to the control circuits for the motor-operated isolation valves in the lines connecting the ECCS accumulators (or core flooding tanks) to the reactor coolant system including consideration of inadvertent closure prior to or during an accident. This description should include discussions of the controls for these valves (e.g., intent of IEEE Std 279-1971), conditions for automatic valve opening (e.g., preselected reactor coolant pressure or ECCS signal) valve position indications, and alarms.

\subsubsection{Motor-Operated Valves and Controls (General) - Describe the} provisions with respect to the motor-operated isolation valves, the reactor coolant system and the relatively low pressure residual heat removal system. This description should include discussions of the valving (e.g., number of valves per line), the controls for the valves (e.g., intent to meet IEEE Std 279-1971), conditions for automatic valve closure (e.g., reactor coolant pressure exceeds postulated pressure related to design pressure of residual heat removal system), and valve interlocks, including diversity provisions, to provide assurance against improper opening when reactor coolant pressure is too high.

6.3.2.17 Manual Actions - Identify all manual actions required to be taken by an operator in order for the ECCS to operate properly. Discuss the information available to the operator, the time delay during which his failure to act properly will have no unsafe consequences, and the consequences if the action is not performed at all.

6.3.2.18 Process Instrumentation - Identify all process instrumentation available to the operator in the control room to assist in assessing post LOCA conditions.

6.3.2.19 Materials - List by commercial name, quantity (estimate where necessary) and chemical composition the materials used in or on the safety feature system. Show that the radiolytic or pyrolytic decomposition products, if any, of each material will not interfere with the safe operation of this or any other engineered safety feature.

\subsubsection{Performance Evaluation}

The functional requirements established for the emergency core cooling system generally are based on safety analyses and tests which consider the predicted effects of a spectrum of postulated accidents. Such analyses should be included in Chapter 15.0, "Accident Analyses". However, having

$$
6.3-5
$$


established certain functional requirements as the performance objectives of an ECCS design, this section of the SAR should include those system evaluations from which it has been concluded that functional requirements have been met with an adequate margin for contingencies. Such evaluations are expected also to provide the bases for any operational restrictions such as minimum functional capacity or testing requirements that might be appropriate for inclusion in the Technical Specifications of the license.

Analyses should be performed to demonstrate that the performance capability of the ECCS will meet the acceptance criteria of the Commission's Interim Policy Statement, issued on June 19, 1971, as amended, using a suitable evaluation model. Describe the assumptions used and the analytical model and discuss the bases for its validity. Provide the results of these analyses. The specific information required is as follows.

\section{For PWRs}

6.3.3.1 Evaluation Model - Discuss the evaluation model including reference to an evaluation model acceptable to the Commission as described in Appendix A, Parts 1, 3, 4 or 5 of the Interim Policy Statement for the appropriate nuclear steam supply system or an appropriate alternative model. Any deviations in the evaluation model used in the analyses from that described in the applicable Part of Appendix A of the Interim Policy Statement should be discussed in detail.

6.3.3.2 ECCS Performance - For the break size range, location and type mentioned in the applicable part of Appendix A of the Interim Policy Statement, provide the following information as a function of time:

(1) the system pressure;

(2) the core flow rate, pressure drop, and inlet and exit quality;

(3) the flow rate out of the pipe break;

(4) emergency core coolant discharge flow rate into the reactor coolant system;

(5) the core reflood rate;

(6) the core and downcomer liquid level during reflood; and

(7) fluid temperature, heat transfer coefficient and cladding temperature at the hot spot.

6.3.3.3 Alternate Analysis Methods - In evaluating breaks smaller than those analyzed using an evaluation model described in the Interim Policy Statement, the method of analysis and the results should be presented as a function of time equivalent to 6.3 .3 .2 above.

6.3.3.4 Fuel Rod Perforations - The presentation of the evaluation results should include curves showing peak clad temperatures, metal water reactions, and percent fuel rod perforations versus pipe break size analyzed. 


\section{For BWRs}

6.3.3.5 Evaluation Mode1 - Discuss the evaluation mode1 and whether the mode1 described in Appendix A, Part 2 of the Interim Policy Statement is used. Any deviations in the evaluation model used in the analyses from that described in Appendix A, Part 2 of the policy statement should be discussed in detail.

6.3.3.6 Fue1 Clad Effects - Provide curves of peak clad temperature, percent clad metal-water reaction, and fuel rod perforations as a function of pipe break size for the various combinations of ECC subsystems evaluated by using the single failure criterion indicated in Table 2-1 of the topical report: "Loss-of-Coolant Accident and Emergency Core Cooling Models for General Electric Boiling Water Reactors", NEDO-10329. A discussion should be included showing the justification for the ECC subsystem combinations used in the evaluation.

6.3.3.7 ECCS Performance - For several breaks that typify small, intermediate and large breaks, provide curves of

(1) peak fuel clad temperature for various rod groups,

(2) core flow,

(3) fuel channel inlet and outlet quality,

(4) heat transfer coefficients,

(5) reactor vessel pressure and water level, and

(6) minimum critical heat flux ratio (MCHFR) as functions of time.

Indicate the time that effective core cooling is initiated, the time the fuel channel becomes wetted (both calculated and based upon item 4 of Appendix A, Part 2), and the time that the temperature transient is terminated.

6.3.3.8 Peaking Factors - For the analyses performed in 6.3.3.6 and 6.3.3.7 above, discuss the range of peaking factors studied and the basis for selecting the combination that resulted in the most severe thermal transient.

6.3.3.9 Fuel Rod Perforations - Curves showing percent fuel rod perforations versus pipe break size analyzed, should be presented.

6.3.3.10 Conformance with Interim Acceptance Criteria - The results pertaining to the range of pipe break sizes analyzed should be summarized to permit evaluation of the extent of conformance with the Commission's Interim Acceptance Criterla delineated in the Interim Policy Statement as amended. The system performance and core mechanical responses that may be described in other parts of the SAR should be referenced to demonstrate conformance with the Interim Acceptance Criteria. 
For all reactors, in addition to the above, provide the following information:

6.3.3.11 Effects of ECCS Operation on The Core - Describe the results of analyses and tests performed to determine the nuclear, mechanical and chemical effects of system operation on the core, reactor coolant system, and ECCS.

6.3.3.12 Use of Dual Function Components - Discuss the extent to which components or portions of the ECCS are required for operation of other systems and the extent to which components or portions of other systems are required for operation of the ECCS. An analysis of how these dependent systems would function should include system priority (which system takes preference); conditions when various components or portions of one system function as part of another system, [Example: when the water level in the reactor is below a limiting value, the recirculation pumps (i.e., residual or decay heat removal pumps), or feed pumps will supply water to the ECCS and not the containment spray system]. Delineate any limitations on operation or maintenance included to assure minimum capability (e.g., storage facility common to both core cooling and containment spray systems shall have provisions whereby the quantity available for core cooling will not be less than some specified quantity).

6.3.3.13 Lag Times - Discuss the range of acceptable lag times associated with system operation; that is, the period between the time an accident has occurred requiring the operation of the system and the time emergency core cooling flow is discharged into the core. Analysis supporting the selection of this range of lag times should include valve opening time, pump starting time, and other pertinent parameters.

6.3.3.14 Thermal Shock Considerations - Discuss thermal shock considerations, both in terms of effect on functioning of the ECCS and the effect on connecting systems.

6.3.3.15 Limits on System Parameters - State the bounds within which principal system parameters must be maintained in the interests of constant standby readiness; e.g., such things as, the minimum poison concentrations in the coolant, minimum coolant reserve in storage volumes, and maximum number of inoperable components.

\subsubsection{Tests and Inspections}

The emergency core cooling system is a standby system, not normally operating. Consequently, a measure of the readiness of the system to operate in the event of an accident must be achieved via tests and inspections. The periodic tests and inspections program should be identified and reasons explained as to why the program of testing planned is believed to be appropriate. The information should include such things as:

$$
\text { 6. } 3-8
$$


(1) Tests planned and why.

(2) Considerations that led to periodic testing and the selected test frequency.

(3) Test methods to be used.

(4) Requirements set for acceptability of observed performance and the bases for them.

(5) A description of the program for inservice inspection, including items to be inspected, accessibility requirements, and the types and frequency of inspection.

Evaluations made elsewhere in the SAR that explain the bases for tests planned need not be repeated but on1y cross-referenced.

Particular emphasis should be given to those surveillance type tests that are of such importance to safety that they may become a part of the Technical Specifications of an operating license. The bases for such surveillance requirements should be developed as a part of the SAR. Results of tests performed and a detailed updated program should be provided (FSAR).

\subsubsection{Instrumentation Requirements}

This section should discuss the instrumentation provisions for various methods of actuation (e.g., automatic, manual, different locations). The conditions requiring system actuation together with the bases for the selection (e.g., during periods when the system is to be available, whenever the reactor coolant system pressure is less than some specified pressure, the core spray system shall be actuated automatically using equipment designed to IEEE Std 279 requirements) should be included in the discussion. Design details and logic of the instrumentation should be discussed in Chapter 7.0 of the SAR.

\subsection{Habitability Systems}

To permit evaluation of the capability of the control room to meet AEC Genera1 Design Criterion 19, a detailed description of the systems incorporated in the design of the control room for habitability during design basis accidents is necessary. The habitability systems for the contro1 room should include shielding, air purification systems, control of climatic conditions within the control room, storage capacity of food and water, and kitchen and sanitary facilities.

$$
\text { 6. 4-1 }
$$


The SAR should include information to show that the habitability systems have been evaluated to provide assurance that the control room will fulfill its intended objectives, and that such objectives are consistent with protection of Genera1 Design Criterion 19.

Information provided should permit a determination of the adequacy of the evaluations; that is, assurance that the evaluations included are correct and complete. Evaluations in other sections having a bearing on the adequacy of the habitability systems should be referenced.

\subsubsection{Habitability Systems Functional Design}

6.4.1.1 Design Bases - This section should provide the bases upon which the functional design of the habitability system (or systems) were established, including, for example, the following information:

(1) The postulated accident conditions and the extent of simu1taneous occurrences that determine the habitability design requirements should be discussed.

(2) The assumptions regarding the sources and amounts of radioactivity that surround and leak into the control room.

(3) The assumed contribution of other engineered safety features (charcoal adsorbers, alternate air intake) in limiting the maximum value of radioactivity in the control room in the event of an accident should be specified.

(4) The requirements, following postulated accidents, for limitations of control room pressure, temperature, radioactivity concentrations, doses, and concentrations of noxious substances.

(5) Fire protection criteria for the control room and other safety related control stations.

6.4.1.2 System Design - This section should discuss the design features and fission product removal and protection capability of the systems, including, for example:

(1) preliminary piping and instrumentation diagrams of the ventilation and other cleanup systems. Final diagrams should be provided (FSAR);

(2) performance objectives (e.g., ventilation flow rates, temperature, humidity, the limits of radioactivity levels) to be maintained and

(3) provisions to intake, exhaust, monitor, and filter. 
The description of external charcoal filter systems should include flow parameters; charcoal type, weight, distribution, test specifications, and acceptance critexia; HEPA filter type and specifications; any additional components; humidity controls; system test and surveillance requirements; and expected efficiencies for iodine removal for each of the expected forms of iodine. Except for humidity control, the same information as above should be included in describing any internal charcoal filter systems.

6.4.1.3 Design Evaluation - Provide a comprehensive discussion of the evaluations of operational systems associated with the control room habitability which serve to indicate or maintain the state of readiness.

Provide an analysis of the capability of these operational systems to perform their functions reliably and accurately during operating periods and under conditions of operating interruptions.

6.4.1.4 Testing and Inspection - This section should provide information about the program of testing and inspection applicable to: (1) preoperational testing, and (2) inservice surveillance to assure continued integrity.

Emphasis should be given to those tests and inspections considered essential to a determination that performance objectives have been achieved and a performance capability maintained throughout the plant lifetime above some pre-established limits. The information provided in this section should include, for example:

(1) the planned tests and their purposes;

(2) the considerations that led to the selected test frequency;

(3) the test methods to be used, including a sensitivity analysis;

(4) the requirements for acceptability of observed performance and the bases for them;

(5) the action to be taken in the event acceptability requirements are not met.

Results of tests performed and a detailed, updated program should be provided (FSAR).

6.4.1.5 Instrumentation Requirement - This section should describe the instrumentation to be employed for the monitoring and actuation of the habitability systems. Design details and logic of the instrumentation should be discussed in Chapter 7.0 of the SAR. 


\section{X Other Engineered Safety Features}

The engineered safety features included in reactor plant designs vary from plant to plant. Accordingly, for each engineered safety feature, component or system provided in a plant and not already referred to in this chapter of the Standard Format, the SAR should include separate sections (numbered 6.5 through 6.X) patterned after the above and providing information on:

6.X.1 Design Bases

6.X.2 System Design

6.X.3 Design Evaluation

6.X.4 Tests and Inspections

6.X.5 Instrumentation Requirements 


\section{INFORMATION TO BE PROVIDED FOR ALL TYPES OF CONTAINMENT}

I. General Information
A. Design Pressure, psig
B. Design Temperature, $F$
C. Free Volume, $\mathrm{ft}^{3}$
D. Design and Maximum Allowable Leak Rates, \%/day

II. Initial Conditions

A. Reactor Coolant System (at design overpower of $102 \%$ and at norma1 1iquid leve1s)

1. Reactor Power Leve1, MWt

2. Average Coolant Temperature, F

3. Mass of Reactor Coolant System Liquid, 1bm

4. Mass of Reactor Coolant System Steam, $1 \mathrm{bm}$

5. Liquid Plus Steam Energy,* BTU

B. Containment

1. Pressure, psig

2. Inside Temperature, $F$

3. Outside Temperature, F

4. Relative Humidity, \%

5. Service Water Temperature, F

6 Refueling Water Temperature (if applicable), F

7. Quench Tank Water Temperature (if applicable), F

C. Stored Water (as applicable)

1. Refueling Water Storage Tank, $\mathrm{ft}^{3}$

2. Quench Spray Tank, $\mathrm{ft}^{3}$

3. A11 Accumulators (safety injection tanks), $\mathrm{ft}^{3}$

4. Condensate Storage Tanks, $\mathrm{ft}^{3}$

* Al1 energies are relative to $32 \mathrm{~F}$. 
III. The Design Basis Accident

Based on the minimum values used for containment analysis listed in Section VII of this table on "Engineered Safety Features" and assuming no offsite power available, the following information should be provided:

Peak Pressure, psig

Peak Temperature, F

Time of Peak Pressure, seconds

Energy Released to Containment at Time of Peak Pressure, $10^{6}$ BTU

Energy Absorbed by Passive Heat Sinks at Time of Peak Pressure, $10^{6}$ BTU

Assumed Pipe Break Area, $\mathrm{ft}^{2}$ $\underline{A} \underline{B} \underline{\mathrm{D}}$ etc.

The above table should be supplemented by a plot of containment pressure versus time for various pipe break areas, up to at least $10^{6}$ seconds. A particular break size should be identified as that producing the design basis accident. A plot of the temperature of the steam-air mix and the temperature of the sump water (or torus water) versus time for the design basis accident, to at least $10^{6}$ seconds, should be provided.

\section{Mass Addition Table}

The masses and enthalpies of the water and/or steam that enters the containment through the broken pipe should be provided with smaller time increments in the blowdown phase than the post blowdown phase. A representative table is given below: 
Time Period

Following Accident

Initiation, seconds
Released to Containment

Enthalpy Mass Rate

BTU/1bm

$1 \mathrm{bm} / \mathrm{hr}$
- Blowdown Over -

$1 \times 10^{3}-2 \times 10^{3}$

$2 \times 10^{3}-4 \times 10^{3}$

V. Blowdown Table

\begin{tabular}{|c|c|c|c|}
\hline Time, seconds & $\begin{array}{l}\text { Blowdown Rate } \\
1 \mathrm{bm} / \mathrm{sec}\end{array}$ & $\begin{array}{l}\text { Enthalpy, } \\
\text { BTU/1bm }\end{array}$ & $\begin{array}{l}\text { Reactor Vessel } \\
\text { Pressure, psig }\end{array}$ \\
\hline \multicolumn{4}{|l|}{0} \\
\hline \multicolumn{4}{|l|}{$t 1$} \\
\hline \multicolumn{4}{|l|}{$t 2$} \\
\hline \multicolumn{4}{|l|}{ t3 } \\
\hline \\
\hline Blowdown over & & & \\
\hline
\end{tabular}

VI. Passive Heat Sinks

Include the following information on the energy absorbing materials within the contalnment. 


\section{A. Material Properties}

\begin{tabular}{|c|c|c|c|}
\hline Material & $\begin{array}{c}\text { Thermal } \\
\text { Conductivity } \\
\text { BTU/hr-F-ft }\end{array}$ & $\begin{array}{c}\text { Heat } \\
\text { Capacity } \\
\text { BTU/1bm-F }\end{array}$ & $\begin{array}{l}\text { Density } \\
\mathrm{lbm} / \mathrm{ft}^{3}\end{array}$ \\
\hline $\begin{array}{l}\text { Paint } \\
\text { Concrete } \\
\text { Stainless Steel } \\
\text { Carbon Steel } \\
\text { Others }\end{array}$ & & & \\
\hline
\end{tabular}

B. Surfaces

1. S1ab 1
a. Area $\mathrm{ft}^{2}$
b. First Material
(e.g. paint, concrete) , Thickness, ft
c. Second Material , Thickness, ft
d. Last Material , Thickness, ft

2. S1ab 2
a. Area $\mathrm{ft}^{2}$
b. First Material , Thickness, ft

C. Heat Transfer Coefficients

Provide a curve of the condensing heat transfer coefficient for the range of pipe and break sizes in III above.

VII. Engineered Safety Systems Information

(To be provide for two conditions: (1) full capacity operation and (2) the capacities used in the containment analysis.

$$
6 . T-4
$$


Ful1

Capacity
Value Used for Containment Analysis

A. Passive Safety Injection System

1. Number of Accumulators (Safety Injection Tanks)

2. Pressure Set Point, psig

B. Active Safety Injection Systems

1. High Pressure Safety Injection

a. Number of Lines

b. Number of Pumps

c. Flow Rate, gpm

2. Low Pressure Safety Injection

a. Number of Lines

b. Number of Pumps

c. Flow Rate, gpm

C. Containment Spray System

1. Recirculation Spray
a. Number of Lines
b. Number of Pumps
c. Number of Headers
d. Flow Rate, gpm

2. Quench Spray
a. Number of Lines
b. Number of Pumps
c. Number of Headers
d. Flow Rate, gpm

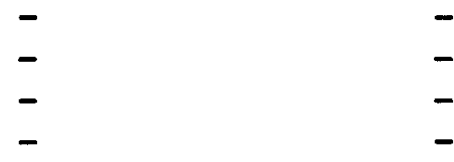

$\begin{array}{lll}- & - \\ - & -\end{array}$


D. Containment Cooling Fan Sys tems

1. Number of Units

2. Air Side F1ow Rate, cfm

3. Heat Removal at Design Temperature, $10^{6} \mathrm{BTU} / \mathrm{hr}$

4. Overall Heat Transfer Rate (BTU/hr-ft ${ }^{2}-{ }^{\circ} \mathrm{F}$ )

E. Heat Exchangers

1. Recirculation Spray System
a. Type
b. Number
c. Heat Transfer Area, $\mathrm{ft}^{2}$
d. Overall Heat Transfer Coefficient, BTU/hr-ft $\mathrm{t}^{2}-\mathrm{F}$
e. Flow Rates:
(1) Recirculation Side, gpm
(2) Exterior Side, gpm

f. Source of Cooling Water

g. Flow Begins, seconds

2. Quench Spray System
a. Type
b. Number
c. Heat Transfer Area, $\mathrm{ft}^{2}$
d. Overal1 Heat Transfer Coefficient, BTU/hr-ft ${ }^{2}-\mathrm{F}$
e. Flow Rates:

(1) Quench Side, gpm

(2) Exterior Side, gpm

f. Source of Cooling Water

g. Flow Begins, seconds

F. Others 


\section{Temperature Distributions and Effects}

Provide an evaluation of the time-temperature response of the containment liner and its effect on liner stresses particularly at penetrations, joints, and other high stress areas.

IX. Assumptions Used in Pressure Transient Analysis (if applicable)
A. Feedwater Valve Closure Time, seconds
B. Steam Line Valve Closure Time, seconds
C. Scram Time, seconds
D. Liquid Carryover, \%

X. Additional Information

A. Sources of energy within the containment versus time during and after blowdown, including primary coolant, decay heat, and energy stored in components and pipes.

B. Heat removal rate versus time for important energy sinks within the containment.

C. Heat removal capability of the containment spray system as a function of water temperature, flow rate, and sink temperature.

D. Heat removal capacity per fan versus the containment's steamair mixture temperature. 
INFORMATION TO BE PROVIDED FOR WATER POOL PRESSURE SUPPRESSION CONTAINMENT (IN ADDITION TO TABLE 6-1)

\section{General Information}

A. Drywe 11

1. Internal design pressure, psig

2. External design pressure, psig

3. Design temperature, F

B. Suppression Chamber

1. Internal design pressure, psig

2. External design pressure, psig

3. Design temperature, F

C. Drywe11 Free Volume Including Vent System

1. Minimum, $\mathrm{ft}_{3}^{3}$

2. Maximum, $\mathrm{ft}^{3}$

D. Pressure Suppression Chamber Free Volume

1. Minimum, $\mathrm{ft}_{3}^{3}$

2. Maximum, $\mathrm{ft}^{3}$

E. Pressure Suppression Pool Water Volume

1. Minimum, $\mathrm{ft}_{3}^{3}$

2. Maximum, $\mathrm{ft}^{3}$

F. Downcomer Submergence, ft

G. Downcomer Loss Factor (for pressure drop purposes)

H. Poo1 Cross Section Area, $\mathrm{ft}^{2}$

I. Pool Depth (norma1), ft

J. Number of Vents

K. Normal Vent Diameter, ft

L. Total Vent Area, $f t^{2}$

M. Number of Downcomers

N. Nominal Downcomer Diameter, ft

$$
6 . \mathrm{T}-8
$$


II. Design Basis Accident Initial Conditions and Calculated Results

A. Effective Accident Break Area (Total), $\mathrm{ft}^{2}$

1. Components of Effective Break Area: (Recirc line)----(Equilizer 1ine)--(Bypass valve)----(Jet pumps)------etc.

B. Break Area/Vent Area

C. Nuclear Steam Supply System -

1. Volume of Water in Vessel, $\mathrm{ft}_{3}^{3}$

2. Volume of Steam in Vessel, $\mathrm{ft}^{3}$

3. Volume of Water in Recirc. Loops, $\mathrm{ft}^{3}$

4. Total $-\mathrm{ft}^{3}$

D. Drywell

1. Initial Temperature, $\mathrm{F}$

2. Initial Pressure, psig

3. Relative Humidity, \%

E. Suppression Chamber

1. Initial Temperature, F

2. Initial Pressure, psig

3. Relative Humidity, \%

F. Pool Initial Temperature, F

G. Calculated Peak Drywe11 Pressure, psig

H. Calculated Drywe11 Margin, \%

I. Calculated Peak Suppression Chamber Pressure, psig

J. Calculated Suppression Chamber Margin, \%

K. Calculated Peak Deck Differential Pressure, psig

L. Calculated Deck Differential Pressure Margin, \%

M. Peak Pool Temperature During Blowdown, F

6. $T-9$ 


\section{TABLE 6-3}

INFORMATION TO BE PROVIDED FOR DUAL CONTAINMENTS (IN ADDITION TO TABLE 6-1)

I. Shield Building
A. Air Annulus Volume, $\mathrm{ft}^{3}$
B. Leak Rate at Design Pressure, \%/day
C. Recirculation Fans

1. Number

2. Type

3. Air Flow Rate, $\operatorname{cfm}$ (at $\Delta \mathrm{P}=$

D. Exhaust Fans

1. Number

2. Type

3. Air Flow Rate, $\operatorname{cfm}($ at $\Delta \mathrm{P}=\ldots$ )

E. Filters

1. Number

2. Type

II. Auxiliary Building
A. Free Volume, $\mathrm{ft}^{3}$
B. Exhaust Fans
1. Number
2. Type
3. Air Flow Rate, $\operatorname{cfm}($ at $\Delta \mathrm{P}=$
C. Filters

1. Number

2. Type

$$
\text { 6. } T-10
$$


INFORMATION TO BE INCLUDED FOR ICE CONDENSER CONTAINMENTS (IN ADDITION TO TABLE 6-1)

I. Lower Chamber
A. Volume, $f t^{3}$
B. Design Pressure, psig
C. Design Temperature, F
D. Peak Pressure, DBA, psig
E. Pressure Margin, \%
F. Normal Operating Temperature, F
G. Norma1 Operating Pressure, psia
H. Norma1 Operating Relative Humidity, \%

II. Upper Chamber
A. Volume, $f t^{3}$
B. Design Pressure, psig
C. Design Temperature, F
D. Peak Pressure, DBA, psig
E. Pressure Margin, \%
F. Normal Operating Temperature, F
G. Normal Operating Pressure, psia
H. Normal Operating Relative Humidity, \%

III. Ice Condenser
A. Ice Weight, 1h
B. Flow Area, $\mathrm{ft}^{2}$
C. Length/Hydraulic Diameter
D. Channel Surface Area, $f t^{2}$
E. Ice Basket Diameter, $\mathrm{ft}$
F. Inlet Door Area, $\mathrm{ft}^{2}$
G. Ice Condenser Flow Area, $\mathrm{ft}^{2}$
H. Volume, $\mathrm{ft}^{3}$
I. Ice Bed Height, ft
J. Inlet Door Opening Pressure, psf
$\mathrm{K}$. Ice Boron Concentration, ppm
L. O.D. , ft
M. I.D. , $\mathrm{ft}$ 
IV. Refrigeration Cooling Capacity
A. Cooling Capacity for Compartment, tons
B. Number of Fan Coolers Per Unit
C. Air Temperature to Insulated Panels, F

V. Subcompartments
A. Volume, $\mathrm{ft}_{2}^{3}$
B. Vent Area, $\mathrm{ft}^{2}$
C. Total Loss Coefficients 


\subsection{INSTRUMENTATION AND CONTROLS}

The reactor instrumentation senses the various reactor parameters and transmits appropriate signals to the regulating systems during normal operation, and to the reactor trip and engineered safety feature systems during abnormal and accident conditions. The information provided in this chapter should emphasize those instruments and associated equipment which constitute the protection system (as defined in IEEE Std 279-1971, "Criteria for Protection Systems for Nuclear Power Generating Stations"). The analysis of regulating systems and instrumentation should be provided, particularly considerations of regulating system-induced transients which, if not terminated in a timely manner, could result in fuel damage, radiation release, or other public hazard. Details of seismic design and testing should be provided in Section 3. IV.

\section{$\underline{7.1}$ Introduction}

\subsubsection{Identification of Safety Related Systems}

List all instrumentation, control, and supporting systems that are safety related. Also list the safety related display instrumentation. Distinguish between those systems designed and built by the nuclear steam supplier and those designed and/or built by others. Identify the systems that are identical to those of a nuclear power plant of similar design that has recently received a construction permit or an operating license and identify those that are different, with a discussion of the differences.

\subsubsection{Identification of Safety Criteria}

List all design bases (including considerations of instrument errors), criteria, safety guides, information guides, standards and other documents that will be implemented in the design of the systems listed in 7.1.1.

The following specific information should be included in this section of the SAR when it applies equally to all safety related instrumentation and control systems; otherwise it should be in the section of this chapter that discusses the system to which the information applies:

7.1.2.1 Design Bases - Provide a description of the technical design bases for all the various functions of the protection system (e.g., scram if reactor vessel water level is _; this is needed because.......; it is required to operate within ). In addition to the reactor scram function, bases should be given for all other protection system functions, including engineered safety features, emergency power, interlocks, bypasses, and equipment protection. Diversity requirements should be stated (see IEEE Std 279-1971). 


\subsubsection{Independence of Redundant Safety Related Systems - The}

criteria and their bases should be presented that establish the minimum requirements for preserving the independence of redundant reactor protection systems (including instrument sensing lines), engineered safety feature systems, and Class IE electric systems* through physical arrangement and separation and for assuring the minimum required equipment availability during any design basis event.* A discussion should be included of the administrative responsibility and control to be provided to assure compliance with these criteria during the design and installation of these systems. The criteria and bases for the installation of electrical cable for these systems should, as a minimum, address:

(1) Cable derating and cable tray fill.

(2) Cable routing in congested areas and areas of hostile environment .

(3) Sharing of cable trays with non-safety related cables or with cables of the same system or other systems.

(4) Fire detection and protection in the areas where cables are installed.

(5) Cable and cable tray markings.

(6) Spacing of wiring and components in control boards, panels, and relay racks.

7.1.2.3 Physical Identification of Safety Related Equipment - A description should be provided of the means proposed to identify physically the reactor protection system and engineered safety feature equipment as safety related equipment in the plant to assure appropriate treatment, particularly during maintenance and testing operations. The description should include the identification scheme used to distinguish between protection systems of each unit at multi-unit stations and between redundant channels of these systems within each unit and a discussion of how it will be evident to the operator or maintenance craftsman, without the necessity for consulting any reference material, whether equipment, cabling, etc., is safety related and, if safety related, which unit and channel is involved.

*Class IE electric systems and design basis events are defined in IEEE Std 308-1971, "Criteria for Class IE Electric Systems for Nuclear Power Generating Stations." 
7.1.2.4 Conformance to IEEE No. 317 - Describe the degree of conformance to IEEE No. 317 (April 1971), "Electrical Penetration Assemblies in Containment Structures for Nuclear Fueled Power Generating Stations."

7.1.2.5 Conformance To IEEE No. 323 - Describe the degree of conformance to IEEE No. 323 (April 1971), "General Guide for Qualifying Class I Electric Equipment for Nuclear Power Generating Stations."

7.1.2.6 Conformance to IEEE No. 336 - Describe the degree of conformance to appropriate electrical quality assurance standards such as IEEE Std 336-1971, "Installation, Inspection, and Testing Requirements for Instrumentation and Electric Equipment During the Construction of Nuclear Power Generating Stations." Appropriate references may be made to other sections of the SAR such as Chapters 3 and 17.

7.1.2.7 Conformance to IEEE No. 338 - Describe the degree of conformance to IEEE Std 338-1971, "Periodic Testing of Nuclear Power Generating Station Protection Systems."

7.1.2.8 Conformance to Safety Guide 22 - Describe the degree of conformance to Safety Guide 22 .

\subsection{Reactor Trip System}

For standardized systems it is preferred that the information listed be supplied in a topical report and that the topical report be referenced in the appropriate place in the SAR.

\subsubsection{Description}

7.2.1.1 System Description - Provide a description of the reactor trip system to include initiating circuits, logic, bypasses, interlocks, redundancy, diversity, and actuated devices. Any supporting systems should be identified and described. Those parts of any system not required for safety should be identified.

7.2.1.2 Design Basis Information - Provide the design basis information required by Section 3 of IEEE Std 279-1971. Provide preliminary logic diagrams, P\&I diagrams, and location layout drawings of all reactor trip systems and supporting systems in the PSAR.

7.2.1.3 Final System Drawings - In the FSAR, provide electrical schematic diagrams for all reactor trip systems and supporting systems, and final logic diagrams, P\&I diagrams and location layout drawings. 


\subsubsection{Analysis}

Provide analyses, including a failure mode and effects analysis, to demonstrate how the requirements of the AEC General Design Criteria, IEEE Std 279-1971, applicable AEC Safety Guides, and other appropriate criteria and standards are satisfied. In addition to postulated accidents and failures, these analyses should include, but not be limited to, considerations of instrumentation installed to prevent or mitigate the consequences of:

(1) spurious control rod withdrawals,

(2) loss of plant instrument air systems,

(3) loss of cooling water to vital equipment,

(4) plant load rejection, and

(5) turbine trip.

The analyses should also discuss the need for and method of changing to more restrictive trip set points during abnormal operating conditions such as operation with fewer than all reactor coolant loops operating.

Reference may be made to other sections of the SAR for supporting systems.

\subsection{Engineered Safety Feature Systems}

For standardized systems it is preferred that the information listed be supplied in a topical report and that the topical report be referenced in the appropriate place in the SAR.

\subsubsection{Description}

7.3.1.1 System Description - Provide a description of the instrumentation and controls associated with the Engineered Safety Features (ESF) including initiating circuits, logic, bypasses, interlocks, sequencing, redundancy, diversity, and actuated devices. Any supporting systems should be identified and described. Those parts of any system not required for safety should be identified.

7.3.1.2 Design Basis Information - Provide the design basis information required by Section 3 of IEEE Std 279-1971. Provide preliminary logic diagrams, P\&I diagrams and location layout drawings of all engineered safety feature instrumentation and control systems and supporting systems for the PSAR review. 
7.3.1.3 Final System Drawings - In the FSAR, provide electrical schematic diagrams for all ESF circuits and supporting systems, and final logic diagrams, P\&I diagrams and location layout drawings.

\section{$\underline{7.3 .2 \quad \text { Analysis }}$}

Provide analyses, including a failure mode and effects analysis, to demonstrate how the requirements of the AEC General Design Criteria and IEEE Std 279-1971 are satisfied and the extent to which applicable AEC Safety Guides and other appropriate criteria and standards are satisfied. In addition to postulated accidents and failures, these analyses should include considerations of (1) loss of plant instrument air systems and (2) loss of cooling water to vital equipment. The method for periodic testing of engineered safety feature instrumentation and control equipment should be described.

\subsection{Systems Required for Safe Shutdown}

For standardized systems it is preferred that the information listed be supplied in a topical report and that the topical report be referenced in the appropriate place in the SAR.

\subsubsection{Description}

Provide a description of the systems that are needed for safe shutdown of the plant, including initiating circuits, logic, bypasses, interlocks, redundancy, diversity, and actuated devices. Any supporting systems should be identified and described. Provide the design basis information required by Section 3 of IEEE Std 279-1971. Provide logic diagrams, P\&I diagrams and location layout drawings for these systems. In the FSAR, provide electrical schematic diagrams.

Describe the provisions taken in accordance with AEC General Design Criterion 19 to provide the required equipment outside the control room for hot and cold shutdown.

\section{$\underline{7.4 .2 \quad \text { Analysis }}$}

Provide analyses which demonstrate how the requirements of the AEC General Design Criteria, IEEE Std 279-1971, applicable AEC Safety Guides and other appropriate criteria and standards are satisfied. These analyses should include considerations of instrumentation installed to permit a safe shutdown in the event of: 
(1) loss of plant instrument air systems,

(2) loss of cooling water to vital equipment,

(3) plant load rejection, and

(4) turbine trip.

\subsection{Safety Related Display Instrumentation}

\subsubsection{Description}

Include a description of the instrumentation systems (including control rod position indicating systems) that provide information to enable the operator to perform required safety functions.

\subsubsection{Analysis}

Provide an analysis to demonstrate that the operator has sufficient information to perform required manual safety functions (e.g., assuring safe control rod patterns, manual engineered safety feature operations, possible unanticipated post-accident operations, and monitoring the status of safety equipment) and sufficient time to make reasoned judgments and take action where operator action is essential. Identify appropriate safety criteria in the PSAR and demonstrate compliance with these criteria in the FSAR.

Information should be provided to identify the information readouts or indications provided to the operator for monitoring conditions in the reactor, the reactor coolant system, and in the containment and safetyrelated process systems, including engineered safety features, throughout all operating conditions of the plant, including anticipated operational occurrences and accident and post-accident conditions (including instrumentation to follow the course of accidents). The information should include the design criteria, the type of readout, number of channels provided, their range, accuracy and location, and a discussion of the adequacy of the design.

\subsection{Al1 Other Instrumentation Systems Required for Safety}

This section should contain information on all other instrumentation systems required for safety that are not included under Reactor Trip, Engineered Safety Features, Safe Shutdown, Safety Related Display Instrumentation Systems or any of their supporting systems, (e.g., cold water slug interlocks, refueling interlocks and interlocks that prevent overpressurization of low pressure systems).

\subsubsection{Description}

Provide a description of all systems required for safety not already discussed, including initiating circuits, logic, bypasses, interlocks,

$$
7.5-1
$$


redundancy, diversity, and actuated deyices. Any supporting systems should be identified and described (reference may be made to other sections of the SAR). Provide the design basis information required by Section 3 of IEEE Std 279-1971. For an FSAR, sufficient schematic diagrams should be provided to permit an independent evaluation of compliance with the safety criteria.

\subsubsection{Analysis}

Provide analyses to demonstrate how the requirements of the AEC General Design Criteria, IEEE Std 279-1971, applicable AEC Safety Guides and other appropriate criteria and standards are satisfied. These analyses should include, but not be limited to, considerations of instrumentation installed to prevent, or mitigate the consequences of,

(1) cold water slug injections,

(2) refueling accidents, and

(3) overpressurization of low pressure systems.

Reference may be made to other sections of the SAR for supporting systems.

\subsection{Contro1 Systems Not Required for Safety}

For standardized systems it is preferred that the information listed be supplied in a topical report and that the topical report be referenced in the appropriate place in the SAR.

\subsubsection{Description}

The following information should be provided with regard to the control systems not requried for safety designed by the nuclear steam system supplier:

(1) Identification of the major plant control systems (e.g., primary temperature control, primary water level control, steam generator water level control) that are identical to those in a nuclear power plant of similar design by the same nuclear steam system supplier that has recently received a construction permit or an operating 1icense; and

(2) A list and discussion of the design differences in those systems not identical to those used in the reference nuclear power plant. This discussion should include an evaluation of the safety significance of each design difference. 


\subsubsection{Analysis}

Provide analyses to demonstrate that these systems are not required for safety. The analyses should demonstrate that the protection systems are capable of coping with all (including gross) failure modes of the control systems. 


\section{CHAPTER 8.0 ELECTRIC POWER}

The electric power system is the source of power for the reactor coolant pumps and other auxiliaries during normal operation, and for the protection system and engineered safety features during abnormal and accident conditions. The information in this chapter should be directed toward establishing the functional adequacy of the safety related electric and power systems and assuring that these systems have adequate redundancy, Independence, and testability in conformance with current criteria. Details of seismic design and testing should be provided in section 3.10 .

\subsection{Introduction}

A brief description of the utility grid and its interconnection to other grids should be included, and the onsite electric system should be described briefly in general terms. The safety loads (i.e., the systems and devices that require electric power to perform their safety functions) should be identified; the safety functions performed (e.g., emergency core cooling, containment cooling), and the type of electric power (a-c or $d-c$ ) required by each safety load should be indicated. The design bases, criteria, safety guides, standards and other documents that w111 be implemented in the design of the safety related electric systems should be presented and discussed.

\subsection{Offsite Power System}

\subsubsection{Description}

A system description and an analysis sufficient to demonstrate compliance with 10 CFR Part 50 and the AEC General Design Criteria (GDC) should be provided. In addition, the SAR should indicate the degree of conformance with AEC Safety Guides, and other applicable standards and criteria (e.g., industry standards normally used by the applicant in the installation of safety systems and internal standards and criteria). In particular, the circuits which supply power for safety loads from the transmission network should be identified and shown to meet GDC 17 . Voltage level and length of each transmission line from the site to the first major substation that connects the line to the grid should be provided. A11 unusual features of these transmission lines should be described (e.g., crossovers or proximity of other lines, rugged terrain, vibration or galloping conductor problems, icing or other heavy loading conditions, high thunderstorm occurrence rate). Describe and provide layout drawings of the circuits that connect the onsite distribution system to the preferred power supply; include transmission lines, switchyard arrangement, rights-of-way, etc.

$$
8.0-1
$$




\section{2 .2 Analysis}

Provide the results of steady-state and transient stability analyses to demonstrate compliance with the last paragraph of GDC 17 . In determining the most critical trangmission line, consider multiple circuit lines that use a common tower as a single line. Provide information and discussion of grid avallability including frequency, duration and causes of outages.

\subsection{Onsite Power Systems}

\subsubsection{A-C Power Systems}

8.3.1.1 Description - Describe the onsite a-c power systems with emphasis placed on those portions of the systems that are safety related. Those portions that are not related to safety need only be described in sufficient detail to permit an understanding of interactions with the safety related portions. The description of the safety related portions should include:

(1) power supply feeders, (1.e., network configuration)

(2) busing arrangements,

(3) loads supplied from each bus,

(4) manual and automatic interconnections between buses, buses and loads, and buses and supplies,

(5) interconnections between safety and non-safety related buses,

(6) redundant bus separation,

(7) equipment capacities,

(8) automatic loading and stripping of buses,

(9) safety related equipment identification,

(10) instrumentation and contro1 systems for the applicable power systems with the assigned power supply identified,

(11) electric circuit protection system network (e.g., selective trip), including setting criteria, and 
(12) the scheme for testing these systems during power operation.

The basis for the power required for each safety load (e.g., motor nameplate rating, pump run-out condition, or estimated load under expected flow and pressure) should be given. The continuous and short term ratings for the onsite power source should be provided. In some cases, the bases for the requested information is engineering judgment or correlation with other similar plants; nevertheless, the information requested should be submitted and all limitations cited. The FSAR should completely update all previously transmitted information and should verify that all systems are adequately sized and that all pertinent criteria are met.

The following conceptual aspects of the onsite electric power system should be described:

(1) starting initiating circuits,

(2) starting mechanism and system,

(3) tripping devices,

(4) interlocks,

(5) permissives,

(6) load shedding circuits,

(7) testing,

(8) fuel oll storage and transfer system,

(9) cooling and heating systems, and

(10) instrumentation and control systems with assigned power supply.

This description should be complete in the FSAR. Any features or components not previously used in similar applications in nuclear generating stations should be identified, Provide single line diagrams of the onsite a-c distribution systems including identification of all safety loads. The physical arrangement of the components of the system should be described in sufficient detail to permit independent verification that single events and accidents will not disable redundant features. Sufficient plant layout drawings should be provided to permit the physical separation and isolation of redundant portions of the system to be evaluated. Provide a preliminary table that illustrates the automatic and manual loading and unloading of each standby power supply. Provide the final table in the FSAR. Include 
the time of each event, size of load, inrush current or starting kVA, identification of redundant equipment, and length of time each load is required. For the safety related systems, describe the bases and provide the design criteria that establish:

(1) motor size,

(2) motor starting torque,

(3) motor insulation,

(4) interrupting capacity of switchgear, load centers, control centers, and distribution panels,

(5) electric circuit protection, and

(6) grounding requirements.

The FSAR should identify all deviations from these criteria, and provide jugtification for said deviations. Sufficient logic and schematic diagrams should be provided to permit an independent evaluation of compliance with the safety criteria.

8.3.1.2 Analysis - Provide analyses to demonstrate compliance with the AEC General Design Criteria, and to indicate the degree of conformance with AEC Safety Guides and other applicable criteria. Especially important are the analyses to demonstrate compliance with GDC 17 and 18, and the discussion to Indicate the degree of conformance with Safety Guides 6 and 9, and IEEE Std 308-1971, "Criteria for Class IE Electric Systems for Nuclear Power Generating Stations." The discussion should identify all aspects of the onsite power system that do not conform to Safety Guides 6 and 9 and IEEE Std 308-1971, and should explain how such deviations are not in conflict with applicable General Design Criteria.

Indentify all safety related equipment that must operate in a hostile environment (e.g., radiation, temperature, pressure, humidity) during and/or subsequent to an accident (e.g., loss-of-coolant accident, steamline break). Tabulate all the conditions under which the equipment must operate. Provide bases, criteria, and analyses of the potential effects of: (1) radlation ( $1 . e$., radiation due to accident conditions superimposed on that for long-term normal operation) on safety related electric equipment throughout the plant; and (2) loss-of-coolant accidents or steamline breaks on all safety related electric equipment within primary reactor containment (e.g., motors, cables) that must operate during and/or subsequent to said accidents. Document the successful completion of any applicable qualification tests for the above cases. 
Where such tests have not been previously completed, document plans and schedules of the type tests proposed. Document the results of said tests (FSAR).

8.3.1.3 Conformance with Appropriate Quality Assurance Standards Describe the degree of conformance to appropriate electrical quality assurance standards such as IEEE Std 336-1971, "Installation, Inspection, and Testing Requirements for Instrumentation and Electric Equipment During the Construction of Nuclear Power Generating Stations." If the information is adequately covered in other sections, cross referencing is acceptable.

8.3.1.4 Independence of Redundant Systems - The criteria and their bases should be presented that establish the minimum requirements for preserving the independence of redundant Class IE Electric Systems* through physical arrangement and separation and for assuring the minimum required equipment availability during any design basis event.* A discussion should be included of the administrative responsibility and control to be provided to assure compliance with these criteria during the design and installation of these systems. The criteria and bases for the installation of electrical cable for these systems should, as a minimum, include:

(1) cable derating and cable tray fil1,

(2) cable routing in congested areas and areas of hostile environment,

(3) sharing of cable trays with non-safety related cables or with cables of the same system or other systems,

(4) fire detection and protection in the areas where cables are installed,

(5) cable and cable tray marking,

(6) spacing of power and control wiring and components associated with Class IE Electric Systems in control boards, panels, and relay racks, and

(7) fire barriers and separation between redundant trays.

*Class IE electric systems and design basis events are defined in IEEE Std 308-1971 
8.3.1.5 Physical Identification of Safety Related Equipment - A description should be provided of the means proposed to identify physically the onsite power system equipment as safety related equipment in the plant to assure appropriate treatment, particularly during maintenance and testing operations. The description should include the identification scheme used to distinguish between redundant channels of the system and a discussion of how it will be evident to the operator or maintenance craftsman, without the necessity for consulting any reference material, whether equipment, cabling, etc., is safety related and, if safety related, which channel is involved.

\subsubsection{D-C Power Systems}

8.3.2.1 Description - Provide a description of the $d-c$ power systems clearly delineating the safety related portions. The non-safety related portion need only be described in sufficient detail to permit an understanding of its interaction with the safety related portions. The description of the safety related portion should include requirements for separation, capacity, charging, ventilation, loading, redundancy, and testing. The safety loads should be clearly identified and the length of time they would be operable in the event of loss of all a-c power should be stated. For an FSAR, sufficient schematic diagrams should be provided to pernit ar indepenoent evaluation of compliance with the safety criteria.

\subsubsection{Analysis - Provide an analysis to demonstrate conipliance} with the AEC General Design Criteria, and describe the degree of conformance with. applicable AEC Safety Guides, IEEE Std 308-1971, and other applicable criteria. Provide the same information described in items 8.3.1.2 through 8.3.1.5 above, as applicable. 


\subsection{AUXILIARY SYSTEMS}

This chapter should provide information concerning the auxiliary systems included in this facility. The information in the PSAR should reflect the preliminary design of the auxiliary systems, and the FSAR information should reflect the final design.

Those systems which are essential for the safe shutdown of the plant or the protection of the health and safety of the public should be identified. The description of the system, the design bases for each system and for critical components, a safety evaluation demonstrating how the system satisfies the design bases, and the testing and inspection to be performed to verify system capability and reliability should be provided. There may be aspects of the auxiliary systems that have little or no relationship to protection of the public against exposure to radiation. In such cases, enough information should be provided to allow understanding of the auxiliary system design and function with emphasis on those aspects of design and operation that might affect the reactor and its safety features or contribute to the control of radioactivity.

The capability of the system to function without compromising the safe operation of the plant under both normal operating or transient situations should be clearly shown by the information provided, i.e., a failure analysis.

Seismic design classifications should be stated with reference to detailed information provided in Chapter 3, where appropriate. Radiological considerations associated with operation of each system under normal and accident conditions (where applicable) should be summarized and reference made to detailed information in Chapters 11 and/or 12 as appropriate.

\subsection{Fuel Storage and Handling}

\subsubsection{New Fuel Storage}

9.1.1.1 Design Bases - The design bases for new fuel storage facilities should be provided and should include such considerations as quantity of fuel to be stored, means for maintaining a subcritical array and the degree of subcriticality provided together with the assumptions used in this calculation including a flooded condition, and design loadings to be withstood.

9.1.1.2 Facilities Description - A description of the new fuel storage facilities, including drawings, and location in the station complex should be provided. 
9.1.1.3 Safety Evaluation - An evaluation of the capability of the new fuel storage facilities to reduce the probability of occurrence of unsafe conditions should be presented and include the degree of subcriticality, governing codes for design, ability to withstand external loads and forces, and safety implications related to sharing (for multiple unit facilities). Details of the seismic design and testing should be presented in section 3.7.

\subsubsection{Spent Fuel Storage}

9.1.2.1 Design Bases - The design bases for the spent fuel storage facilities should be provided and should include such considerations as quantity of fuel to be stored, means for maintaining a subcritical array, degree of subcriticality provided together with the assumptions used in this calculation, shielding requirements, and design loadings to be withstood.

9.1.2.2 Facilities Description - A description of the spent fuel storage facilities, including drawings, and location in the station complex should be provided.

9.1.2.3 Safety Evaluation - An evaluation of the protection of the spent fuel storage facilities against unsafe conditions should be presented and include the degree of subcriticality, governing codes for design, ability to withstand external loads and forces, ability to assure continuous cooling, provisions to avoid accidental dropping of heavy objects on spent fuel, material compatibility requirements, radiological considerations (details should be presented in Chapter 12), and safety implications related to sharing (for multiple unit facilities). Additional guidance regarding acceptable design of the spent fuel storage facilities is given in AEC Safety Guide 13.

\subsubsection{Spent Fuel Pool Cooling and Cleanup System}

9.1.3.1 Design Bases - The design bases for the cooling and cleanup system for the spent fuel facilities should be provided and should include the requirements for continuous or intermittent cooling, the quantity of spent fuel to be cooled, the requirements for pool water temperature and cleanliness from fission and corrosion products, and level and radiation shielding requirements.

9.1.3.2 System Description - A description of the cooling and cleanup system, including description of the instrumentation utilized, should be provided. The FSAR should include a detailed, updated description and drawings . 
9.1.3.3 Safety Evaluation - An evaluation of the cooling system should be provided including the capability for spent fuel cooling during normal and abnormal conditions, provisions to assure that pool water will not be lost at the rate greater than the makeup capability, and ability to maintain acceptable pool water conditions. The radiological evaluation of the cleanup system should be presented in Chapters 11 and 12. Additional guidance regarding acceptable coolant makeup requirements is given in AEC Safety Guide 13.

9.1.3.4 Inspection and Testing Requirements - The inspection and testing requirements for the cooling and cleanup system should be described.

\subsubsection{Fuel Handling System}

A description of the fuel handling system, including the equipment for transporting and handling fuel from the time it reaches the plant until it leaves the plant should be provided. Included should be descriptions of the tools and servicing equipment necessary to perform the various reactor vessel servicing and refueling functions. The description, including preliminary drawings, should present an outline of the refueling procedure and should address safety aspects of the equipment design, where applicable. Detailed description and drawing should be included in the FSAR. A discussion of how the system design would prevent accidental dropping of a fuel cask a greater distance than the 10 CFR Part 71 design criteria should be provided.

\subsection{Water Systems}

This section of the SAR should provide discussions of each of the water systems associated with the plant. Because these auxiliary water systems vary in number, type, and nomenclature for various plant designs, the Standard Format does not assign specific subsection numbers to these systems. The applicant should provide separate subsections (numbered 9.2.1 through 9.2.x) for each of the systems. As they apply to a particular plant, these subsections should provide information on:

(1) design bases,

(2) system description including drawings,

(3) safety evaluation,

(4) tests and inspections, and

(5) instrumentation applications for each system.

The following paragraphs provide examples of systems that should be discussed, as appropriate to the individual plant, and identify some specific information 
that should be provided in addition to the items identified above. The examples are not intended to be a complete list of systems to be discussed in this section.

\subsubsection{Station Service Water System}

Describe the capability of the service water system to meet the single failure criterion (when this system is safety related), the ability to withstand adverse environmental occurrences, requirements for normal operation and for operating during and subsequent to postulated accident conditions including loss of offsite power, provisions for reactor compartment flooding during the post-LOCA period, if required, and the ability of the system to detect and prevent excessive leakage of radioactive material to the environment. Include a failure analysis to demonstrate that a single failure will not result in the loss of all, or an unacceptable portion of the cooling function (considering failures of active and passive components, and diverse sources of electric power for pump, valves and control purposes), capability of the system to function during abnormally high and low water levels, prevention of long term corrosion and organic fouling which may degrade system performance, and safety implications related to sharing (for multiple unit facilities). Cross reference paragraphs $2.4 .11 .5,2.4 .11 .6$, and 2.4 .12 where applicable.

\subsubsection{Cooling System for Reactor Auxiliaries}

Discuss the capability of the reactor system auxiliaries to meet the single failure criterion when required, the ability to withstand adverse environmental occurrences, requirements for normal operation and for operating during and subsequent to postulated accident conditions including loss of offsite power, and requirements for leakage detection and containment of leakage. Include a failure analysis to demonstrate that a single failure will not result in the loss of all, or an unacceptable portion of, the cooling function (considering failures of active and passive components, and diverse sources of electric power for pumps, valves and control purposes), the means for preventing or controlling leakage of activity to the outside environment, leakage detection provisions, prevention of long term corrosion which may degrade system performance, and safety implications related to sharing (for multiple unit facilities).

\subsubsection{Demineralized Water Make-Up System}

\subsubsection{Potable and Sanitary Water Systems}

An evaluation of radiological contamination (including accidental), and safety implications of sharing (for multiple unit facilities) should be presented. 


\section{2 .5 U1timate Heat Sink}

A description of the ultimate heat sink to be used to dissipate waste heat from the plant during normal, shutdown and accident conditions should be provided. Additional guidance regarding acceptable features of the ultimate heat sink is given in AEC Safety Guide 27. Cross reference paragraphs 2.4.11.5, 2.4.11.6, and 2.4.12 where app1icable.

\subsubsection{Condensate Storage Facilities}

A discussion of the environmental design considerations, requirements for leakage control (including mitigation of environmental effects), 1imits for radioactivity concentration, code design requirements, and material compatibility and corrosion control should be given. An analysis of storage facility failure and provisions for mitigating environmental effects should be provided. The evaluation of radiological considerations should be presented in Chapter 12.

\subsection{Process Auxiliaries}

This section of the SAR should provide discussions of each of the auxiliary systems associated with the reactor process system. Because these auxiliary systems vary in number, type, and nomenclature for various plant designs, the Standard Format does not assign specific subsection numbers to these systems. The applicant should provide separate subsections (numbered 9.3.1 through 9.3.x) for each of the systems. These subsections should provide information on:

(1) design bases,

(2) system description,

(3) safety evaluation,

(4) tests and inspections, and

(5) instrumentation applications for each system.

The following paragraphs provide examples of systems that should be discussed, as appropriate to the individual plant, and identify some specific information that should be provided in addition to the items identified above. The examples are not intended to be a complete list of systems to be discussed in this section. For example, the Boron Recovery system and the Failed Fuel Detection System should both be discussed in this section. 


\subsubsection{Compressed Air Systems}

Describe the compressed air systems that provide station air for service and maintenance uses and include discussion of provisions for meeting the single failure criterion for safety related compressed air systems, air cleanliness requirements, and environmental design requirements. The evaluation of the compressed air system should include a failure analysis (including diverse sources of electric power), maintenance of air cleanliness to assure system reliability, and safety implications related to sharing (for multiple unit plants).

\subsubsection{Process Sampling System}

The design bases for the sampling system for the various plant fluids should include consideration of sample size and handling to assure that a representative sample is obtained, requirements to minimize to the extent practical hazards to plant personnel, and system pressure, temperature and code requirements. The points from which samples will be obtained should be delineated. The evaluation of the sampling system should provide assurance that representative samples will be obtained, and that sharing (for multiple unit facilities) will not adversely affect plant safety. The radiological evaluation for normal operation should be provided in Chapter 12 .

\subsubsection{Equipment and Floor Drainage System}

Describe the drainage systems for collecting the effluent from high activity and low activity liquid drains from various specified equipment items and buildings. An evaluation of radiological considerations for normal operation and postulated spills and accidents, including the effects of sharing (for multiple unit plants), should be presented in Chapters 11 and 12 .

\subsubsection{Chemical, Volume Control, and Liquid Poison Systems}

The design bases for the chemical, volume control, and liquid poison systems should include consideration of the capability for the control of reactor coolant chemistry for reactivity and corrosion control, capability for maintaining the required reactor coolant system inventory, code design requirements, and system design to detect and control the release of radioactive system effluents to the environment. The evaluation of the chemical, volume control, and liquid poison systems should include an analysis of the effects of component malfunctions, an analysis of the capability to control the concentrations of tritium, boron, and other chemicals in the reactor coolant system, an analysis of the availability and reliability of the system (including heat tracing when required), and an analysis of the capability to isolate the system in the event of pipe breaks outside containment. The radiological evaluation for normal operation should be presented in Chapter 11 and 12 . 


\subsubsection{Failed Fuel Detection System}

9.4 Air Conditioning, Heating, Cooling, and Ventilation Systems

The following paragraphs provide examples of systems that should be discussed, as appropriate to the individual plant, and identify some specific information that should be provided. The examples are not intended to be a complete list of systems to be discussed in this section. For example, the ventilation system for the Diesel Building and the Containment Ventilation System should both be described in this section.

\subsubsection{Control Room}

9.4.1.1 Design Bases - The design bases for the air treatment system for the control room and other auxiliary rooms (e.g., relay rooms and emergency switchgear rooms) considered to be the control areas should be provided and include design criteria (e.g., single failure), ambient temperature requirements, criteria for plant operator comfort and safety, requirements for radiation protection and monitoring of abnormal radiation levels, and environmental design requirements.

\subsubsection{System Description - A description should be presented of the} air treatment systems for the control room, including preliminary drawings. Provide detailed description and drawings (FSAR).

9.4.1.3 Safety Evaluation - An evaluation of the control room air treatment system should be provided and should include discussion of ability to detect airborne contaminants (smoke, radiation, etc.) and to filter them upon admission to the extent practical to the control room or to expedite their discharge from the control room, capability of filters for iodine and particulate removal, ability to meet the criteria, and capability for assuring required ambient temperature level and anticipated degradation of control room equipment performance if temperature levels are exceeded. Analysis of dose levels in the control room under accident conditions should be presented in Chapter 15.

9.4.1.4 Inspection and Testing Requirements - The inspection and testing requirements for the control room air treatment system should be described.

\subsubsection{Auxiliary Building}

A description of the heating and ventilating system for the various items of equipment in the Auxiliary Building, should be provided. The required and design ambient temperature limits should be listed. Discuss the design bases, system design, design evaluation, test and inspection requirements and instrumentation applications. Provide final description and drawings (FSAR). 
9.4.3 Radwaste Area

9.4.3.1 Design Bases - The design bases for the air handling system for the radwaste area should be presented and should include requirements for meeting the single failure criterion, ambient temperature limits, preferred direction of air flow from areas of low potential radioactivity to areas of higher potential radioactivity, differential pressures to be maintained and measured, requirements for monitoring of abnormal radiation levels, and requirements for treatment of exhaust air.

9.4.3.2 System Description - A description should be provided of the air handling system for the radwaste area, including preliminary drawings. Provide final description and drawings (FSAR).

9.4.3.3 Safety Evaluation - An evaluation of the radwaste area air handling system should be presented including a system failure analysis (including effects of inability to maintain preferred air flow patterns). Evaluation of radiological considerations for normal operation should be presented in Chapters 11 and 12 .

\subsubsection{Inspection and Testing Requirements - The inspection and} testing requirements for the radwaste area air handling system should be provided.

\subsubsection{Turbine Building}

9.4.4.1 Design Bases - The design bases for the air handling system for the turbine-generator area in the Turbine Building should be presented and should include ambient temperature limits, preferred direction of air flow from areas of low potential radioactivity to areas of higher potential radioactivity, requirements for monitoring of abnormal radiation levels, and requirements for treatment of exhaust air.

9.4.4.2 System Description - A description should be provided of the air handling system for the Turbine Building, including preliminary drawings. Provide final description and drawings (FSAR).

9.4.4.3 Safety Evaluation - An evaluation of the Turbine Building air handling system should be presented including a system failure analysis (including effects of inability to maintain preferred air flow patterns). Radiological considerations for normal operation should be evaluated in Chapters 11 and 12 .

9.4.4.4 Inspection and Testing Requirements - The inspection and testing requirements for the Turbine Building air handling system should be provided. 


\subsection{Other Auxiliary Systems}

\subsubsection{Fire Protection System}

9.5.1.1 Design Bases - The design bases for the fire protection system should be provided and should include extent of station coverage, type of fire extinguishing equipment and material to be provided for each area, requirements for fire monitoring, criteria for minimizing the potential for fires, requirements to assure that operation of the fire protection system would not produce an unsafe condition, seismic design criteria for the fire protection system, and requirements to assure that failure of any portions of the fire protection system not designed to Category I requirements would not damage other Category I equipment.

9.5.1.2 System Description - A description of the fire protection and detection system, including preliminary drawings, should be provided. Provide final description and drawings (FSAR).

9.5.1.3 System Evaluation - An evaluation of the fire protection and detection system should be presented and should include an analysis of potential adverse effects of fire protection system operation (such as flooding of engineered safety feature equipment), design features incorporated in the unit design to minimize the potential for fire occurrences, and an analysis of the reliability of fire detection equipment.

9.5.1.4 Inspection and Testing Requirements - The inspection and testing requirements for the fire protection system should be provided.

\subsubsection{Communications Systems}

9.5.2.1 Design Bases - The design bases for the communication systems for intra-plant and plant-to-offsite communications should be provided and should include a discussion of the use of diverse system types.

9.5.2.2 Description - A description and evaluation of the communication systems should be provided. Provide final description and drawings (FSAR).

9.5.2.3 Inspection and Testing Requirements - The inspection and testing requirements for the communication systems should be provided.

\subsubsection{Lighting Systems}

A description of the normal lighting system for the plant should be provided. A description of the emergency lighting system should be provided including design criteria and a failure analysis. 


\subsubsection{Diese1 Generator Fuel Oil Stoxage and Transfer System}

9.5.4.1 Design Bases - The design bases for the fuel oil storage and transfer system for the diesel generator should be provided and should include the requirement for onsite storage capacity, capability to meet design criteria (e.g., single failure criterion), code design requirements, and environmental design bases.

A description of the diesel generator fuel oil storage and transfer system, including drawings, should be provided. A detailed description and drawings should be provided (FSAR).

An evaluation of the fuel oil storage and transfer system should be provided and should include the potential for material corrosion, a failure analysis to demonstrate capability to meet design criteria (e.g., single failure criterion), ability to withstand environmental design conditions, and the plans by which additional oil may be procured, if required.

\subsubsection{Diese1 Generator Cooling Water System}

The design bases for the cooling water system should be provided and should include a discussion of the ability to meet the single failure criterion. A description of the cooling water system, including drawings, should be provided.

\subsubsection{Diesel Generator Starting System}

The design bases for the starting system should be provided and should include a discussion of the ability to meet the single failure criterion. A description of the starting system, including drawings, should be provided.

\subsubsection{Diesel Generator Lubrication System}

The design bases for the lubrication system should be provided and should include a discussion of the ability to meet the single failure criterion. A description of the lubrication system, including drawings, should be provided. 


\subsection{STEAM AND POWER CONVERSION SYSTEM}

This chapter of the SAR should provide information concerning the plant steam and power conversion system. For purposes of this chapter, the steam and power conversion system (heat utilization system) should be considered to include:

(1) The steam system and turbine generator units of an indirectcycle reactor plant, as defined by the secondary coolant system, or

(2) The steam system and turbine generator units in a directcycle plant, as defined by the system extending beyond the reactor coolant system isolation valves.

There will undoubtedly be many aspects of the steam portion of the plant that have little or no relationship to protection of the public against exposure to radiation. The SAR is, therefore, not expected to deal with this part of the plant to the same depth or detail as those features playing a more significant safety role. Enough information should be provided to allow understanding in broad terms of what the secondary plant (steam and power conversion system) is, but emphasis should be on those aspects of design and operation that do or might affect the reactor and its safety features or contribute toward the control of radioactivity. The capability of the system to function without compromising directly or indirectly the safety of the plant under both normal operating or transient situations should be shown by the information provided. Where appropriate, the evaluation of radiological aspects of normal operation of the steam and power conversion system and subsystems should be summarized in this chapter, and presented in detail in Chapters 11 and/or 12 .

\subsection{Summary Description}

A sumnary description should be provided of the steam and power conversion system, indicating principal design features. An overall system flow diagram and a summary table of the important design and performance characteristics including a heat balance at rated power and at stretch power should be included. The description should indicate those system design features that are safety related.

\subsection{Turbine-Generator}

\subsubsection{Design Bases}

The design bases for the turbine-generator equipment should be provided and should include the performance requirements under normal, upset, emergency and faulted conditions, intended mode of operation (base loaded or load following), functional limitations imposed by the design 
or operational characteristics of the reactor coolant system (rate at which electrical load may be increased or decreased with and without reactor control rod motion or steam bypass), and design codes to be applied.

\subsubsection{Description}

A description of the turbine-generator equipment including moisture separation, use of extraction steam for feedwater heating, and control functions which could influence operation of the reactor coolant system, should be provided including drawings. Overspeed controls and possible redundancy of controls should be described.

\subsubsection{Turbine Missiles}

Potential turbine missiles should be identified. Analysis for determining missile source, energy and mass should be provided. Criteria for protection against missiles should be provided including identification of structures, systems and components to be protected. Preliminary drawings showing orientation of the turbine with respect to important structures should be provided.

\section{$\underline{10.2 .4 \quad \text { Evaluation }}$}

An evaluation of the turbine-generator and related steam handling equipment should be provided. This evaluation should include a summary discussion of the anticipated operating concentrations of radioactive contaminants in the system, radiation levels associated with the turbine components and resulting shielding requirements, and the extent of access control necessary based on radiation levels and shielding provided. Details of the radiological evaluation should be provided in Chapters 11 and 12 .

\subsection{Main Steam Supply System}

\subsubsection{Design Bases}

The design bases for the main steam line piping from the steam generator in the case of an indirect cycle plant, or from the outboard isolation valve in the case of a direct cycle plant, should be provided and should include performance requirements, environmental design bases, inservice inspection requirements, and design codes to be applied. Steam lines to and from feedwater turbines should be included in the descriptions. 


\subsubsection{Description}

A description should be provided of the main steam line piping including drawings showing interconnected piping.

\subsubsection{Evaluation}

An evaluation of the design of the main steam line piping should be provided and should include an analysis of the ability to withstand limiting environmental and accident conditions, and provisions for permitting inservice inspections to be performed. Appropriate references should be made to seismic classifications in Chapter 3.

\subsubsection{Inspection and Testing Requirements}

The inspection and testing requirements of the main steam line piping should be described. Describe the proposed requirements for preoperational and inservice inspection of steam-line isolation valves, or crossreference other sections of the SAR where this is described.

\subsubsection{Water Chemistry (PWR)}

A discussion of the proposed secondary side water chemistry and its effectiveness for corrosion control should be included. Also, the effect of water chemistry chosen on the radioactive iodine partition coefficients in the steam generator and air ejector should be discussed.

\subsection{Other Features of Steam and Power Conversion System}

This section of the SAR should provide discussions of each of the principal design features and subsystems of the steam and power conversion system. Because these systems vary in number, type, and nomenclature for various plant designs, the Standard Format does not assign specific subsection numbers to these systems. The applicant should provide separate subsections (numbered 10.4.1 through 10.4.x) for each. These subsections should provide information on:

(1) design bases,

(2) system description,

(3) safety evaluation,

(4) tests and inspections, and

(5) instrumentation applications for each subsystem or feature. 


\subsubsection{Circulating Water System}

The description of the circulating water system should include discussion of performance requirements, dependence upon the system for cooling during shutdown, anticipated operational occurrences and accidents, control of the circulating water chemistry, corrosion, environmental influences and potential interaction of cooling towers, if any, with the plant structure. Cross references to para. 2.4.11.5 and 2.4.11.6 should be provided where applicable.

\subsubsection{Condensate Clean-up System}

The design bases for the condensate clean-up system should include the fraction of condensate flow to be treated, impurity levels to be maintained, and design codes to be applied. The evaluation of the condensate clean-up system should include an analysis of anticipated impurity levels, an analysis of the contribution of impurity levels from the secondary system to reactor coolant system activity levels, and performance monitoring.

\subsubsection{Condensate and Feedwater Systems}

The design bases for the condensate and feedwater systems should include design codes to be applied, criteria for isolation from the steam generator or reactor coolant system, supply of condensate available for emergency purposes inservice inspection requirements, and environmental design requirements. The evaluation of the condensate and feedwater systems should include an analysis of component failure, effects of equipment malfunction on the reactor coolant system, and an analysis of isolation provisions to preclude release of radioactivity to the environment in the event of a pipe leak or break.

\subsubsection{Steam Generator Blowdown Systems (PWR)}

A summary of the design bases for the steam generator blowdown system should include performance requirements, sampling criteria, isolation requirements, design codes to be applied, environmental design bases, and primary-to-secondary leakage limitations. The evaluation of the steam generator blowdown system should include an analysis of radioactivity discharge rates, a failure analysis of system components, system performance during abnormally high primary-to-secondary leakage, and an analysis of steam generator shell-side radioactivity concentration during system isolation. Details of the radiological evaluation for normal operation should be presented in Chapters 11 and 12 . 
The following paragraphs provide examples of subsystems and features that should be discussed, as appropriate to the individual plant, and identify some specific information that should be provided in addition to the items identified above.

\subsubsection{Main Condensers}

The description of the main condensers should include performance requirements, anticipated inventory of radioactive contaminants during power operation and during shutdown, anticipated air leakage limits, contro1 functions which could influence operation of the reactor coolant system, and potential for hydrogen build-up.

\subsubsection{Main Condensers Evacuation System}

The description of the evacuation systems for the main condensers should include performance requirements for start-up and normal operation, anticipated radioactive contamination discharge rates, evaluation of the capability to limit or control loss of radioactivity to the environment, and control functions which could influence operation of the reactor coolant system. The evaluation of the estimate of potential radioactivity leakage to the environment in the event of a malfunction of the turbine gland sealing system should be provided in Chapter 15. Details of the radiological evaluation should be provided in Chapter 11 .

\subsubsection{Turbine Gland Sealing System}

The discussion of the turbine gland sealing system should include identification of the source of non-contaminated steam, a description of potential radioactivity leakage to the environment in the event of a malfunction, and discussion of the means to be used to monitor system performance. The inspection and testing requirements should be described. Details of the radiological evaluation should be provided in Chapter 11.

\subsubsection{Turbine Bypass System}

The design bases for the turbine bypass system should include performance requirements, capability to meet design criteria, design codes to be applied, and environmental criteria. The evaluation of the turbine bypass system should include a failure analysis to determine the effect of equipment malfunctions on the reactor coolant system. 


\subsection{RADIOACTIVE WASTE MANAGEMENT}

The purpose of the information to be provided in this chapter is to provide assurance that the plant has sufficient installed capacity and treatment equipment in the radioactive waste (radwaste) systems to reduce the radioactivity to levels which will not be in excess of the appropriate limits for. the general public or plant personnel and are as low as practicable. Wherever appropriate, summary tables should be provided. When said information is not available at the PSAR stage, or is based on engineering estimates or assumptions, said limitations should be so noted.

\subsection{Source Terms}

The sources of radioactivity which serve as input into the various radioactive waste systems should be defined explicitly. The mathematical model used to determine the specific activity of each isotope in the primary coolant should be given and all assumptions justified. In addition to a presentation of the specific isotopic inventory in the coolant, the isotopic inventory in the fuel plenums and gaps for the entire core should also be presented. The delineation of all the activities in the coolant and in the plenum and gap of the fuel elements should, as a minimum, take into account the power densities of the core, burnups and fuel failure which are consistent with experience and design. State the fraction of plenum and gap activity assumed to be released to the coolant. The fraction which is chosen should be consistent with past experience, heat loadings on the fuel pins and stresses caused by anticipated operational occurrences. Discuss the fuel experience that has been gained for the type of fuel that will be used, including the failure experience, the burnup experience, and the thermal conditions under which the experience was gained. If this information is presented in other sections of the SAR, only cross-referencing is necessary.

If escape rate coefficients are used, a justification of each number used should be presented. The variation of the escape rate coefficients with. power densities and half-life should be presented and justified. The basis upon which each escape rate coefficient is derived should be presented.

A complete derivation and justification of activated corrosion source terms should be presented. All assumptions used in the derivation should be stated. The activation of water and constituents ordinarily found in the makeup to the reactor coolant system should also be taken into account. Production of isotopes (e.g., N-16) should be listed and justified. Previous pertinent experience should be cited. 
The inspection and testing requirements for the steam generator blowdown system should be provided. 
In order to evaluate the adequacy of various ventilation systems, provide estimates of the leakage rate from the reactor coolant system and other fluid systems containing radioactivity. Summarize the sources of leakage and estimate their contribution to the total quantity. Provide estimates of the escape of gases from each leakage source and describe their subsequent transport and release. State and justify all assumptions. Cite previous pertinent experience. Discuss leakage measurements and control methods. The principal discussions of coolant leakage in other sections of the SAR should be cross-referenced.

Identify all sources of radioactive releases which are not normally part of the radioactive waste systems such as steam generator blowdown, containment purging and gland seal leakage. Provide estimates of the escape of such radioactive effluents from each source and describe the subsequent transport and release path.

\subsection{Liquid Waste Systems}

\subsubsection{Design Objectives}

The design objectives of the various liquid waste systems should be stated in terms of expected annual activity releases (by nuclide), and exposures to individuals and the population in light of the requirements of $10 \mathrm{CFR}$ Parts 20 and 50 .

\subsubsection{Systems Descriptions}

The input waste streams into the various subsystems of the radioactive liquid waste system should be identified by nuclide concentration and flow rate on process flow diagrams and/or tables. Concentrations and quantities for both normal operation and for conditions resulting from anticipated operational occurrences should be provided. The source term of radioactivity for each input stream should be identified and justified. Detailed process flow diagrams should be presented; the principal flow paths through each system should be indicated clearly (for example, by use of multi-colored process lines). Provide preliminary piping and instrumentation diagrams of the liquid radwaste system. Indicate the effect of each process on the streams. All bypasses through which waste could circumvent process equipment and be released to the environment and all discharge points to the environment should be indicated clearly. To provide information for use in the evaluations of Chapter 12, those 1ines containing significant radioactivity that are to be field-run should be indicated on the piping and instrumentation diagrams. All systems that are used to reduce levels of radioactivity in liquid effluents should be included. State the capacity and expected decontamination factor for each isotope for each piece of equipment. Cite pertinent previous experience. 


\section{2 .3 System Design}

Describe each piece of equipment, size and/or capacity, through-put rates and storage capabilities. Indicate the design pressure and temperature of each piece of equipment, and cite pertinent previous experience with such equipment. Indicate if the quality classification will be in accordance with Safety Guide 26, and identify and justify each exception.

Indicate seismic classification of equipment and buildings in which it is housed. Assuming failure of all non-Category I (seismic) equipment and annual average meteorology, indicate the computed dose at the site boundary, and justify acceptability of doses.

Show the process instrumentation and the radiation instrumentation on the piping and instrumentation diagram, and describe this instrumentation. If this information is presented in other sections of the SAR, only crossreferencing is necessary.

Provide the design criteria and controls which limit the radiation exposure of operating personnel to a level as low as practicable for lines that normally carry radioactive fluids and that would be field routed.

\subsubsection{Operating Procedures}

Describe the operating procedures that will be used for all liquid radwaste management equipment and cite pertinent previous experience on the effectiveness of such procedures.

\subsubsection{Performance Tests}

Performance tests that will be conducted on individual unit processes and on overall systems on a periodic basis to verify the decontamination factors and other aspects of a given design should be stated. Cite pertinent previous experience with such tests, including specific isotope removals.

\subsubsection{Estimated Releases}

The expected releases from the liquid radwaste system in curies per year per nuclide should be stated separately for each liquid system. The expected releases should cover normal operation and anticipated operational occurrences. Compare the expected releases of liquid effluents with those in the Technical Specifications and with the design objective. 


\section{2 .7 Release Points}

All release points from the liquid radwaste systems to the environment should be identified clearly on process flow diagrams, on general arrangement drawings, and on a site plot plan.

\subsubsection{Dilution Factors}

All dilution, dispersion or concentration factors and pathways that are used in evaluating the release of radioactive effluents should be stated and justified. Plans to recirculate effluents from discharge to intakes or to achieve internal dilution prior to discharge should be described. Major discussions of dilution factors in other sections of the SAR (e.g., perhaps section 2.4.12) should be cross-referenced.

\subsubsection{Estimated Doses}

Estimate the following doses at the boundary of the restricted area (or other point if appropriate justification is provided pursuant to $10 \mathrm{CFR}$ 20.106) that would be received by the general public as a result of releasing the radioactive effluents by the paths and with the dilution factors mentioned above:

(1) The maximum whole body dose to an individual (mrem/yr);

(2) The maximum organ dose to an individual (mrem/yr);

(3) The whole body dose to the population (mrem/yr).

\subsection{Gaseous Waste Systems}

\subsubsection{Design Objectives}

The design objectives of the various gaseous waste systems should be stated in terms of expected annual activity releases (by nuclide) and exposures to individuals and the population, in the light of the requirements of $10 \mathrm{CFR}$ Parts 20 and 50 . As used in this section, gaseous waste includes noble gases and airborne halogens and particulates.

\subsubsection{Systems Descriptions}

The input waste streams into the various subsystems of the radioactive gaseous waste system should be identified by nuclide concentration and flow rate on process flow diagrams and/or tables. Concentrations and quantities for both normal operating and conditions resulting from anticipated 
operational occurrences should be provided. The source term of radioactivity for each input should be presented; the principal flow paths through each system should be indicated clearly (for example, by use of multi-colored process lines). Provide preliminary piping and instrumentation diagrams of the gaseous radwaste system. Liquid seals should be properly shown, including a description of precautions taken so as not to lose the liquid seals permanently. Explain how special considerations (e.g., filling of the charcoal tanks) have been resolved. Vents and secondary flow paths for each system should be indicated. All bypasses through which waste could circumvent process equipment and be released to the environment and all discharge points to the environment should be indicated clearly. All ducting and piping containing significant radioactivity that is to be field run should be indicated on the process flow diagrams. All systems used to reduce levels of radioactivity in gaseous effluents should be included. State the capacity and expected decontamination factor for each isotope for each piece of equipment. Cite pertinent previous experience concerning the effectiveness of these systems.

\section{$11.3 .3 \quad$ System Design}

Describe each piece of equipment, size and/or capacity, through-put rates and storage capabilities. Indicate the design pressure and temperature of each piece of equipment, and cite pertinent previous experience with such equipment. Indicate if the quality classification of the equipment will be in accordance with Safety Guide 26, and identify and justify each exception. Identify and justify equipment that is not designed to withstand a hydrogen explosion.

Indicate the seismic classification of equipment and buildings in which it is housed. Assuming failure of all non-Category I (seismic) equipment and annual average meteorology, indicate the computed dose at the site boundary, and justify the acceptability of doses.

Show the process instrumentation (including hydrogen analyzers) and radiation instrumentation on the piping and instrumentation diagrams, and describe this instrumentation. If this information is presented in other sections of the SAR, only cross-referencing is necessary.

Provide the design criteria and controls which limit the radiation exposure of operating personnel to a level as low as practicable for lines that normally carry radioactive fluids and that would be field routed.

$11 \cdot 3-2$ 


\subsubsection{Dilution Factors}

All dilution factors which are used in evaluating the release of gaseous radioactive effluents should be stated and justified.

\subsubsection{Estimated Doses}

Estimate the following at the boundary of the restricted area (or other point if appropriate justification is provided pursuant to $10 \mathrm{CFR} 20.106$ ) doses that would be received by the general public as a result of releasing the radioactive effluents by the paths and with the dilution factors mentioned above:

(1) The maximum whole body dose to an individual (mrem/yr);

(2) The maximum organ dose to an individual from halogens and particulates (mrem/yr);

(3) The whole body dose to the population (mrem/yr).

Tabulate all sources of radioactive release points, and the contribution of each source to the yearly dose at the boundary. Discuss the assumptions made in the calculations to attain the cited values.

\subsection{Process and Effluent Radiological Monitoring Systems}

A complete description should be given for liquid and gaseous systems separately. Provide summary tables as appropriate. (See AEC Safety Guide 21.)

\subsubsection{Design Objectives}

State the design objectives of the radiological monitoring systems for normal operation and anticipated operational occurrences in relation to the requirements of 10 CFR Parts 20 and 50, and AEC General Design Criterion 64. Distinguish the differences between the design objectives for these situations and those for accident situations. Include considerations related to postulated accidents releases and of redundancy, range, independence, and diversity of components.

\subsubsection{Continuous Monitoring}

For each possible location of effluent release monitoring provide: 


\subsubsection{Operating Procedures}

Describe the operating procedures to be used for gaseous waste systems and cite pertinent previous experience on the effectiveness of such procedures.

\subsubsection{Performance Tests}

Performance tests that will be used on a periodic basis to verify the decontamination factors and other aspects of a given design should be stated. Cite pertinent previous experience with such tests.

\subsubsection{Estimated Releases}

The expected releases from the gaseous waste systems in curies per year per nuclide should be stated separately for each system. The expected releases should cover normal operation and anticipated operational occurrences. Compare the expected releases of gaseous effluents with those in the Technical Specifications and with the design objective.

\subsubsection{Release Points}

All release points of gaseous waste to the environment should be identified clearly on process flow diagrams, on general arrangement drawings, and on a site plot plan.

For high stacks, provide:

(1) base elevation,

(2) orifice elevation,

(3) orifice inside diameter,

(4) effluent velocity, and

(5) heat input.

For building vents, provide a general description of the vent including (1) shape, (2) effluent velocity, and (3) heat input. 
(1) the basis for selecting the location;

(2) the expected concentrations or radiation levels;

(3) the quantity to be measured (e.g., external radiation level, gross concentration, isotopic concentration);

(4) the detector type, sensitivity and range, considering items (1), (2) and (3) above, and, for remote devices, the type and arrangement of the sampler and estimates of sampling line interferences or losses;

(5) setpoints and the bases for their selection; and

(6) the type and locations of annunciators and alarms, and the system or operator actions which they initiate.

\section{$11.4 .3 \quad$ Sampling}

For each location subject to periodic sampling, provide:

(1) the basis for selecting the location;

(2) expected composition and concentrations;

(3) the quantity to be measured (e.g., gross or 1sotopic concentrations);

(4) sampling frequency and procedures;

(5) analytical procedure and sensitivity;

(6) influence of results on plant operations; and

(7) expected flow.

\subsubsection{Inservice Inspection, Calibration, and Maintenance}

For every instrument or logical grouping of instruments, as appropriate, describe the procedures governing inservice inspection, calibration, and maintenance. Also describe the arrangements for obtaining independent audits and verifications. 


\subsection{Solid Waste System}

This section should describe in detail the solid radwaste capabilities of the plant.

\subsubsection{Design Objectives}

The design objectives of the solid radwaste system should be stated in terms of volumes, forms and activities, and the radiation levels that can be accommodated.

\subsubsection{System Inputs}

The assumed system inputs based on volume or weight and isotopic inventories (curies) should be derived and justified. The inventories should be consistent with source terms presented under Section 11.1. Liquid and solid input streams should be identified on a detailed process flow diagram. A detailed process flow diagram for the total solid radwaste system should be presented.

\subsubsection{Equipment Description}

A description should be presented of all the equipment in the solid radwaste system. Capacities, through-put rates and storage capabilities should be stated. The operating procedures which will be followed in the utilization of the solid radwaste equipment should be stated. Cite pertinent previous experience with such equipment.

Provide the design criteria and controls which limit the radiation exposure of operating personnel to a level as low as practicable.

\subsubsection{Expected Volumes}

The expected volumes of solid wastes, the associated curie content and the principal nuclides that will be shipped from the site should be derived and justified. Experience from similar plants already operating should be presented.

\section{$\underline{11.5 .5 \quad \text { Packaging }}$}

The packaging containers of the solid radwastes should be defined in detail including the type of container, the manner in which it is to be packed and the permissible levels of activity. Indicate conformance with applicable standards. 


\subsubsection{Storage Facilities}

A detailed description should be presented of the storage facilities available for packaged solid radwastes including capacity, exact location on a plot plan and general arrangement and details for removal of the solid radwastes. State the expected onsite storage period and the decay realized by such storage.

\subsubsection{Shipment}

The manner in which the radwastes will be shipped from the site should be stated. The allowed locations on the site where the shipping containers or vehicles may be stored should be identified.

\subsection{Offsite Radiological Monitoring Program}

Describe the monitoring program with respect to its capability to determine, in conjunction with effluent monitoring, estimates of individual and population exposure beyond the site boundary, at the design and accident levels of radiation and radioactive effluents. Wherever appropriate, differences between the preoperational and operational programs should be delineated.

\subsubsection{Expected Background}

Enumerate the expected (or measured) background levels of radiation and radioactivity (and their variation in time and space), both from natural and man-made sources.

\subsubsection{Critical Pathways}

Based on the particular environment (e.g., hydrology, meteorology, ecology, resource utilization) and using expected liquid and gaseous releases (provided elsewhere in this chapter), describe the pathways of human exposure from plant operation and from accidents likely to account for most of the exposure. Provide the mathematical models to be used to make exposure estimates, and describe the effluent and environmental monitoring data which will be taken to confirm the critical pathways. List and justify all assumptions made, or relevant information to be developed (e.g., reconcentration factors, food consumption rates). 


\subsubsection{Sampling Media, Locations and Frequency}

Provide the basis for the choice of sampling media, sampling locations, and frequency of sampling in the light of 11.6 .1 and 11.6.2. (The complete program need not be presented here, but must appear in the appropriate section of the Technical Specifications.)

\section{6 .4 Analytical Senstivity}

Describe the size and physical characteristics of each type of sample, the kinds of radiological analyses to be performed and the measuring equipment to be used, and derive and justify the sample detection sensitivity.

\subsubsection{Data Analysis and Presentation}

Describe the kinds of mathematical and statistical analyses to be performed on the resultant data, and give an indication of the type of format to be used in the presentation of results.

\subsubsection{Program Statistical Sensitivity}

Derive and justify, in the light of the parameters described above, the overall statistical sensitivity of the program to achieve its objectives of estimating probable exposures to man from plant operation and from accidents. 


\subsection{RADIATION PROTECTION}

The purpose of the information to be provided in this chapter is to permit a determination that external and internal radiation exposures to persons at the site boundary and to plant personnel from plant operation, including anticipated operational occurrences, and from postulated accidents will be kept as low as practicable and within applicable limits.

\subsection{Shielding}

\subsubsection{Design Objectives}

Describe the design objectives of plant shielding for normal operation, including anticipated operational occurrences, with respect to meeting the requirements of $10 \mathrm{CFR}$ Parts 20 and 50 . The maximum and average external dose rates from normal operation, including anticipated operational occurrences, that will be allowed at the boundary of the restricted area and in areas within the plant where plant personnel, construction workers or site visitors are permitted should each be identified.

\subsubsection{Design Description}

Provide scaled layouts and cross sections of buildings that contain process equipment for treatment of radioactive fluids. In the FSAR provide a detailed plot plan showing the total plant layout within the site boundary, and explicitly identifying all outside storage areas and the location of railroad spurs or sidings.

Describe design criteria for the erection and dimensions of shield walls, for penetrations through shield walls, and for acceptable radiation levels in the control room, at valve stations, sample stations and other areas likely to be occupied during normal operational and maintenance activities. Provide justification of the thickness of shielding to be provided, including the geometric and physical models, and assumptions and data used.

To permit evaluation of the capability of the control room to meet AEC General Design Criterion 19, a layout drawing of the control room should be provided. Scaled isometric views of the control room and descriptions of all shielding required to maintain habitability of the control room during the course of accidents should be provided. Provide justification of the thickness of shielding to be provided, including the geometric and physical models, and assumptions and data used.

$$
12 \cdot 0-1
$$




\subsubsection{Source Terms}

The total quantity of the principal nuclides in process equipment that contains or transports radioactivity should be identified as a function of operating history. Expected maximum and average values of the radioisotopic inventory should be stated. The sources should be consistent with those presented in Chapter 11. Provide an estimate of dose rate at the site boundary per curie of stored waste (including shipping casks).

Other radioactive items that are not clearly assignable to the above categories should be listed in this section and evaluated similarly. For Instance, the contribution to exposure of Nitrogen-16 from the turbine building should be considered here.

Identify the steps taken to assure that field run process piping that may carry radioactive materials is so designated and routed with appropriate regard for minimizing radiation exposures to plant personnel.

\subsubsection{Area Monitoring}

Provide the locations and design criteria of the types of instruments to be used for area radiation monitoring, and the criteria used to determine the necessity for and location of the equipment. In the FSAR describe their operational characteristics, including type of detector, sensitivity, range, method of calibration, setpoints (and their bases), and the location and type of annunciators and alarms (and the system or operator actions they initiate), and describe the maintenance and calibration programs to be followed. Provide the type and location of power sources, and indicating and recording devices. Indicate the manner in which data will be recorded. Include accident considerations and other needs for high ranges of instruments.

\subsubsection{Operating Procedures}

Describe the operating procedures to assure that external exposures will be kept as low as practicable during plant operation and maintenance. Cite relevant previous experience on the effectiveness of such procedures.

\section{1 .6 Estimates of Exposure}

Provide a summary of the estimated peak external dose rates and annual doses at selected in-plant locations, at the boundary of the restricted area, at visitor centers and in the control room, from normal operation including 
anticipated operational occurrences and maintenance activities. Provide an estimate of the yearly man-rem exposures from the plant as designed. Compare the estimated doses with experience from relevant operating plants.

\subsection{Ventilation}

\subsubsection{Design Objectives}

Describe the design objectives of the plant ventilation systems for normal emergency operation, Including anticipated operational occurrences, with respect to meeting the requirements of $10 \mathrm{CFR}$ Parts 20 and 50 . The final designs should be submitted in the FSAR.

The maximum and average airborne radioactivity levels for normal operation, including anticipated operational occurrences, that will be allowed in areas within plant structures and within the restricted area where plant personnel, construction workers, or site visitors are permitted should each be identified.

\subsubsection{Design Description}

Provide as complete a description as possible of the ventilation system for each building which can be expected to contain radioactive materials.

The description should include building volumes, expected flow rates, and filter characteristics, and the design criteria on which these are based. Reference to appropriate sections of Chapter 9 may suffice.

Provide a separate description of the control room ventilation system to permit evaluation of its capability to meet AEC General Design Criterion 19 with respect to inhalation dose. Indicate the locations of air intakes and describe filter characteristics. Reference to appropriate sections of Chapter 9 may suffice.

\subsubsection{Source Terms}

In addition to the information provided in Section 12.1 .3 , also provide estimates of equipment leakage resulting in airborne radioactivity within plant buildings. Reference to appropriate sections of Chapter 11 may suffice. 


\subsubsection{Airborne Radioactivity Monitoring}

Provide the locations and design criteria of the types of fixed instruments to be used for airborne radioactivity monitoring, and the criteria used to determine the necessity for and location of the equipment. In the FSAR describe their operational characteristics, including sampling lines (if any), detector type, sensitivity, range, and calibration; filter characteristics; type and location of power sources and indicating and recording devices; setpoints and their bases; type and location of annunciators and alarms and the system or operator actions they initiate; and the maintenance and calibration programs to be followed. Describe any special portable instrument or grab sample methods used to check the fixed system. Indicate the manner in which data will be recorded. Considerations should include normal plant operation, including anticipated operational occurrences, and postulated accident conditions.

\subsubsection{Operating Procedures}

Provide a description of plant operating procedures to assure that onsite inhalation exposures will be kept as low as practicable during plant operation and maintenance. In the FSAR the description should be detailed. Cite relevant previous experience on the effectiveness of such procedures.

\subsubsection{Estimates of Inhalation Doses}

The expected annual inhalation doses to plant personnel and peak air concentrations should be estimated for each building in the plant. The estimates should be compared with experience from relevant operating plants. Describe the methods used and list and justify all assumptions.

\subsection{Hea1th Physics Program}

\subsubsection{Program Objectives}

Describe the health physics program organization and objectives.

\subsubsection{Facilities and Equipment}

Describe the design criteria for the available health physics facilities and equipment, including handling methods and special shielding for external protection; respiratory equipment and protective clothing; and portable and laboratory equipment. In the FSAR, provide the final design details including the operational characteristics, sensitivities, calibration and maintenance procedures and locations. 


\subsubsection{Personne1 Dosimetry}

Describe the methods, equipment and procedures for external and internal dosimetry of plant personnel, including sensitivity, calibration, processing and recording. In the FSAR the description should be detalled. 


\subsection{CONDUCT OF OPERATIONS}

This chapter of the SAR should provide information relating to the framework within which operation of the plant will be conducted.

The operation of the plant entails a myriad of instructions and procedures of varying detail for the operating staff. The details of such procedures should not be included in the SAR, but information should be provided to indicate generally how the applicant intends to conduct operations, and to assure that the licensee will maintain a technically competent and safety-oriented staff.

\subsection{Organizational Structure of Applicant}

\subsubsection{Corporate Organization}

This section should describe the structure and qualifications of the applicant's and its contractors' corporate organizations. The following specific information should be included.

13.1.1.1 Corporate Functions, Responsibilities and Authorities Corporate functions, responsibilities and authorities with respect to plant design, construction, quality assurance, testing, operation and other applicable activities should be described.

13.1.1.2 Applicant's In-house Organization - A description should be provided of the applicant's corporate management and technical support staffing and in-house organizational relationships established for the design and construction review and quality assurance functions, and of the responsibilities and authorities of personnel and organizations described in 13.1.1.1 above.

13.1.1.3 Interrelationships with Contractors and Suppliers - The working interrelationships and organizational interfaces among the applicant, the nuclear steam supply system manufacturer, the architect-engineer, and other suppliers and contractors should be described. 
13.1.1.4 Applicant's Technical Staff - The SAR should include a description of the applicant's corporate (home office) technical staff specifically supporting the operation of the nuclear plant, including a description of the duties, responsibilities, and authority of the "Engineer in Charge" (as defined in ANSI N18.1) and the assigned engineering technical staff, including numbers of personnel, qualifications, educational backgrounds (disciplines) and technical experience. Technical support to the corporate technical staff may be provided by the use of outside consultants. If such arrangements are to be used, the specific areas of responsibility and functional working arrangements of these support groups should be provided.

\subsubsection{Operating Organization}

This section should describe the structure, functions and responsibilities of the operating organization. The following specific information should be included.

13.1.2.1 Plant Organization - Provide a comprehensive description of the plant organizational arrangement (organization chart) to show the title of each position in the operations, technical and maintenance groupings, the number of persons assigned to common or duplicate positions (technicians, shift operators, health physicists, repairmen) and the positions requiring licenses in accordance with 10 CFR Part 55.

13.1.2.2 Personne1 Functions, Responstbilities and Authorities The functions, responsibilities and authorities of all personnel positions should be described, including a specific succession to responsibility for overall operation of the plant in the event of absences, incapacitation of personnel or other emergencies.

13.1.2.3 Shift Crew Composition - Describe the proposed shift crew composition Including position titles, license qualifications and number of personnel on each shift (the number of reactors and generating units, and the plant and control room layout bear a relationship to shift crew composition).

\subsubsection{Qualification Requirements for Nuclear Plant Personne1}

This subsection should describe the proposed minimum qualification requirements for onsite plant personnel. It is expected that these qualification requirements will meet or exceed the minimum qualification 
requi rements set forth in the current ANSI N18.1 document, "Standard for Selection and Training of Personnel for Nuclear Power Plants." If this is not the case, justification should be provided.

The following specific information should be included.

13.1.3.1 Minimum Qualification Requirements - The minimum qualification requirements should be stated for all plant operating, technical and maintenance support personnel (Plant Superintendent/Plant Manager or equivalent down through licensed and non-licensed plant operators, health physicists, technicians and repairmen).

13.1.3.2 Qualifications of Plant Personnel - The qualifications of the initial appointees to (or incumbents of) these positions should be presented in resume format for all plant managerial and supervisory technical personnel (operating, technical and maintenance). The resumes should identify Individuals by position title and, as a minimum, should describe the formal education, the training, and the experience (including prior AEC 1icensing) of the individuals. If at the time of SAR submittal certain positions are vacant, the schedule for filling those positions should be provided and, as the positions are filled, the resumes should be added to the SAR by amendment. Provide complete staff qualifications (FSAR).

\subsection{Training Program}

\subsubsection{Program Description}

A degcription of the proposed nuclear training program in nuclear and other subjects important to safety should be provided. The FSAR should provide a description of the training program as it was actually carried out, noting any changes from that described in the PSAR. The FSAR should be revised when the program is changed or upgraded significantly. Guidance on the required training is available in ANSI N18.1 and the AEC Licensing Guide, "Operating Licenses, Division of Reactor Licensing," November 1965. The following specific information should be included.

\subsubsection{Program Content - The program description should in-} clude the proposed subject matter content of the formal training program in nuclear and other subjects important to safety (related technical training) for Licensed Senior Reactor Operator (SRO) and Licensed Reactor Operator (RO) candidates, the length of time to be devoted to each aspect of the training program, and plans for retraining to remain current. 
13.2.1.2 Coordination with Preoperationa1 Tests and Fuel Loading A chart should be provided to show the schedule of each part of the training program for each functional group of employees in the organization in relation to the schedule for preoperational testing and fuel loading.

13.2.1.3 Practical Reactor Operation - Practical (on-the-job) plant operation to be included as a part of the nuclear training program for RO and SRO candidates should be described, with the length of time to be devoted to this aspect of the training program.

13.2.1.4 Reactor Simulation Training - Plant simulator training to be included as a part of the nuclear training program for RO and SRO candidates (if applicable) should be described with the length of time devoted to such training.

13.2.1.5 Previous Nuclear Training - Any previous nuclear training allowable to RO and SRO candidates, such as U. S. Navy Nuclear Power Training Program or other experience that may establish eligibility for RO or SRO license examination, should be described.

13.2.1.6 Other Scheduled Training - Other formal (on-the-job) training programs to be provided for RO and SRO candidates (e. g., preoperational testing, startup,) should be described.

13.2.1.7 Training Programs for Non-licensed Personnel - Training programs to be provided for personnel not requiring licenses (certain managers, supervisors, operators, health physicists, technicians and repairmen) should be described.

13.2.1.8 General Employee Training - General employee training to be provided to all persons regularly employed in the plant should be described.

13.2.1.9 Responsible Individual - State the position title of the individual responsible for conduct and administration of the plant training program.

\subsubsection{Retraining Program}

A description of the retraining program should be provided in the FSAR, and should include the applicable items in 13.2.1 and the frequency with which retraining is accomplished. 


\subsubsection{Replacement Training}

A description of the replacement training program should be provided in the FSAR and should include the items in 13.2.1 above.

\subsubsection{Records}

Describe provisions for maintaining records of qualifications, experience, training and retraining for each member of the plant organization. The documents should also describe the methods to be used for evaluating training program effectiveness.

\subsection{Emergency P1anning}

This section of the SAR should describe the applicant's plans for coping with emergencies. The information to be included is described in Section 50.34 (a)(10) of $10 \mathrm{CFR}$ Part 50. The minimum items to be discussed are set forth in 10 CFR Part 50, Appendix E - Emergency Plans for Production and Utilization Facilities - Section II.

The information to be included in the FSAR is described in Section 50.34 (b) (6)(v) of $10 \mathrm{CFR}$ Part 50. The minimum items to be discussed in the FSAR are set forth in $10 \mathrm{CFR}$ Part 50, Appendix E, Sections III and IV. Guidance on emergency planning is available in "Guide to the Preparation of Emergency Plans for Production and Utilization Facilities," December 1970, U. S. Atomic Energy Commission.

\subsection{Review and Audit}

This section should describe the applicant's program for assuring the performance of independent review and audit of plant operations in order to determine if the plant is being operated safely and within the terms of the license. Although this is often performed by the committee method, particularly by applicants initially embarking on a nuclear commitment, the use of committees is only one approach to review and audit. What is important is that the proper technical capability be provided and that the organization and allocation of responsibility and authority be such that review and audit is responsibly performed in a manner which assures independence of reviewers from line responsibility for plant operation. Guidance on the essential elements of a satisfactorily comprehensive review and audit program is available in the proposed standard ANS 3.2, "Standard for Administrative Controls for 
Nuclear Power Plants," Draft No. 7, March, 1972. Section 4.1 of ANS3.2 points out that organizational approaches to providing the review and audit function may differ. Applicants should not draw the inference from the discussion of the committee approach in the following sections that other review and audit techniques are unacceptable.

\subsubsection{Review and Audit - Construction}

If the applicant proposes to use a review and audit committee or a nuclear design review board during the design and construction of the plant as part of the quality assurance program, the SAR should include a written charter for the review and audit group describing the group's responsibilities and administrative procedures. If, on the other hand, a designated organizational unit is to provide the review and audit function, a similar description of the administrative procedures used to assure the timely and comprehensive review of matters within the purview of the unit should be provided.

The description of administrative procedures for organizational units, including the charters of any committees, should include the subjects within the purview of the review, and the mechanism for convening review meetings (if not always periodic). The charter should indicate the provision for the use of subgroups and consultants, and for the use of sequential or parallel reviews of multi-discipline subjects by Individual specialists in lieu of scheduled meetings of the group, when such sequential or parallel reviews are proposed. The responsibility for appointment of the group should be designated and the time (in relation to scheduled fuel loading) that the group will be appointed and functional should be stated. Describe the responsibility and authority of the group and the requirements for recording, reporting, approval and dissemination of meeting minutes or other reports of its activities.

\subsubsection{Review and Audit - Test and Operation}

In the FSAR, the information indicated in 13.4 .1 should be provided and the following additional information added:

(1) The composition of the group (numbers and qualifications) established to audit and evaluate both personnel and equipment should be stated. The measures to prevent degradation of the qualifications of the review and audit groups should be described, including alternate members who may serve in lieu of regular members (usually in the form 
of minimum qualifications requirements for various technical specialties or disciplines associated with nuclear power plant). Where outside consultants are used on the review and audit group, qualifications and active participation, including voting rights, should be delineated.

(2) The meeting frequency should be stated.

(3) The quorum required to conduct business and designation of non-voting members, if any, should be stated.

\subsection{Plant Procedures}

The SAR should include a commitment to conduct safety-related operations by detailed written procedures. In addition, the FSAR should include a 1ist of titles of procedures (that indicate clearly their purpose and applicability), and a description of the review, change and approval procedures for all plant operating, maintenance, and testing procedures.

Guidance regarding implementation of plant procedures is contained in the proposed standard ANS 3.2.

\subsection{Plant Records}

\subsubsection{Plant History}

The SAR should include a commitment to keep a recorded history of the plant, in accordance with 10 CFR Part 50, Appendix B, Section XVII, Quality Assurance Records. Further guidance regarding maintenance of plant records is provided in the proposed standard ANS 3.2.

\subsubsection{Operating Records}

The FSAR should describe provisions for maintaining operating records such as power levels, and records of principal maintenance activities and of abnormal occurrences for specified periods of time (usually 5 to 6 years).

\subsubsection{Event Records}

Provisions should be described in the FSAR for maintaining records of occurrences such as radioactive releases and environmental surveys, which are generally kept for the service life of the plant. 


\subsection{Industria1 Security}

This section should describe the applicant's plans for protection against industrial sabotage. Guidance is contained in AEC Safety Guide 17, "Protection Against Industrial Sabotage" and in the proposed standard ANS 3.2. Detailed security measures for the physical protection of the facility against industrial sabotage should be withheld from public disclosure as provided in Section 2.790 of 10 CFR Part 2.

\subsubsection{Personnel and Plant Design}

This subsection of the SAR should describe the organization, administration, and conduct of the industrial security program. Describe those features of the plant design and arrangement that enhance industrial security and reduce the vulnerability of the plant to deliberate acts which may adversely affect the plant and public safety.

Describe personnel selection policies, employee performance and evaluation procedures, and the industrial security training program used to assure that reliable and emotionally stable personnel are selected, maintained, and assigned to the plant staff.

\subsubsection{Security Plan}

The FSAR should include the following additional information.

13.7.2.1 Access Control - Means for control of access should be described, including administrative and physical controls for personnel and material, such as: security measures to be employed at the exclusion area radius or site boundary, entrances to the reactor control room, building, containments, vital equipment areas and rooms where intentional or unintentional manipulations of controls or other actions would seriously affect plant operations and safety; alarm and electrical/ electronic protection and surveillance systems or devices; provisions for the manning and operation of access control points.

13.7.2.2 Control of Personnel by Categories - Measures should be described for the control of personnel by categories such as general visitors, utility employees not members of the regular plant staff, contractor and vendor personnel, and plant staff, including personnel monitoring and accountability controls. 
13.7.2.3 Access Control During Emergencies - Describe the general methods of controlling access in emergencies such as fires and industrial accidents (i.e., compatibility of industrial security plan with emergency plans and procedures).

13.7.2.4 Surveillance of Vital Equipment - Describe the program for surveillance and monitoring of vital equipment, components and sensitive materials such as nuclear fuel and radioactive sources. The description should include the methods established for detecting physical changes in the status of equipment, components or materials on a periodic basis, such as the operational availability of engineered safeguards, valve positions and inspection of nuclear fuel upon receipt.

13.7.2.5 Potential Security Threats - Discuss measures for dealing with potential security threats and the liaison developed with Federal, state and local law enforcement agencies. This section should include statements regarding reporting to the Commission incidents involving at tempted or actual breach of industrial security controls or attempted acts of sabotage.

13.7.2.6 Administrative Procedures - Describe administrative procedures developed for investigation of security incidents, reports and audits of the industrial security program. 


\subsection{INITIAL TESTS AND OPERATION}

This chapter of the SAR should provide information relating to the period of initial operation, with particular emphasis on tests planned to demonstrate the degree to which the plant does, in fact, meet the design criteria. Explanations for any special limits, conditions, surveillance requirements, and procedures to be in force during the initial period of operation and until such time as acceptable design performance is demonstrated should be included.

Throughout other parts of the SAR, limits, conditions, surveillance requirements, and procedures for plant operation may have been established. For some plants, however, these may be made more restrictive during the period of initial operation and relaxed to their final condition only as actual operation demonstrates their acceptance from a safety viewpoint. Such matters should be discussed in this chapter.

\subsection{Test Program}

This section of the SAR should Include a discussion of the preoperational testing program including its objectives, a list of test titles, and a schedule of test sequence, in accordance with the guidance contained in the AEC document "Guide for the Planning of Preoperational Testing Programs." This section should also include a discussion of intial fuel loading and the startup and power ascension program including a list of tests and a schedule of test sequence, in accordance with guidance contained in the AEC document "Guide for the Planning of Inftial Startup Programs." Further guidance on testing is contained in proposed standard ANS 3.2, and in 10 CFR Part 50, Appendix B, Criterion XI, "Test Contro1."

The following specific information should be included.

\subsubsection{Administrative Procedures (Testing)}

Describe the system used for preparing, reviewing, approving and executing all testing procedures and instructions and for evaluating, documenting and approving the test results, including the organizational responsibilities and personnel qualifications for the applicant and his contractors.

\subsubsection{Administrative Procedures (Modifications)}

The administrative procedures should be described for incorporating any needed system modifications or procedure changes, based on the results of 
the tests (e.g., test procedure inadequacies or test results contrary to expected test results).

14.1.3 Test Objectives and Procedures (FSAR)

Describe the test objectives and the general methods for accomplishing these objectives, the acceptance criteria that will be used to evaluate the test results, and the general prerequisites for performing the tests, including special conditions to simulate normal and abnormal operating conditions of the tests listed.

\subsubsection{Fuel Loading and Initial Operation (FSAR)}

Discuss the procedures that will guide fuel loading, attainment of initial criticality, and ascension to power, including safety and precautionary measures to be used to assure safe operation of the plant.

\subsubsection{Administrative Procedures (System Operation) (FSAR)}

Describe the methods that will be used during the preoperational testing and initial operation period to demonstrate the adequacy and feasibility of normal and emergency operating procedures. Reference to appropriate sections of Chapter 13 may suffice.

\subsection{Augmentation of Applicant's Staff for Initial Tests and Operation (FSAR)}

This section should describe the applicant's plans for the assignment of additional personnel to supplement his staff during startup and power testing. Guidance on the required staff expansion is contained in "Guide to the Planning of Preoperational Testing Programs" and in "Guide for the Planning of Initial Startup Programs." The following specific information should be provided.

\subsubsection{Organizational Functions, Responsibilities and Authorities}

The functions, responsibilities and authorities of the various organizations established as augmenting organizations to the applicant's normal operating organization during initial tests and operations should be described.

\subsubsection{Interrelationships and Interfaces}

The working interrelationships and organizational interfaces of all augmenting groups during the initial tests and operations should be specified. 
14.2.3 Personnel Functions, Responsibilities and Authorities

The functions, responsibilities and authorities of key augmenting personnel positions should be described.

\subsubsection{Personnel Qualifications}

The qualifications of the appointees to the positions above should be presented. Resumes are acceptable means of providing this information. 


\subsection{ACCIDENT ANALYSES}

The evaluation of the safety of a nuclear power plant is accomplished, in part, by analyses made of the response of the plant to postulated disturbances in process variables and to postulated malfunctions or failures of equipment. Such safety analyses provide a significant contribution in the selection of the design specifications for components and systems from the standpoint of public health and safety. These analyses are a focal point of the Commission's construction permit and operating license reviews of plants.

In previous chapters of the SAR, the structures, systems, and components important to safety should have been evaluated for effects of anticipated process disturbances and for susceptibility to malfunctions and failures. In this chapter, it is expected that the consequences of certain of those failures and abnormal situations will be examined to evaluate the capability built into the plant to control or accomodate such failures and situations (or to identify the limitations of expected performance).

It is recognized that situations analyzed may range from an anticipated operational occurrence (such as a loss of electrical load resulting from a line fault) to postulated accidents of low probability (such as the sudden $108 s$ of integrity of a major component). They should include an accident whose consequences are not exceeded by any other accident considered credible in order that the site evaluation required by $10 \mathrm{CFR}$ Part 100 may be conducted.

Table 15-1 lists events that are representative of those that should be evaluated by the applicant in this chapter of the SAR. The applicant should list the events that have been considered and provide the information indicated in the following sections.

\subsection{General}

This section should provide a brief discussion of the principles and general philosophy upon which the analyses are based, and an explanation of any significant differences in approach or scope from that presented in this guide.

The evaluation of each event should be presented in a separate sequentially number subsection (1.e., 15.1.1 through 15.1.X) containing at least the following information: 


\subsection{Event Evaluation}

15.1.X.1 Identification of Causes - For each event evaluated there should be included a description of the occurrences that lead to initiating the event under consideration and the bases upon which credibility or probability of each occurrence in the sequence is determined.

The following should be provided:

(1) Starting conditions and assumptions.

(2) A step-by-step sequence of the course of each accident identifying all protection systems required to function at each step.

(3) Identification of any operator actions necessary.

The discussion should show the extent to which reactor protective systems must function, the effect of failure of protective functions, the credit taken for designed-in safety features, reactor protective characteristics, and the performance of backup protective systems, during the entire course of the event analyzed. The discussion should also include credit taken for the functioning of other systems (e.g., control) and consequences of failure.

The analyses given should be such as to permit an independent evaluation of the adequacy of the protection system as related to the event under study. The results can be used to determine which functions, systems, interlocks, and controls are safety related and what readouts are required by the operator under anticipated operational occurrence and accident conditions.

15.1.X.2 Analysis of Effects and Consequences - The analysis of effects and the attendant consequences should be supported by sufficient information, including, for example:

(1) The methods, assumptions, and conditions employed in estimating the course of events and the consequences. Include here a discussion of the method of detection and the time required by the human operator or automatic equipment to evaluate the occurrence and isolate the system or take other remedial action. 
(2) The mathematical or physical model employed, describing any simplification or approximations introduced to perform the analyses. The applicable parameters of those listed in Table 15-2 should be provided in tabular form. The table should show two columns. One column should indicate the conservative assumption used in postulated accident calculations while the other indicates what the applicant believes to be realistic assumptions. If the conservative assumptions are known to differ from those used by the staff, the staff assumptions should also be tabulated.

(3) Identification of any digital computer program or analog simulation used in the analysis with principal emphasis upon the input data and the extent or range of variables investigated. This information should include figures showing the analytical model, flow path identification, actual computer listing, and complete listing of input data. The detailed description of mathematical models and digital computer programs or listings are preferably included by reference (to documents available to the AEC) with only summaries provided in the SAR text.

(4) Describe the physical or mathematical models used in the analyses and the bases for their use with specific reference to:

(a) the distribution and fractions of fission product inventory assumed to be released from the fuel,

(b) The concentrations of radioactive or fission product inventory airborne in the containment atmosphere and buildup on filters during the post-accident time intervals analyzed,

(c) the conditions of meteorology, topography or other circumstances, and combinations of adverse conditions, considered in the analyses.

(5) Identify the time-dependent characteristics, activity, and release rate of the fission products, or other transmissible radioactive materials within the containment system that could escape to the environment via leakages in the containment boundaries and leakage through lines that could exhaust to the environment.

(6) The considerations of uncertainties in calculational methods, in equipment performance, in instrumentation response characteristics, or other indeterminate effects taken into account in the evaluation of the results. (see paragraph (2) above.) 
(7) Explain the conditions and assumptions associated with the events analyzed, including any reference to published data or research and development investigations in substantiation of the assumed or calculated conditions.

(8) Discuss the extent of system interdependency (containment system and other engineered safety features) contributing directly or indirectly to controlling or limiting leakages from the containment system, or other sources (e.g., from spent fuel handling areas), such as the contribution of: (a) containment water spray systems, (b) containment air cooling systems, (c) air purification and cleanup systems, (d) reactor core spray or safety infection systems, and (e) post-accident heat removal systems.

(9) The results and consequences derived from each analysis and the margin of protection provided by whatever system is depended upon to limit the extent or magnitude or the consequences.

(10) For appropriate accidents, discuss and present the results of calculations of potential integrated whole body and thyroid doses from exposure to radiation as a function of distance and time after the accident. Include specific results for the two-hour dose at the exclusion boundary and the dose for the course of the accident at the outer boundary of the low population zone for whole body doses from direct radiation, and thyroid doses from inhalation.

For calculations of loss-of-coolant accidents, the extent of compliance with the assumptions given in AEC Safety Guide 3 for Boiling Water Reactors, and Safety Guide 4 for Pressurized Water Reactors should be indicated. For calculations of steam line break accidents for boiling water reactors, the extent of compliance with the assumptions given in Safety Guide 5 should be indicated. For calculations of other postulated accidents the use of comparably conservative assumptions should be described. 
TABLE 15-1

REPRESENTATIVE TYPES OF EVENTS

TO BE ANALYZED IN CHAPTER 15.0 OF THE SAR

1. Uncontrolled control rod assembly withdrawal from a subcritical condition (assuming the most unfavorable reactive conditions of the core and reactor coolant system), including control rod or temporary control device removal error during refueling.

2. Uncontrolled control rod assembly withdrawal at the critical power (assuming the most unfavorable reactive conditions of the core and reactor coolant system) which yields the most severe results (hot at zero power, full power, etc).

3. Control rod misoperation or sequence of misoperations.

4. Chemical and volume control system malfunction.

5. Partial and total loss of reactor coolant flow force including trip of pumps and pump shaft seizures.

6. Start-up of an inactive reactor coolant loop or recirculating loop at incorrect temperature.

7. Loss of external electrical load and/or turbine stop valve closure, including, for BWRs closure of main steam isolation valve.

8. Loss of normal and/or emergency feedwater flow.

9. Loss of all a-c power to the station auxiliaries (station blackout).

10. Heat removal greater than heat generation due to (1) feedwater system malfunctions, (2) a pressure regulator fallure, or inadvertent opening of a relief valve or safety valve, and (3) a regulating instrument failure.

11. Failure of the regulating instrumentation, causing for example, a power-coolant mismatch. Include reactor coolant flow controller failure resulting in increasing flow.

12. Internal and external events such as major and minor fires, flood, storms or earthquakes. 
$\underline{\text { TABLE } 15-1 \text { (cont'd.) }}$

13. Loss of coolant accidents resulting from the spectrum of postulated piping breaks within the reactor coolant pressure boundary and relief and safety valve blowdowns.

14. Spectrum of postulated steam and feedwater system piping breaks inside and outside containment.

15. Inadvertent loading and operation of a fuel assembly into an improper position.

16. Waste gas decay tank leakage or rupture.

17. Failure of air ejector lines (BWR).

18. Steam generator tube rupture (PWR).

19. Failure of charcoal or cryogenic system (BWR).

20. The spectrum of rod ejection accidents (PWR).

21. The spectrum of rod drop accidents (BWR).

22. Break in instrument line or other lines from reactor coolant pressure boundary that penetrate containment.

23. Fue1 handling accident.

24. Small spills or leaks of radioactive material outside containment.

25. Fuel cladding failure (BWR, PWR) combined with steam generator leak (PWR).

26. Control room uninhabitability.

27. Failure or overpressurization of low pressure residual heat removal system.

28. Loss of condenser vacuum. open.

29. Turbine trip with coincident failure of turbine bypass valves to 
TABLE 15-1 (cont'd.)

30. Loss of service water system.

31. Loss of one (redundant) d-c system.

32. Inadvertent operation of ECCS during power operation.

33. Turbine trip with fallure of generator breaker to open.

34. Loss of instrument air system.

35. Malfunction of turbine gland sealing system. 
PARAMETERS TO BE TABULATED* FOR POSTULATED ACCIDENT ANALYSES

I. Data and assumptions used to estimate radioactive source from postulated accidents
A. power level
B. burn-up
C. percent of fuel perforated
D. release of activity by nuclide
E. lodine fractions (organic, elemental and particulate)
F. reactor coolant activity before the accident (and secondary coolant activity for PWR)

II. Data and assumptions used to estimate activity released
A. primary containment leak rate
B. secondary containment leak rate
C. valve movement times
D. adsorption and filtration efficiencies
E. recirculation system parameters (flow rates vs. time, mixing factor, etc.)
F. containment spray parameters (flow rate, drop size, etc.)
G. containment volumes
H. all other pertinent data and assumptions

III. Dispersion Data
A. boundary and LPZ distances
B. $x / Q$ 's (for time intervals of 2 hours, 8 hours, 24 hours, 4 days, 30 days)

IV. Dose Data
A. method of dose calculation
B. dose conversion assumptions
C. peak (or $f(t)$ ) concentrations in containment
D. doses

As applicable to the event being described. 


\subsection{TECHNICAL SPECIFICATIONS}

In accordance with the Atomic Energy Act and Section 50.36 of 10 CFR Part 50, each operating license issued by the Atomic Energy Commission must contain Technical Specifications that include those technical operating limits, conditions, and requirements imposed upon plant operation in the interest of the health and safety of the public. The applicant for an operating license proposes Technical Specifications and bases for its plant which are reviewed by the AEC regulatory staff and modified as necessary before becoming a part of the operating license. A summary statement of the bases or reasons for all specifications, other than those dealing with design features and administrative controls, should be included.

Throughout the previous sections of the Standard Format, the necessity for Identification of safety limits, limiting conditions and surveillance requirements has been indicated. It is from such information that the Technical Spectfications and supporting bases are developed.

The Technical Specifications should include:

(1) Definition of key terms used in the specifications that are not defined in applicable regulations or guides or are not generally accepted terminology.

(2) Specification of (a) safety limits which should assure protection of the integrity of certain physical barriers which guard against the uncontrolled release of radioactivity and (b) limiting safety system settings which will initiate automatic protective action to correct the most severe abnormal situation anticipated before a safety limit is exceeded.

(3) Specification of limiting conditions for operations which are the lowest functional capability or performance levels of equipment required for safe operation of the plant, to include remedial action, to be taken.

(4) Specification of surveillance requirements which relate to the tests, calibrations, and inspections required to assure that the quality of systems and components is maintained and that operation is within the safety limits and limiting conditions for operation.

(5) Description of those design features which are not covered by the above and which could have a significant effect on safety if altered or modified. 
(6) Specification of administrative controls which relate to organization and management, procedures, review and audit, and records and reports which are necessary to assure safe operation.

Representative subjects for Technical Specifications are suggested in Tables 16-1 and 16-2. Individual plants may require specifications which differ from these suggested tables; these should be individually justified. Additional guidance on the contents of the Technical Specifications is provided in a document entitled "Guide to Content of Technical Specifications for Nuclear Reactors" prepared by the AEC and available from the Director of Regulation.

In accordance with Section 50.34 of 10 CFR Part 50, an application for a construction permit is required to include preliminary Technical Specifications. The regulations require an identification and justification for the selection of those variables, conditions, or other items which are determined as a result of the preliminary safety analysis and evaluation to be probable subjects of Technical Specifications for the plant, with special attention given for those items which may significantly influence the final design. The objective of providing preliminary Technical Specifications is to identify those items that would require special attention at the construction permit stage to avoid the necessity for any significant change in design to support the final Technical Specifications, e.g., particularly those specifications that affect the type, capacity, or number of components in safety-significant systems. Such components and systems cannot be easily modified after the plant is built and the FSAR is submitted for approval by the AEC.

The preliminary Technical Specifications and bases proposed by an applicant for its plant should be included in Chapter 16.0 of the PSAR. The preliminary Technical Specifications should be complete, i.e., to the fullest extent possible, numerical values and other pertinent data should be provided. For each specification the applicable sections that develop, through analysis and evaluation, the details and bases for the specification should be referenced.

As an alternate to providing complete preliminary Technical specifications, the applicant may state that his final Technical Specifications will be the same as those for a licensed plant of similar design, except for the following two categories of exception:

(1) Those specifications that do not conform to the applicant's operating practices or his plans for operation of the plant. 
(2) Those specifications that are expected to change as a result of differences between the design of the applicant's plant and that of the licensed plint.

If this procedure is followed, the licensed plant should be specified and the applicant should provide a list of those specifications requiring exception and the alternate specifications and bases proposed. Also, for each specification of the licensed plant referenced and for each alternate specification for its plant, an applicant should reference the section of the SAR that develops, through analysis and evaluation, the details and bases for the Technical Specifications.

\section{For FSARs}

The Technical Specifications and bases proposed by an applicant for its plant should be included as Chapter 16 of the FSAR. Except for the specifications covering design features and administrative controls, each specification selected should be provided in the FSAR with bases in the form of a summary statement of the technical and operational considerations which justify the selection. For each specification the applicable sections of the FSAR which fully develop, through analysis and evaluation, the details and bases for the specification should be referenced. 
REPRESENTATIVE SUBJECTS FOR PWR TECHNICAL SPECIFICATIONS

I. Definitions

II. Safety Limits and Limiting Safety System Settings
A. Reactor Core
B. Reactor Coolant System Pressure
C. Protective Instrumentation

III. Limiting Conditions For Operation

A. Reactor Coolant System

1. Operational Components

2. Heatup and Cooldowns

3. Reactor

4. Maximum Reactor Coolant Activity

5. Maximum Reactor Coolant Oxygen, Chloride, and Fluorlde Concentration

6. Leakage of Reactor Coolant

B. Chemical and Volume Control System

C. Engineered Safety Features

1. Safety Injection and Residual Heat Removal Systems

2. Containment Cooling and Iodine Removal Systems

3. Component Cooling System

4. Service Water System

5. Extended Maintenance

D. Steam and Power Conversion System

E. Containment System

1. Containment Integrity

2. Internal Pressure

F. Electrical System

G. Refueling 
H. Effluent Releases

1. Liquid Waste

2. Gaseous Waste

I. Control Rod and Power Distxibution Limits

1. Shutdown Reactivity

2. Power Distribution Limits

3. Quadrant Power Tilt Limits

4. Rod Insertion Limits

5. Rod Misalignment Limitations

6. Inoperable Rod Position Indicator Channels

7. Inoperable Rod Limitations

8. Rod Drop Time

9. Rod Position Deviation Monitor

10. Quandrant Power Tilt Monitor

11. Notification

J. Core Surveillance Instrumentation

IV. Surveillance Requirements

A. Operational Safety Review

B. Reactor Coolant System In-Service Inspection

C. Reactor Coolant System Integrity Testing

D. Contalnment Tests

1. Leakage Rate Test, Pre-operational

2. Leakage Rate Test, Post-operational

3. Containment Inspection

4. Containment Modifications

5. Residual Heat Removal System

E. Engineered Safety Features

1. System Tests

2. Component Tests

F. Emergency Power Systems Tests

1. Diesel Generators

2. Station Batteries 
G. Main Steam Stop Valves

H. Auxiliary Feedwater System

I. Reactivity Anomalies

J. Environmental Monitoring Survey

V. Design Features
A. Site
B. Containment
C. Reactor
D. Fuel Storage

VI. Administrative Controls
A. Responsibility
B. Plant Staff Organization
C. Plant Staff Qualifications
D. Retraining and Replacement Training
E. Review and Audit

1. Plant Nuclear Safety Committee

2. Company Nuclear Review Board

F. Action to be Taken in the Event of an Abnormal Occurrence

G. Action to be Taken if a Safety Limit is Exceeded

H. Radiation and Respiratory Protection Program

I. Industrial Security Program

J. Records Retention

K. Reporting Requirements 


\section{TABLE $16-2$}

REPRESENTATIVE SUBJECTS FOR BWR TECHNICAL SPECIFICATIONS

I. Definitions

II. Safety Limits and Limiting Safety System Settings

A. Fuel Cladding Integrity

B. Reactor Coolant System

III. Limiting Conditions for Operation

A. Reactor Protection System

B. Protective Instrumentation

1. Primary Containment Isolation Functions

2. Emergency Core Cooling Subsystems Actuation

3. Control Rod Block Actuation

4. Air Ejector Off-gas System

5. Reactor Building Ventilation Isolation and Standby Gas Treatment System Initiation

C. Reactivity Contro1

1. Reactivity Limitations

2. Control Rod Withdrawa1

3. Scram Insertion Times

4. Control Rod Accumulators

5. Reactivity Anomalies

D. Standby Liquid Control System

1. Normal Operation

2. Operation with Inoperable Components

E. Core and Containment Cooling Systems

1. Core Spray and LPCI Subsystems

2. Emergency Service Water Subsystem

3. FWCI Subsystem

4. Automatic Pressure Relief Subsystems 
5. Isolation Condenser System

6. Minimum Core and Containment Cooling System Availability

7. Extended Maintenance

F. Primary System Boundary

1. Thermal Limitations

2. Pressurization Temperature

3. Coolant Chemistry

4. Coolant Leakage

5. Safety and Relief Valves

6. Structural Integrity

7. Jet Pumps

G. Containment Systems

1. Primary Containment

2. Standby Gas Treatment System

3. Secondary Containment

4. Primary Containment Isolation Valves

H. Radioactive Materials

1. Airborne Effluents

2. Mechanical Vacuum Pump

3. Liquid Effluents

4. Radioactive Waste Storage

5. Environmental Monitoring

I. Auxiliary Electrical Systems

1. Diese1 Generators

2. Station Batteries

J. Refueling

1. Refueling Interlocks

2. Core Monitoring

3. Fuel Storage Pool Water Level 
IV. Surveillance Requirements
A. Control Rod System
B. Liquid Poison System
C. Emergency Core Cooling System
D. Solenoid Actuated Pressure Relief Valves
E. Control Rod Drive Pump Coolant Injection
F. Reactor Coolant System Chemistry and Activity
G. Reactor Coolant System Leakage Rate
H. Reactor Coolant System Inspection
I. Reactor Coolant System Safety Valves
$\mathrm{J}$. Containment Oxygen Concentration
K. Containment Pressure and Suppression Chamber
- Water Temperature and Leve1
L. Containment Leakage Rate
M. Containment Isolation Valves
N. Containment Access Control
0 . Containment Vacuum Relief
P. Containment Spray System
Q. Shutdown and Refueling Operations
1. Source Range Monitoring System
2. Refueling Platform Interlocks

R. Station Process Effluents

S. Protective Instrumentation

T. Auxiliary Power Sources

V. Design Features
A. Site
B. Reactor
C. Containment
D. Fuel Storage

VI Administrative Controls
A. Responsibility
B. Plant Staff Organization
C. Plant Staff Qualifications
D. Retraining and Replacement Training 
E. Review and Audit

1. Plant Nuclear Safety Committee

2. Company Nuclear Review Board

F. Action to be Taken in the Event of an Abnormal Occurrence

G. Action to be Taken if a Safety Limit is Exceeded

H. Operating Procedures

I. Radiation and Respiratory Protection Program

J. Industrial Security Program

K. Records Retention

L. Reporting Requirements 


\subsection{QUALITY ASSURANCE}

In order to provide assurance that the design, construction, and operation of the proposed nuclear power plant are in conformance with applicable regulatory requirements and with the design bases specified in the license application, it is necessary that a Quality Assurance Program (QA Program) be established by the applicant. In this chapter of the SAR, the applicant should provide a description of the QA Program to be established and executed during the design and construction of the nuclear power plant. In addition, the FSAR should describe the QA Program to be established and executed during operation of the nuclear power plant. The QA Program must be established at the earliest practical time consistent with the schedule for accomplishing the activity. Where some portions of the QA Program have not yet been established at the time the SAR is prepared because the activity will be performed in the future, the description should also provide a schedule for implementation. The program must meet the requirements of Appendix B of 10 CFR Part 50. The inspection and survey systems required by Sections 0.55 a of $10 \mathrm{CFR}$ Part 50. (Codes and Standards Rule) may be used in partial fulfullment of these requirements to the extent that they are shown by the description of the QA Program to satisfy the applicable requirements of Appendix $B$.

In order to facilitate the presentation of the information, the QA Program for each of the major organizations involved in executing the QA Program should include the information described (elther separately for each organization or integrally for all organizations) in accordance with the following outline. It is not intended to dictate the format of any QA Program Manual; that is left to the discretion of the applicant.. It is required, however, that the description address at a minimum each of the criteria in Appendix $B$ in sufficient detail to enable the reviewer to determine whether al1 the requirements of the Appendix will be satisfied. Reference to appropriate portions of other sections may suffice.

Where a portion of the quality assurance program to be implemented will conform to a particular quality assurance standard, such as those adopted by the American National Standards Institute, the description, to the extent described in the standard, may consist of a statement that the particular standard will be followed. Where safety guides have been issued on acceptable methods of implementing portions of the quality assurance program, the description should specifically indicate whether the regulatory position of the safety guides will be followed.

\subsection{Quality Assurance During Design and Construction}

\subsubsection{Organization}

Organization charts for the project should be provided that denote the lines and areas of responsibility, authority, and communication within

$$
17.0-1
$$


each of the major organizations involved, including those of the applicant, the architect-engineer, the nuclear steam system supplier, the constructor, and construction manager (if different from the constructor). In addition, a single overall organization chart should be included denoting how these companies interrelate for the specific project. These charts and attendent discussions should clearly indicate the organizational location of, organizational freedom of, and authority of the individual or groups assigned the responsibility for checking, auditing, inspecting, or otherwise verifying that an activity has been correctly performed. The charts and discussions should indicate the degree of involvement on the part of the applicant to verify the adequacy of implementation of the QA programs implemented by the applicant's contractors and suppliers, even for those cases where the applicant has delegated to other organizations the work of establishing and implementing the quality assurance program, or any part thereof.

\subsubsection{Quality Assurance Program}

The structures, systems, and components to be covered by the QA Program should be identified along with the major organizations participating in the program and the designated functions of these organizations. The written policies, procedures, or instructions which implement or will implement the QA Program should be described. Where these written policies, procedures, or instructions are not yet effective, a schedule for their implementation should be provided.

\subsubsection{Design Control}

A description of the design control measures should be provided. Included should be measures to assure that appropriate quality standards are specified in design documents and that deviations from such standards are controlled; measures for the selection and review of suitability of application of materials, parts, equipment and processes; measures for the identification and control of design interfaces and for coordination among participating organizations; measures for verifying or checking adequacy of design such as by design reviews, alternate or simplified calculational methods or suitable testing programs; and measures to assure that design changes, including field changes, will be subject to design control measures commensurate with those applied to the original design and will be reflected in accurate "as built" drawings and specifications.

\subsubsection{Procurement Document Control}

A description of the procurement document control measures should be provided. Included should be measures to assure that applicable regulatory requirements, design bases, and other requirements such as QA Program 
requirements which are necessary to obtain adequate quality are included or referenced in procurement documents.

17.1.5 Instructions, Procedures, and Drawings

A description should be provided of the measures to assure that activities affecting quality will be prescribed by documented instructions, procedures, or drawings and will be accomplished in accordance with these instructions, procedures, or drawings.

\section{1 .6 Document Control}

A description of document control measures should be provided. Included should be measures to assure that documents, including changes, are reviewed for adequacy and approved for release by authorized personnel and are distributed to and used at the location where the prescribed activity is performed.

\subsubsection{Control of Purchased Material, Equipment, and Services}

A description of the measures for the control of purchased material, equipment, and services should be provided. Included should be measures for source evaluation and selection; for assessing the adequacy by means of objective evidence of quality furnished by the contractor; for inspection at the contractor source; and for examination of products upon delivery. A description should also be provided of the measures taken to assure that documentary evidence that the material and equipment conform to the procurement requirements is available at the plant site prior to installation or use of such material or equipment.

\subsubsection{Identification and Control of Materials, Parts, and Components}

A description of the measures for the identification and control of materials, parts, and components should be provided to assure that incorrect or defective items will not be used.

\subsubsection{Control of Special Processes}

A description of the measures for the control and accomplishment of special processes should be provided. Included should be a listing of the special processes. The measures to assure that such special processes are controlled and accomplished by qualified personnel using qualified procedures should also be included.

The following are considered examples of special processes that should be addressed : 
(1) Welding

(2) Casting

(3) Nondestructive testing (NDT)

(4) Electrochemical machining

(5) Explosive forming

(6) Removal of undesirable substances during shop and site cleaning, degreasing, and flushing

\subsubsection{Inspection}

A description of the program for the inspection of activities affecting quality should be provided indicating specifically the items and activities to be covered. Included should be an organizational description of the individuals or groups performing inspections, indicating the independence of the inspection group from the group performing the activity being inspected, and a description of how the inspection program for the involved organizations has been or will be established.

\subsubsection{Test Control}

A description of the test program to assure that all testing required to demonstrate that structures, systems, and components will perform satisfactorily in service should be provided. Included should be an outline of the test program; procedures to be developed; means for documenting and evaluating test results of the item tested; and designation of the responsibility for performing the various phases of the program. Where a test program is used to verify the adequacy of a specific design feature, a description of the qualification testing of a prototype unit should be included.

\subsubsection{Control of Measuring and Test Equipment}

A description of the measures to assure that tools, gages, instruments, and other measuring and testing devices are properly controlled, calibrated and adjusted at specified periods to maintain accuracy within necessary limits should be provided.

\subsubsection{Handling, Storage, and Shipping}

A description of the measures employed to control handling, storage, shipping, cleaning and preservation of items in accordance with work and inspection instructions to prevent damage or deterioration should be provided. 


\subsubsection{Inspection, Test, and Operating Status}

A description of the measures to indicate the inspection and test status of items to prevent inadvertent bypassing of such inspections and tests should be provided. A description should also be provided of the measures for indicating the operating status of structures, systems, and components of the nuclear power plant to prevent inadvertent operation.

\subsubsection{Nonconforming Materials, Parts, or Components}

A description of the measures to control nonconforming materials, parts, or components to prevent their inadvertent use or installation should be provided. Included should be the means for identification, documentation, segregation, and disposition of nonconforming material and notification to affected organizations.

\subsubsection{Corrective Action}

A description of the corrective action measures established to assure that conditions adverse to quality are identified and corrected and that the cause of significant conditions adverse to quality is determined and corrective action taken to preclude repetition should be provided.

\subsubsection{Quality Assurance Records}

A description of the program for the maintenance of records to furnish evidence of activities affecting quality should be provided. Included should be means for identifying the records, retention requirements for the records including duration, location and assigned responsibility, and means for retrieving the records when needed.

\section{1 .18 Audits}

A description of the system of audits to verify compliance with all aspects of the QA Program and to determine the effectiveness of the QA Program should be provided. Included should be means for documenting responsibilities and procedures for auditing; required frequency of audits; audit results; and designating management levels to which audit results are reported.

\subsection{Quality Assurance Program For Station Operation}

In the FSAR the applicant should provide a description of the proposed QA Program that will govern the quality of all safety related items during operating phase activities. These activities include operating, maintaining, repairing, refueling, and modifying subsequent to the pre- 
operational phase. The description of the proposed QA Program should include each of the QA criteria (Appendix B of 10 CFR Part 50), as outlined in Section 17.1 above. 